\title{
Abstracts from the 2005 Annual Conference of the Canadian Pain Society
}

\author{
May 11 to 14, 2005, Halifax, Nova Scotia
}

\section{INAUGURAL COMMUNITY PUBLIC EVENT WEDNESDAY, MAY 11, 2005}

\section{7:30 PM - PAIN - BREAKING THE SILENCE}

\section{Chair: Anita Unruh PhD}

Health and Human Performance, Occupational Therapy, Dalhousie University, Halifax, Nova Scotia

Speakers: $\underline{\text { Helen Tupper RN, Terry Bremner, Mary MacDonald BA BeD }}$

\section{Brief Description:}

An inaugural event open to people living with pain, their families, the general public and conference attendees. The personal face of pain in everyday life experience focusing on three issues: 1) chronic pain can happen to anyone, 2) disbelief of others causes serious harm, and 3) a meaningful life is possible with chronic pain will be presented in a dramatic dialogue, edited, directed and produced by Catherine Seton of The Story Project and Co-chair of the patient Advisory Committee, Wasser Pain Management Centre, Mount Sinai Hospital, Toronto, Ontario.

\begin{tabular}{c}
\hline PAIN EDUCATION DAY \\
THURSDAY, MAY 12, 2005 \\
\hline 8:30 AM - KEYNOTE SPEAKER \\
INTERVENTIONAL TECHNIQUES FOR PAIN \\
MANAGEMENT \\
\hline
\end{tabular}

\section{Ivar Mendez MD PhD FRCSC FACS}

Department of Neurosurgery, Dalhousie University and Queen

Elizabeth II Health Sciences Centre, Halifax, Nova Scotia

Chair: Mary Lynch MD FRCPC

Department of Psychiatry, Dalhousie University and

Queen Elizabeth II Health Sciences Centre, Halifax, Nova Scotia

\section{Brief Description:}

The presentation will focus on the use of spinal cord and peripheral nerve stimulators for the treatment of chronic pain. Particular emphasis will be given to the indication, patient assessment, surgical technique and clinical outcomes of patients treated with plantable stimulators. Our institution's experience in the neurosurgical area of treatment of chronic pain syndromes with electrical stimulators will be highlighted.

\section{9:15 AM - PLENARY SESSION}

CANCER CARE / PALLIATIVE CARE

Chair: Stephanie Stark BN RN

Expanded Role Nurse Acute Pain Service, Department of Anaesthesia, Queen Elizabeth II Health Sciences Centre, Halifax, Nova Scotia Speakers: Roanne Segal, Medical Oncologist;

S Robin Cohen PhD (Psychology); Larry Broadfield BScPharm MHSc; Paul McIntrye MD CCFP

\begin{abstract}
EXERCISE INTERVENTIONS FOR PATIENTS WITH MALIGNANCY Roanne Segal MD, FRCPC

Associate Professor and Medical Oncologist, Department of Medicine, Division of Medical Oncology, TOH Integrated Cancer Program, University of Ottawa, Ottawa, Ontario

Exercise has been shown to have a role in the primary and secondary management of several chronic diseases including diabetes, cardiovascular disease, and osteoporosis. Over the last decades advances in therapies have resulted in cancer now emerging as a chronic illness. To attain this result, patients are receiving combinations of therapies including surgery, chemotherapy, hormonal and radiation therapy that is delivered over a prolonged period of time. These complex therapies have resulted in an improved overall survival but at a cost of increasing side effects.

Side effects generally can be divided into two categories: 1) physical and functional, including fatigue, cardiovascular deconditioning, changes in weight or lean body mass, and muscle weakness; and 2) emotional changes, including depression, anxiety, stress, poor body image, and low self-esteem. These comorbidities may have a significant impact on quality of life.

There is now specific research in patients living with cancer which has demonstrated the potential benefits of exercise including helping to maintain muscle mass, restore or blunt the decline in cardiopulmonary function, muscular strength and bone mineral density. In addition there is mounting evidence that exercise throughout the trajectory of the illness may promote or improve psychological well being.

This review will summarize the research evaluating exercise as a self-care modality for individuals at risk for, or living with cancer.
\end{abstract}

\section{TOTAL PAIN: CANCER PAIN AND QUALITY OF LIFE $\underline{\text { S Robin Cohen PhD }}$} Departments of Oncology and Medicine, McGill University, Montreal, Quebec

Participants will:

a. Have a clear understanding of the concept of total pain.

b. Understand how all aspects of the person can affect the cancer pain experience.

c. Understand how having cancer affects the pain experience.

d. Understand how cancer pain can impact on different aspects of the patient's quality of life.

e. Be able to relate the concept of total pain to actual cases.

Most chronic pain is affected by many different aspects of the person as well as their circumstances. In the case of cancer pain, the circumstances are dire - whether or not the person will eventually be cured, cancer always has a life-threatening aspect. While the Melzack-Wall Gate Control Theory was proposed in 1965 and widely accepted in theory, in practice it is common to see cancer pain treated by focusing only on the body. In the numerous cases where psychological, social, or spiritual distress contribute to the bodily sensation described as pain, this results in ineffective pain control (a sub-optimal decrease in pain or unnecessary toxicity). The concept of "total pain" will be presented in the context of cancer pain and quality of life. Please bring your experience with you to provide examples of the clinical usefulness of this concept! 
DEVELOPMENT OF CANCER PAIN GUIDELINES FOR NOVA SCOTIA Larry Broadfield BScPharm MHSc

Cancer Care Nova Scotia, Halifax, Nova Scotia

\section{MEDICAL MANAGEMENT ASPECTS}

Paul McIntyre MD CCFP

Assistant Professor, Departments of Family Medicine and Medicine; and Head, Division of Palliative Medicine Dalhousie University/Capital Health, Queen Elizabeth II Health Sciences Centre, Halifax, Nova Scotia

\section{1:15 AM - PLENARY SESSION LITIGATION AND PATIENT DISTRESS}

\section{Chair: John Clark MD FRCPC}

Director, Chronic Pain Centre, Calgary Health Region; and Clinical Professor of Anesthesia, University of Calgary, Calgary, Alberta Speakers: Mary Lynch MD FRCPC, Terry Bremner, Ray Wagner LLB

\section{MEDICAL-LEGAL ASPECTS OF CHRONIC PAIN SURVIVING PERSONAL INJURIES CLAIMS AND LITIGATION Mary Lynch MD FRCPC \\ Department of Psychiatry, Dalhousie University and Queen Elizabeth II Health Sciences Centre, Halifax, Nova Scotia}

\section{Learning Objectives:}

a. Participants will have heightened awareness of what they and their patients will be confronted with as they go through the insurance claims and litigation process.

b. Participants will be equipped with strategies to assist their patients in dealing with a medical legal claim and litigation.

According to recent figures announced during the Global Day Against Pain 2004 co-sponsored by the World Health Organization, the International Association for the Study of Pain (IASP) and the European Federation of IASP Chapters, more than $50 \%$ of patients still suffer severe and intolerable pain after surgery and trauma, and one in five adults suffer from chronic pain. A significant percentage of patients presenting with chronic pain after injury are left with disabilities and losses, and end up in the midst of the web of personal injuries claims and litigation. Health care professionals become involved both in assisting patients in the treatment of the pain, and as experts called upon by the courts in determining the quantum of damages for which the injured party should be compensated. Litigation involves an adversarial process, and strategies used by opposing counsel, fall into themes that can be classified as pain denying and patient blaming. The experience is at best demoralizing and at worst re-traumatizing for the patient. This session will present strategies that clinicians may use in an effort to minimize the stress patients experience as they go through the process.

\section{PATIENT REPRESENTATIVE: HIS PERSONAL EXPERIENCE} Terry Bremner, Founding Member Chronic Pain Association of Canada (CPAC)

\section{LEGAL PERSPECTIVE}

Ray Wagner LLB, Lawyer with special expertise in personal injuries litigation, Halifax, Nova Scotia
1:30 PM - WORKSHOP \#1

FUNDAMENTALS OF ADDICTION MEDICINE FOR THE PAIN CLINICIAN

Dr Roman D lovey MD ${ }^{1}$, Dr Douglas Gourlay MD MSc FRCPC FASAM $^{2}$, Ms Marilyn Galonski RN BScN ${ }^{3}$

1Physician Director and Pain Consultant, Alcohol and Drug

Treatment Program, Credit Valley Hospital, Mississauga; ${ }^{2}$ Medical Consultant in Pain and Chemical Dependency, Centre for Addiction and Mental Health \& The Wasser Pain Management Centre, Mount Sinai Hospital; ${ }^{3}$ Care Coordinator, Wasser Pain Management Centre, Mount Sinai Hospital, Toronto, Ontario

Attendees of this workshop will discuss:

a. how current knowledge regarding the process of addiction may affect pain treatment.

b. practical strategies and tools to assess patients for risk of misusing prescribed substance.

c. a "universal precautions" approach to the management of the patient with pain using controlled substances.

d. strategies for efficient documentation to protect the physician as well as the patient.

The modern management of moderate to severe chronic pain often requires the long-term use of opioid analgesics. Abuse and addiction to prescribed opioids pose significant threats to public and individual health and complicate the treatment of pain by creating barriers to the optimum use of opioids. By acquiring some fundamental knowledge of addiction medicine and learning some practical patient triage and management strategies, pain clinicians can reduce the risk of harm to patients and society. By understanding the essentials of appropriate documentation, clinicians can reduce the risk of harm to themselves.

\section{1:30 PM - SESSION 101 \\ 2:45 PM - SESSION 104 \\ HOW TO SET UP A MULTI-DISCIPLINARY PROGRAM}

Chair: Kenneth Chisholm MD FRCPC

Department of Anesthesia, Dalhousie University; and Queen

Elizabeth II Health Sciences Centre, Halifax, Nova Scotia

Speakers: Sandy Lefort PhD RN, Douglas Cane PhD

THE CHRONIC PAIN SELF-MANAGEMENT PROGRAM:

ONE APPROACH TO COMMUNITY CARE

Sandra M LeFort RN PhD

Associate Professor and Director, School of Nursing, Memorial

University of Newfoundland, St John's, Newfoundland

Learning Objectives:

a. Participants will be able to identify processes and content for a communitybased chronic pain education program.

b. Participants will learn ways to enhance the self-management of chronic pain. An estimated $17 \%$ or Canadians suffer from chronic pain problems such as musculoskeletal pain, chronic headache, and other conditions. Living with chronic pain can result in severe distress, disability and major disruption in individual and family functioning. It also has a high economic cost to the person with pain and to society as a whole. In spite of the high prevalence and severe impact of the condition, access to specialized pain services in very limited in Canada. To address this need, a low-cost, accessible community-based patient education program was developed. The goal of the program is to give people the skills and confidence to better manage their chronic pain to improve their every day quality of life. Two RCT's of this program provide evidence of its effectiveness. This session will review the basic processes and content of the program and discuss how it can be used in community care of those with chronic pain. 
QEII PAIN SELF-MANAGEMENT PROGRAM

Douglas Cane PhD

Psychologist, Queen Elizabeth II Health Sciences Centre, Halifax, Nova Scotia

Learning Objectives:

a. Participants will be able to identify the benefits to patients, staff, and health care facilities of providing pain management services through a multidisciplinary program.

b. Participants will be able to identify the resources required to establish a multidisciplinary pain management program.

c. Participants will be able to identify strategies to promote the development of a multidisciplinary program within a public health facility.

Multidisciplinary pain management programs are recognized to be an effective and efficient means of providing pain management services to individuals with chronic pain. However, the establishment of a multidisciplinary program requires the commitment of considerable time and energy, and ongoing support from the host health facility. Based on the experience of establishing a multidisciplinary program at a publicly funded, tertiary care hospital, this presentation describes the resources required to develop and implement a multidisciplinary program and the challenges faced in doing so. Strategies for developing and maintaining support from the host institution are also discussed.

\section{1:30 PM - SESSION 102 \\ 2:45 PM - SESSION 105 PAIN AND SLEEP}

\section{Chair: Benjamin Rusak PhD}

Director of Research, Department of Psychiatry, Dalhousie

University and Queen Elizabeth II Health Sciences Centre, Halifax,

Nova Scotia; and Vice President Research, Canadian Sleep Society

Speakers: Katherine Harman PT PhD, Christine T Chambers, PhD

RPsych, Alexander J Clark MD FRCPC

\section{INSOMNIA}

Katherine Harman PT PhD

School of Physiotherapy, Dalhousie University, Halifax, Nova Scotia

\section{Learning Objectives:}

a. Participants will gain a better understanding of the complexity of insomnia in the presence of chronic pain.

b. Participants will learn of three non-pharmacologic interventions for insomnia. Insomnia is a highly prevalent complaint among those with pain-related conditions (1-3). The results of prolonged insomnia include impairment of cognitive performance, persistent fatigue and mood disturbance $(4,5)$. The two experiences together create a complicated clinical picture that often also includes significant psychological challenges such as fear, [6;7]depression (8) or anxiety (9) that might be attributed to pain or insomnia. Complex situations such as these create a clinical challenge to successful rehabilitation (10).

Insomnia that persists can lead to behaviours and beliefs which may contribute to the persistence of the problem (11). It is these maladaptive behaviours and beliefs that are the target of cognitive-behavioural intervention (12). Non-pharmacologic approaches to insomnia are believed to provide the individual with skills that will assist them to self-manage effectively and for longer periods than recommended for medications (13). This approach complements the multidisciplinary rehabilitation philosophy of self-management. There are three 'levels' of insomnia management: sleep hygiene, stimulus control and sleep restriction. Individualised counselling is often added to address dysfunctional beliefs about sleep that might contribute to sleep onset difficulties (13). A brief description of the three components will be presented.

Research into insomnia and chronic pain is limited $(10,14,15)$, and findings describe different explanations for the complexity and high incidence of the clinical problem. The cognitive-behavioural approach to insomnia has value and will help provide patients with the tools they need to manage their symptoms.
References

1. Haythornthwaite JA, Hegel MT, Kerns RD. Development of a sleep diary for chronic pain patients. J Pain Symptom Manage 1991;6:65-72.

2. Moffitt PF, Kalucy EC, Kalucy RS, Baum FE, Cooke RD. Sleep difficulties, pain and other correlates. J Int Med 1991; 230:245-9.

3. Wooten V. Medical causes of insomnia. In: Kryger MH, Roth T, Dement WC, eds Principles and Practice of Sleep Medicine. Philadelphia: WB Saunders Co, 1989:456-75.

4. Carskadon MA, Dement WC. Normal human sleep: an overview. In: Kryger MH Roth T, Dement WC, eds. Principles and Practice of Sleep Medicine. Philadelphia: WB Saunders Company, 1989:3-13.

5. Chugh DK, Weaver TE, Dinges DF. Neurobehavioural consequences of arousals. Sleep 1996;19:S198-S201.

6. Dijkstra A, Vlaeyen J, Rijnen H, Nielson W. Readiness to adopt the self-management approach to cope with chronic pain in fibromyalgic patients. Pain 2001;90:37-45.

7. Vlaeyen J, Linton S. Fear-avoidance and its consequences in chronic musculoskeletal pain: a state of the art. Pain 2000;85:317-32.

8. Wilson K, Eriksson M, D'Eon JL, Mikail S, Emery P. Major depression and insomnia in chronic pain. Clin J Pain 2002;18:77-83.

9. McCracken L, Gross RT. Does anxiety affect coping with chronic pain? Clin J Pain 1993;9:253-9.

10. Harman K, Pivik RT, D'Eon JL, Wilson K, Swenson JR, Matsunaga L. Sleep in depressed and nondepressed participants with chronic low back pain: Electroencephalographic and behavioural findings. Sleep 2002;25:775-83.

11. Currie S, Wilson K, Pontefract A, deLaplante L. Cognitive-behavioural treatment of insomnia secondary to chronic pain. J Cons Clin Psychol 2000;68:407-16.

12. Morin C, Blais F, Savard J. Are changes in beliefs and attitudes about sleep related to sleep improvements in the treatment of insomnia? Behav Res Ther 2002;40:741-52.

13. Morin C. Insomnia: psychological assessment and management. New York: The Guildford Press, 1993.

14. Currie S. Chronic pain and poor sleep: An assessment of sleeping and waking patterns and activity via ambulatory recordings. Ottawa: Carleton University, 1993.

15. Wittig RM, Zorick FJ, Blumer D, Heilbronn M, Roth T. Disturbed sleep in patients complaining of chronic pain. J Nerv Ment Disord 1982;170:429-31.

\section{PAIN AND SLEEP IN THE PEDIATRIC POPULATION}

Christine T Chambers PhD RPsych

Canada Research Chair in Pain and Child Health, Departments of Pediatrics and Psychology, Dalhousie University and IWK Health Centre, Halifax, Nova Scotia

Learning Objectives:

a. Participants will have a heightened awareness of the complex relationship between sleep and pain in children.

b. Participants will reflect on the importance of sleep in pediatric pain assessment and management.

Chronic pain is a widespread health issue among children and adolescents. Pediatric chronic pain places a burden on the health care system in the form of frequent physician consultations, medication use, and hospitalization. Chronic pain in children is often associated with mood disruptions and significant levels of functional disability. Little is known about the long-term course of chronic pain in children, although there is some evidence that these difficulties persist into adulthood. An area that has received little scientific investigation is the role that sleep disturbances play in pediatric chronic pain. It is likely that pain interferes with the quality and quantity of some children's sleep, and that underlying common factors may contribute to both the experience of pain and to sleep disturbance. It is also likely, however, that the consequences of insufficient sleep can contribute to the heightening of pain experiences in children. This presentation will provide an overview of existing research examining the relationship between sleep and pain in children and will explore the importance of sleep as a variable to consider in pediatric pain assessment and management.

\section{PAIN MEDICATIONS, HOW TO OPTIMIZE SLEEP Alexander I Clark MD FRCPC}

Medical Director, Chronic Pain Centre, Calgary Health Region and Clinical Professor of Anesthesia, University of Calgary, Calgary, Alberta

\section{Learning Objectives:}

a. Participants will learn which medications used to treat pain can be effective in enhancing sleep.

b. Participants will learn effective prescribing strategies of these medications.

c. Participants will be equipped with strategies to improve sleep hygiene. 
Sleep difficulties are a frequent problem experienced by $50-70 \%$ of individuals who have chronic pain and are under-reported, under-diagnosed and under-treated. Sleep changes can include one or more of an increase in sleep onset latency, frequent nighttime awakening, early morning awakening and poor sleep quality. Multiple factors can contribute to this problem - pain, thoughts, habits and lifestyle.

Non-pharmacological solutions for improving sleep include stimulus control, sleep restriction and worry control. These solutions should not be used as single interventions but in association with each other.

The mainstay of a pharmacological approach for improving sleep is the use of the antidepressant medications which can improve pain perception as well as sleep disorders. The most commonly used antidepressant medications are the tricyclic antidepressants such as amitriptyline, nortriptyline and imipramine. Low doses of sedative anti-psychotics have been reported to improve chronic insomnia in the elderly but their efficacy in chronic pain is unclear. The use of hypnotics in long-term therapy of poor sleep is not supported by robust evidence and should be avoided.

Reference

1. Stiefel F, Stagno D. Management of insomnia in patients with chronic pain conditions. CNS Drugs 2004;18:285-96.

$\begin{array}{r}\hline \text { 1:30 PM - SESSION } 103 \\ 2: 45 \text { PM - SESSION } 106 \\ \text { ACUTE CARE PAIN MANAGEMENT FOLLOWING SURGERY } \\ \hline\end{array}$

Chair: Darlene Davis RN

Acute Pain Service, Queen Elizabeth II Health Sciences Centre, Halifax, Nova Scotia

Speakers: Kim Horrill MScN ACNP, Shandran Baker

\section{AMBULATORY REGIONAL ANESTHESIA / ANALGESIA PROGRAM} Kim Horrill MScN ACNP

Nurse Practitioner/Clinical Nurse Specialist, St. Joseph's Health

Care, London, Ontario

\section{TITLE TBA}

David Goldstein MSc FRCP

Department of Anesthesia, Queen's University, Kingston Ontario

\section{4:00 PM - KEYNOTE SPEAKER \\ THE GENETICS OF PAIN}

\section{Leffrey S Mogil PhD}

EP Taylor Professor of Pain Studies, McGill University, Montreal, Quebec

Learning Objectives:

a. Participants will be aware of the various methodologies that can be employed to study inherited variability in pain-related traits.

b. Participants will be able to identify genes that have been recently implicated in pain variability in humans and mice.

Genetic approaches attempt to explain variability in biological systems, and pain is associated with much variability, including in the propensity to develop painful pathologies. Genetic linkage mapping efforts in mice and targeted genetic association studies in humans are beginning to identify those genes underlying much of the considerable variability noted in these traits. These efforts may lead to novel clinical treatments for pain and/or facilitate the patient-centered, individualized treatment of pain using current pharmaceuticals.
SCIENTIFIC PROGRAM

FRIDAY, MAY 13, 2005

8:30 AM - KEYNOTE SPEAKER

MECHANISMS THAT DRIVE BONE CANCER PAIN

\section{Patrick Mantyh PhD}

VA Center and Department of Preventive Sciences, University of Minnesota, Minnesota, Minneapolis

Chair: Terence J Coderre PhD

Department of Anesthesia, McGill University and McGill Centre for Research on Pain, Montreal, Quebec

Bone cancer pain can be severe and is relatively common, as it frequently arises from metastases from breast, prostate, and lung tumors. To define the mechanisms that give rise to bone cancer pain, we developed mouse models and this, coupled with recent clinical data, suggests that there are inflammatory, neuropathic and tumorigenic components involved in the generation and maintenance of bone cancer pain. Understanding the different factors that drive cancer pain may allow the development of mechanism based therapies to treat this chronic pain state.

10:00 AM - PLENARY SESSION
RESEARCH AND TREATMENT FOR THE FEAR OF PAIN

Chair: Manon Choinière PhD

Centre de recherche, Institut de cardiologie de Montréal, Montreal, Quebec

Speakers: Gordon Asmundson PhD, Johan Vlaeyen PhD

\section{EMPIRICALLY SUPPORTED VULNERABILITY FACTORS: AN UPDATE ON FEAR AVOIDANCE MODELS}

Gordon JG Asmundson PhD

Professor, Anxiety and Illness Behaviours Laboratory, University of Regina, Regina, Saskatchewan

Learning Objectives:

a. To teach fundamentals of fear-avoidance models of chronic pain.

$b$. To review and update knowledge of current research in the area.

c. To outline treatment implications.

Fear models have been the impetus for advances in understanding maladaptive cognitive and behavioural patterns often associated with chronic pain. The purpose of this presentation will be several fold. First, an overview of postulates of the fear based models will be provided. While several distinct models have been proposed, they are similar in that each holds that cognitive, physiological, and behavioural responses to pain represent components of a phobic response that serves to maintain pain over time. Comparisons to common notions of chronic fear and anxiety will be drawn. Second, studies conducted by ourselves and others that implicate anxiety sensitivity (ie, an individual difference variable denoting proneness to experience fear in response to anxiety-like sensations) as being predictive of fear of pain, painspecific avoidance, and functional disability will be reviewed. The available evidence suggests that anxiety sensitivity and related constructs denote vulverability factors for chronic pain. Third, emerging empirical strategies for evaluating the postulates of the fear models will be highlighted. Behavioural genetics and cognitive experimental approaches underway in our laboratory will be highlighted. Finally, treatment implications stemming from the fear models and related empirical evidence will be briefly profiled as an introduction to Professor Vlaeyen's presentation.

\section{FEAR REDUCTION IN CHRONIC PAIN: PROCEDURES AND CURRENT FINDINGS \\ Johan WS Vlaeyen PhD}

Associate Professor, Behavioral Medicine, University of Maastricht, Maastricht, The Netherlands

Learning Objectives:

Participants will be able:

a. To understand learning theory and fear mechanisms that contribute to the development of chronic disability in musculoskeletal pain. 
b. To be able to identify pain-related fear in musculoskeletal pain and use existing assessment tools

c. To understand theory-based cognitive-behavioral treatments in the management of pain-related fear.

The early notion that, in chronic patients, the lowered ability to accomplish tasks of daily living is merely the consequence of pain severity has now been reconsidered. Indeed, a steadily increasing number of studies are showing that physical performance and self-reported disability levels in chronic pain are associated with cognitive and behavioral aspects of pain rather than sensory and biomedical ones. Fear-avoidance models have been proposed, and an increasing number of studies have successfully tested its major assumptions. Laboratory studies have shown that exposure to the feared stimuli produces one of the strongest means for the reduction of fear, and recently this method has been applied in patients suffering chronic pain and pain-related fear. In this presentation, we will briefly review existing methods for fear reduction in behavioral medicine. Second, we will describe the exposure in vivo treatment and the application of behavioral experiments as the state of the art method for the reduction of painrelated fear in chronic pain. Third, we will review the experimental evidence on the effects of exposure in chronic pain patients, both in the laboratory as in the clinical setting. Finally, the issue whether not only patients, but health care providers as well can be fear-avoidant will be addressed and illustrated with recent study results from our research group.

\section{1:30 AM - HOT TOPICS IN PAIN RESEARCH}

\section{Chair: Ian Beauprie MD FRCPC}

Department of Anesthesia, Dalhousie University and Queen Elizabeth II Health Sciences Centre, Halifax, Nova Scotia Speakers: Janice Rae RN MN, Jean-Sébastien Walczak MSc, David W Haley PhD, Vanessa Palter BScH

\section{POST-SURGICAL PAIN MANAGEMENT: IMPACT OF AN ACUTE PAIN SERVICE}

Tracy Hyndman RN MN1', Dr Dorothy Hughes RN PhD², Janice Rae RN MN3

${ }^{1}$ Clinical Nurse Specialist, Acute Pain Service, Calgary Health

Region; ${ }^{2}$ Associate Professor, University of Calgary; ${ }^{3}$ Clinical Nurse Specialist, Acute Pain Service, Calgary Health Region, Calgary,

\section{Alberta}

AIM: The aim of this study was to determine if there was a difference between patients cared for by the Acute Pain Service (APS) and those who received standard post-surgical (SPS) pain management.

METHODS: A retrospective quantitative design was used to determine the impact of an APS on post-surgical inpatients in three adult hospitals within the Calgary Health Region (CHR). The sample size $(n=455)$ for this study was based on the Postoperative Pain Management Quality Assessment Survey conducted within the surgical services portfolio from September 1, 2001 to August 31, 2002. Parametric and non-parametric statistics were used to evaluate the data. The research protocol was submitted to the Conjoint Health Research Ethics Board and received ethical approval.

RESULTS: The APS group and SPS group were significantly different with regards to reason for admission $(\mathrm{p}<0.001 *)$, age $(\mathrm{p}<0.001 *)$, surgical category (Fisher's exact test $=0.001^{*}$ ), and primary modality used (Fisher's exact test $\left.=0.000^{*}\right)$. The APS group reported lower resting pain scores $(p=0.001 *)$, lower moving pain scores $(p=0.000 *)$, were more likely to report never experiencing moderate to severe pain $\left(p=0.006^{*}\right)$, were more likely to report much less pain than expected $\left(\mathrm{p}=0.003^{*}\right)$ and were more likely to receive education about their pain management $\left(\mathrm{p}=0.043^{*}\right)$.

CONCLUSION: This is the first Canadian study to demonstrate that an APS makes a difference to pain intensity, pain frequency, patient expectations, and patient education. A prospective research study should be conducted to further determine if the APS in the CHR is making a difference to post-surgical pain management.

*Very significant
DEVELOPMENT OF THE SAPHENOUS NERVE CONSTRICTION INJURY MODEL OF NEUROPATHIC PAIN IN MICE

lean-Sébastien Walczak MSc ${ }^{1}$, Pierre Beaulieu MD PhD ${ }^{1,2}$

${ }^{1}$ Departments of Pharmacology and ${ }^{2}$ Anesthesiology, Faculty of Medicine, Université de Montréal - CHUM, Montreal, Quebec

Learning Objectives:

a. Participants will be aware of the importance of using the mice saphenous nerve in the study of pain.

b. Participants will be able to understand the development of a model of neuropathic pain by behavioral testing in mice.

BACKGROUND AND AIMS: The saphenous nerve is an exclusively sensory nerve which is useful to study pain mechanisms in the well-known in vitro skin-nerve preparation. We have recently developed a new model (Saphenous Partial Ligation, SPL) of neuropathic pain in the rat and we extended this model to mice.

METHODS: All procedures conformed to the CCAC guidelines. Male C57Bl6 mice $(n=24)$ were operated through a small incision on the anterior surface of the thigh and the saphenous nerve was exposed. In the operated group, three loose ligatures were performed around the nerve, whereas the sham group had their saphenous nerve exposed but left intact. Cold and mechanical allodynia as well as mechanical and thermal hyperalgesia were assessed every other day during one week and then weekly during one month postsurgery on ipsi- and contralateral plantar surfaces of the hind paws.

RESULTS: From postoperative day 3 to day 28, operated mice displayed clear behavioral signs of neuropathic pain in the four modalities tested. No such behavior was observed in the sham group.

CONCLUSIONS: These results show that a model of neuropathic pain can be developed on the saphenous nerve in mice. This model would provide a potent tool to clarify peripheral mechanisms of neuropathic pain using strains of mice that lack or overexpress genes of interest.

\section{DO STEROIDS DURING DELIVERY ALTER RELATIONS BETWEEN NEONATAL PAIN AND STRESS REACTIVITY IN PRETERM INFANTS? David W Haley PhD ${ }^{1,2}$, Ruth E Grunau PhD ${ }^{1,2}$,}

Joanne Weinberg $\mathrm{PhD}^{1,3}$, Alfonso Solimano $\mathrm{MD}^{2}$

${ }^{1}$ Centre for Community Child Health Research, BC Research Institute for Children's \& Women's Health, University of Vancouver; ${ }^{2}$ Department of Pediatrics, and ${ }^{3}$ Department of Anatomy and Cell Biology, University of British Columbia, Vancouver, British Columbia

INTRODUCTION: Corticosteroids affect multiple aspects of physiology. Previously we reported that cumulative neonatal pain predicted dampened cortisol response to stress at 32 weeks gestation in infants born extremely preterm, who were free of postnatal steroid exposure. However, another lab recently reported that prenatal steroids given to the mother suppressed infants cortisol response to heel-lance.

OBJECTIVE: To examine whether exposure to prenatal steroids, rather than prior pain, might account for down-regulation of infant cortisol to stress.

METHODS: $\mathrm{N}=30$ preterm infants born extremely low gestational age $\leq 28$ weeks ( 16 boys, 14 girls) participated in the study at 32 weeks postconceptional age. Infants who had received analgesia or sedation in the 72 hours prior to study, or received any post-natal dexamethasone were excluded. Plasma cortisol was obtained $20 \mathrm{~min}$ following a standard series of nursing procedures (diaper change, girth measurement, temperature, mouth care). Medical chart review included number of prenatal dexamethasone courses administered to the mother during delivery, and cumulative neonatal procedural pain exposure (defined as the number of skin breaking procedures since birth), in addition to neonatal characteristics. RESULTS: Hierarchical regression analysis showed that higher cumulative neonatal procedural pain exposure predicted lower cortisol responses to stress $(t=-2.22, p=.05)$, after controlling for prenatal dexamethasone, postnatal illness severity and morphine exposure since birth.

CONCLUSION: Pain-related alterations in infant cortisol response to stress were not accounted for by prenatal steroids. 
EFFECTIVENESS OF COGNITIVE-BEHAVIOURAL TREATMENT IN A GROUP PROGRAM FOR PATIENTS WITH CHRONIC NON-CANCER PAIN

Vanessa Palter BScH ${ }^{1}$, Jenny Lam-McCulloch MSc MPhil(c) ${ }^{2}$, Kathy Ross RN BScN ${ }^{3}$, Ted Robinson MD CCFP FCFP4 ${ }^{1}$ Third Year Medical Student, University of Toronto; ${ }^{2}$ Department of Anaesthesia, Sunnybrook and Women's College Health Sciences Centre; ${ }^{3}$ Clinical Coordinator, Pain Management Program, Sunnybrook and Women's College Health Sciences Centre; 4Pain Management Program, Sunnybrook and Women's College Health Sciences Centre, Toronto, Ontario

\section{Learning Objective:}

a. Participants will have a greater understanding of what constitutes the long and short term effects of CBT therapy for individuals with chronic non-cancer pain. AIM: To determine whether the techniques learned in a CognitiveBehavioural Treatment (CBT) group are effective in improving general functioning and mood in patients living with chronic non-cancer pain (CNCP). BACKGROUND: The purpose of CBT is to teach individuals the skills necessary to control pain and disability (1). Research suggests that CBT in adults with chronic pain is effective and may play an important role in controlling pain symptoms (2).

METHODS: Patients completed a series of standardized questionnaires at week 1, week 9, and 3-4 months after completing the CBT program. Questionnaires were used to measure pain levels, anxiety, depression, anger, pain disability perception, active and passive coping, and general health perception. Group interventions include education, learning coping skills, guided pain imagery, cognitive strategies such as modifying negative thoughts, pacing, and goal setting. CBT is conducted in a group to enhance self-efficacy through peer support and learning.

RESULTS: Seventy patients completed the nine-week group program and provided the full complement of questionnaires. 20/70 patients provided follow-up data 3-4 months post-program completion. Patients reported increased control of their pain, as well as a significant improvement in their levels of depression, and disability perception. They also reported increased active and decreased passive coping, and a trend was observed towards decreased anxiety.

CONCLUSIONS: CBT has been shown to be effective in mitigating the effects of CNCP. Further data from larger numbers would help clarify how well the effects of the CBT program were sustained and even increased as participants continued to apply the strategies after completing the program.

\section{References}

1. Bradley L. Cognitive-behavioral therapy for primary fibromyalgia. J Rheumatol 1989;16(Suppl 19):131-6.

2. Morley S, Eccleston C, Wiliams A. Systematic review and meta-analyses of randomized controlled trials of cognitive behaviour therapy and behavioural therapy for chronic pain in adults, excluding headache. Pain 1999;80:1-13.

1:00 PM - TRAINEE SESSION
"SHOW ME THE MONEY!": STRATEGIES FOR TRAINEES
ON HOW TO GET FUNDED FOR PAIN RESEARCH

\section{Christine T Chambers PhD RPsych}

Canada Research Chair in Pain and Child Health, Departments of Pediatrics and Psychology, Dalhousie University and IWK Health Centre, Halifax, Nova Scotia

\section{Learning Objective:}

a) Participants will learn how to apply strategies for preparing successful funding applications

This interactive session will provide an opportunity for trainees to learn the basics of grant writing and strategies for completing successful funding applications, including operating and salary awards. An overview of common sources of funding for undergraduate, graduate, and post-graduate research will be provided. Common errors made by trainees on funding applications and ways to avoid them will be discussed. In addition, issues specific to applying for funding for research in the area of pain (eg, addressing ethical issues) will be discussed. The content of the session will be appropriate for new trainees who have never applied for funding before, as well as seasoned trainees who are interested in learning how to set themselves up for funding as a new, independent investigator.

\begin{tabular}{c}
\hline 1:30 PM - WORKSHOP \#2 \\
CLINICAL RELEVANCE OF NEW ADVANCES IN THE \\
PLACEBO EFFECT ON PAIN AND ANALGESIA \\
\hline
\end{tabular}

Chair: Serge Marchand PhD

Université de Sherbrooke, Chair, UQAT-UdeS in Pain, Sherbrooke, Quebec

Speakers: Serge Marchand PhD, Pierre Rainville PhD,

Jon StoessI MD, Leora Swartzman PhD, Fabrizio Benedetti MD

\section{FROM EXPERIMENTAL TO CLINICAL IMPLICATIONS OF PLACEBO ANALGESIA}

Serge Marchand PhD

Université de Sherbrooke, Sherbrooke, Quebec

Studying the effect of placebo analgesia in experimental pain presents the advantage of controlling the different parameters of the induced pain (onset, duration, intensity, repetition). However, one concern with experimental studies is the generalizability of findings to clinical settings. On the other hand, clinical trials may present some limitations because of the natural variability of the pain condition over time.

For example, placebo effects have been suggested to be more potent on clinical than experimental pain. However, this proposition is based on the comparison of the magnitude of placebo analgesia between studies using different methodologies or between different groups of subjects within the same study. During this talk, we will present some of our data using a design where placebo analgesia has been measured for both experimental and clinical pain in the same subjects. We will describe how the combination of experimental and clinical pain in the same experimental design permit better understanding of different factors such as the role of expectation and conditioning on the placebo response. Finally, the potency and persistency of the placebo induced analgesia will be discussed.

\section{CEREBRAL MECHANISMS OF PLACEBO ANALGESIA}

Pierre Rainville PhD

Université de Montréal, Montreal, Quebec

\section{THE PLACEBO EFFECT: THE CASE OF PARKINSONISM} Jon StoessI MD ${ }^{1}$,Sara Lidsone ${ }^{2}$, Raul de la Fuente-Fernandez ${ }^{2}$ 1University of British Columbia, Pacific Parkinson's Research Centre, Canada Research Chair in CNS Disorders; 2Pacific Parkinson's Research Centre, University of British Columbia and Vancouver Coastal Health Research Institute, Vancouver, British Columbia

Learning Objectives:

a. Participants will be aware of the importance of the placebo effect in medical and surgical treatment of Parkinson's disease.

b. Participants will understand the role of dopamine release in mediating both the expectation and the experience of therapeutic benefit in Parkinson's disease.

c. Participants will understand the rationale for considering dopamine release as a potential factor mediating the placebo effect in other conditions.

A beneficial response to placebo is commonly seen in studies of medication used for Parkinson's disease (PD). Contrary to popular belief, the placebo response may not be restricted to the earliest stages of a trial, and may indeed be sustained throughout. This is particularly evident in trials of surgical therapies, where responses to sham treatment may persist throughout the study, and be of considerable magnitude. One recent study of human fetal midbrain transplantation demonstrated that the best predictor of outcome was not which treatment the patients actually received, but rather, which treatment they thought they received (1). Using positron emission tomography with the dopamine receptor ligand [11C] raclopride, we demonstrated that placebo administration in PD was associated with a substantial level of dopamine release. In the dorsal (motor) striatum, patients who experienced a greater degree of subjective improvement demonstrated higher levels of dopamine release. In contrast, in the ventral striatum, a similar degree of dopamine release was seen in all subjects. We believe that ventral striatal dopamine release underlies the expectation of benefit, whereas in the case of PD, dopamine release in the dorsal striatum led to symptom relief. Given that therapeutic benefit can be seen as a form of 
reward, we believe that the expectation of therapeutic benefit that underlies the placebo effect in other conditions may also be in part mediated by dopamine release. However, other more disease-specific mechanisms likely contribute to the experience of symptom relief in those conditions.

\section{Reference}

1. McRae C, Cherin E, Yamazaki TG, et al. Effects of perceived treatment on quality of life and medical outcomes in a double-blind placebo surgery trial. Arch Gen Psychiatry 2004;61:412-20.

\section{EXAMINING PLACEBO MECHANISMS WITHIN THE CONTEXT OF CLINICAL TRIALS: METHODOLOGICAL APPROACHES AND ETHICAL CHALLENGES \\ Leora Swartzman PhD \\ Associate Professor, Department of Psychology, The University of Western Ontario, London, Ontario}

\section{Learning Objectives:}

a. Understand experimental designs used to clarify placebo mechanisms in clinical trials.

b. Appreciate how the 'balanced placebo design' can build on these approaches, but violates the ethical principle of 'informed consent'.

c. Understand how 'authorized deception' can serve as a potential solution to this ethical challenge.

The most straightforward way to clarify placebo mechanisms is to manipulate participants' expectations while holding constant the pharmacological (or other) properties of the administered intervention. The ethical challenge, however, particularly in a clinical context, is that this may involve deception, which conflicts with the ethical principal of 'informed consent'. Accordingly, clinical investigators interested in studying placebo mechanisms thus far have used non-deceptive research paradigms, such as comparing an open versus closed (1), or an open versus double-blind (2) administration of a therapeutic agent. One drawback of these paradigms is that they do not fully manipulate expectancy and pharmacology in a factorial design, and thus do not permit a rigorous evaluation of drug versus expectancy effects and their interaction. In contrast, in the 'balanced placebo design' (3) both expectancies and the pharmacological agent are manipulated. This paradigm however, involves deception of study participants. 'Authorized deception' (4) is an approach proposed to obtaining informed consent that would warn prospective participants about the potential deception, thereby preserving 'informed consent'.

\section{References}

1. Amanzio M, Pollo A, Maggi G, Benedetti F. Response variability to analgesics: A role for non-specific activation of endongenous opioids. Pain 2001;90:205-15.

2. Benedetti F, Pollo A, Lopiano L, Lanotte M, Vighetti S, Rainero I. Conscious expectation and unconscious conditioning in analgesic, motor, and hormonal placebo/nocebo responses. J Neurosci 2003;23:4315-23.

3. Rohsenow DJ, Marlatt, GA. The balanced placebo design: Methodological considerations. Addictive Behaviors 1981;6:107-22

4. Wendler D, Miller FG. Deception in the pursuit of science. Arch Intern Med 2004;164:597-600.

\section{FUTURE DIRECTIONS IN THE FIELD OF PLACEBO AND PAIN Fabrizio Benedetti MD}

Professor, Clinical and Applied Physiology Program, Department of Neuroscience, University of Turin Medical School, Turin, Italy

Learning Objectives:

a. Participants will have a heightened awareness about the future research needs in the field of placebo.

b. Participants will be informed about the implications and applications of placebo research both in clinical trials design and medical practice.

A brief introduction on the recent advances in placebo research will be followed by a discussion on the current and future approaches necessary to better understand the intricate psychophysiological mechanisms of the placebo response. In particular, it will be shown that the neurobiological approach, with its brain imaging methods, single neuron recording in humans and endocrine-immune techniques, is likely to shed light on the mechanisms of this complex phenomenon.

In light of these recent advances, the placebo response is likely to become one of the most interesting and fruitful models to understand mind-body interactions. Not only does this add new scientific knowledge to the biology of human beings and their brains, but it also leads to new concepts in clinical trials design and routine medical practice.
1:30 PM - SESSION 107

ORGANIZATION OF HEALTH SERVICES FOR CHRONIC PAIN

Chair: Allen Finley MD

Pediatric Anesthesia, IWK Health Centre, Halifax, Nova Scotia Speakers: Patrician Dobkin PhD, Paul Taenzer PhD

\section{A GLOBAL PERSPECTIVE OF ORGANIZATIONAL ISSUES AND INITIATIVES}

Patricia L Dobkin PhD 1 , Lucy Boothroyd MSc ${ }^{2}$

1Associate Professor, Department of Medicine, McGill University;

${ }^{2}$ Research Associate, Québec Health Technology Assessment

Agency, Montreal, Quebec

Learning Objectives:

a. Participants will learn how health services are provided to patients with chronic pain in various jurisdictions.

b. Participants will be able to identify key issues facing policy makers deciding how to provide health services for chronic pain patients.

Dr Dobkin will outline how three jurisdictions with different health care systems on three continents in the developed world provide services for patients with chronic pain. Australia, France, and the American Veteran's Health Administration were selected because they have identified pain as a priority, differ considerably in their approaches, and raise important issues for consideration. The key issues to be discussed during this workshop are: 1) overall vision, ie, what types of pain and which populations are covered; 2) structure of health care services ie, primary, secondary and tertiary care; 3) health professionals' roles and responsibilities by level of care; 4) continuity of care and integration of care; and 5) patient outcomes and quality of services. Challenges experienced by most health care systems, eg, access and integration of services, will be examined and innovations found throughout the world to address these problems will be presented. Given that the Minister of Health and Social Services mandated the Québec Agency for Health Technology Assessment to conduct this work, how this knowledge is being transferred to policy makers will be highlighted.

THE CALGARY MODEL: CHALLENGES AND SOLUTIONS Paul Taenzer PhD ${ }^{1}$, Valerie Wiebe RN MN², Ted Braun MD ${ }^{3}$ ${ }^{1}$ Clinical Service Manager, Calgary Health Region Chronic Pain Centre; ${ }^{2}$ Director, Regional Pain Program, Calgary Health Region; ${ }^{3}$ Medical Director, Regional Pain Program, Calgary Health Region, Calgary, Alberta

OVERALL AIM: To introduce participants to an integrated service delivery model for chronic pain developed by the Calgary Health Region (CHR).

Learning Objectives:

After the session, participants will:

a. Be familiar with the conceptual foundations for the CHR's Regional Pain Program (RPP)

b. Understand the process used to obtain stakeholder support from the regional executive to the clinical leaders in the community.

c. Be familiar with the process and results of the regional strategic planning process for pain management.

d. Understand how the original tertiary service delivery model for chronic pain is being levered to create an integrated education, service delivery, research and evaluation model.

METHOD: In 2003, the CHR, RPP initiated a planning process to develop a strategic plan for enhancing access and quality of care for patients with pain. The goal was to develop an integrated systems model of care across continuum (hospital and community) across the lifespan from pediatrics to geriatrics. All stakeholders including the professional training faculties from the University of Calgary, community providers in private practice and service delivery units within the CHR have been active participants. RESULTS: The RPP has developed a strategic plan for pain management. Priorities include a variety of initiatives to support chronic disease management and primary care reform, implementation of a chronic pain service in all hospitals, a variety of strategies to improve quality and enhance coordination of care. 
CONCLUSIONS: Current trends and changes in Canada's health system provide opportunities to meet the needs of chronic pain patients in a variety of innovative ways: enhanced access and improved quality of care can be achieved by extending service delivery beyond the tertiary care chronic pain centres.

\section{1:30 PM - SESSION 108 \\ COMPLEMENTARY MEDICINE AND CHRONIC PAIN: TOWARDS A UNIFIED APPROACH}

\begin{abstract}
Chair: Mark Ware MD
McGill Pain Centre and Montreal General Hospital, Montreal, Quebec Speakers: Mark Ware MD MRCP (UK) MSc (Workshop Chair) ${ }^{1}$, Jennifer Cogan MD MSc FRCPC ${ }^{2}$, Yoram Shir MD ${ }^{1}$

1McGill Pain Center, McGill University Health Centre (MUHC); 2Montreal Heart Institute, University of Montreal, Montreal, Quebec OVERALL AIMS: The purpose of this workshop is to introduce concepts of complementary and alternative medicine (CAM) within a chronic pain management framework.

Learning Objectives:

a. Participants will be of the epidemiology of CAM use in chronic pain.

b. Participants will be able to discuss clinical evidence for different types of energy medicine.

c. Participants will be aware of dietary considerations in chronic pain.

d. Participants will identify research priorities for CAM therapies and chronic pain.
\end{abstract}

EPIDEMIOLOGY OF CAM USE BY PATIENTS WITH CHRONIC PAIN Dr Ware will discuss the epidemiology of CAM use by pain patients and the perceptions of benefit. An overview of the evidence base for some of these practices will be provided. Gaps in the research knowledge base will be discussed.

\section{AN OVERVIEW OF SELECTED MIND-BODY AND ENERGY TECHNIQUES}

Dr Cogan will provide an overview of the field of Energy Medicine. She will present the various modalities that are included in this rubric, the underlying rational for their use, the evidence for their efficacy and discuss where and how they can integrated into mainstream medical care.

\section{AN OVERVIEW OF OUR KNOWLEDGE OF THE EFFECT OF DIET} ON ACUTE AND CHRONIC PAIN

Dr Shir will present an overview of our knowledge of the effect of diet on acute pain in animals and will describe his research pertaining to the effect of specific dietary components on chronic pain behaviour in experimental animals. An overview on the effect of diet on pain in humans will be provided.

\begin{tabular}{c}
\hline 1:30 PM - SESSION 109 \\
ADVANCES IN POST-STROKE THALAMIC PAIN AND \\
SPINAL CORD PAIN \\
\hline
\end{tabular}

Chair: Rob Brownstone MD PhD

Division of Neurosurgery, QEII Health Sciences Centre, Halifax, Nova Scotia

Speakers: Akbar Panju MDChB FRCPC, Christine Short MD FRCPC

\section{ADVANCES IN THE UNDERSTANDING AND MANAGEMENT OF POST-STROKE THALAMIC PAIN \\ Akbar Panju MBChB FRCPC}

Medard DeGroote Chair in Medicine, Professor of Medicine, McMaster University, Chief of Medicine, Hamilton Health Sciences and Medical Director, Michael G DeGroote Institute for Pain Research and Care, Hamilton, Ontario

\section{CLASSIFICATION AND MANAGEMENT OF PAIN IN SPINAL CORD INJURY \\ Christine Short MD FRCPC}

Physical Medicine and Rehabilitation, QEII Health Sciences Centre, Nova Scotia Rehabilitation Centre Site, Halifax, Nova Scotia

\begin{tabular}{c} 
4:00 PM - SESSION 110 \\
PAEDIATRIC PAIN MANAGEMENT IN \\
THE 21ST CENTURY: MOVING FORWARD USING \\
E-HEALTH TECHNOLOGIES \\
\hline
\end{tabular}

Chair: Bonnie Stevens RN PhD

Faculty of Nursing, University of Toronto and The Hospital For Sick Children, Toronto, Ontario

Speakers: Jennifer Stinson BScN MSc, Simon Beggs PhD,

Bonnie Stevens RN PhD

OVERALL AIMS: E-health technologies can help children, parents, and clinicians learn more about pain assessment and management and thus make informed decisions about the treatment of children's pain. This symposium brings together experts in pain with various types of expertise with e-health. Presentations will focus on the opportunities and challenges of pain-based e-health technologies such as web-based systems and mobile hand-held devices. A major focus of this session will be on presenting state-of-the-art e-health strategies that target children, parents, health care professionals and other lay consumers with the common aim of alleviating pain in children.

Delegates will learn:

a. About the opportunities and challenges of using e-health technologies to improve the assessment and management of pain in infants, children and adolescents.

b. About usability testing as a method of evaluating user performance and satisfaction during the design and development of health information systems such as Web-based systems and mobile hand-held devices such as cellular telephones and personal digital assistants (PDAs).

c. About current research efforts in the development and validation of innovative Web-based systems and mobile hand-held devices to aid clinicians, children and their families, and other health care consumers in decision making regarding pain assessment and management.

DESCRIPTION OF WORKSHOP: Despite our increasing knowledge of pain, infants and children continue to experience less than optimal pain relief. To enhance pain management, we need to develop innovative strategies to educate children, parents, other lay consumers and health professionals on the best ways to assess and manage pain in children. This symposium will highlight a number of e-health technologies that offer an exciting and promising avenue for addressing the issues that perpetuate the under-treatment of pain in children. Mobile hand-held devices such as the newly developed "e-Ouch" measure can be used in the assessment of pain. Web-based systems such as the "AboutKidsHealth" web-site at Sick Kids are being developed to help children, families, health care professionals and lay consumers learn about pain from the basic neurobiology of pain in children, to the latest pain treatment strategies. These technologies can also be used to dispel misconceptions about pain and provide accurate information using interactive, narrated animation to educate users on pain assessment and management. This session outlines methods and challenges encountered during the development and testing of e-health technologies in pediatric pain.

\section{E-OUCH: USABILITY TESTING OF AN ELECTRONIC PAIN DIARY FOR ADOLESCENTS WITH ARTHRITIS \\ Jennifer Stinson RN MSc CPNP \\ University of Toronto, Faculty of Nursing and Sick Kids, Toronto, Ontario}

Chronic pain is a significant problem for children and adolescents with chronic illnesses such as arthritis. Chronic pain significantly impairs children's quality of life, causing physical disability and emotional distress. Assessment is the crucial first step in the effective management of pain. While paper diaries for assessing chronic pain in children exist, they rely on attention span, recall, and compliance and often do not include the multidimensional aspects of pain. Electronic pain diaries using a Personal Digital Assistant (PDA) have the potential to maximize the compliance, validity and reliability of pain assessment data. However, there has been no research evaluating the usability of electronic pain diaries; we do not know how children and adolescents interact with PDA technology (ie, user behavior) and how this interaction affects usability.

This session discusses a qualitative usability testing approach based on the concept of a "hermeneutical circle" that was employed to determine the usability and intuitiveness of the e-Ouch pain diary user interface and helped to further refine the prototype. The benefits of employing a User 
Centred Design (UCD) approach early in the design phase of e-health technologies will be discussed. Furthermore, the knowledge generated from this study can serve as a model for the development of assessment instruments using electronic approaches (eg, web-based, PDA) and for other paediatric populations with chronic pain.

\section{WEB-BASED INFORMATION SYSTEM FOR HEALTH CARE PROFESSIONALS: THE DEVELOPMENTAL NEUROBIOLOGY OF PAIN} Simon Beggs PhD

University of Toronto Centre for the Study of Pain and Sick Kids, Toronto, Ontario

Basic science research has made great advances in recent years in elucidating the mechanisms underlying the developmental neurobiology of pain. This knowledge is reflected in health care practices, particularly neonatal critical care, where a fundamental understanding of postnatal developmental neurobiology has led to improved assessment and pain management. This knowledge is particularly relevant to the specific treatment modalities of pain in this age group. As more advances are made, the issue of knowledge dissemination becomes more pertinent. This session discusses a recently developed Web-based approach to understanding developmental biological issues aimed at informing health-care professionals of the mechanistic aspects of neonatal pain.

\section{EXPLORING THE HEALTH INFORMATION NEEDS OF CHILDREN AND PARENTS IN REGARDS TO A PAIN INTERNET SITE: A PILOT PROJECT \\ Dr Bonnie Stevens RN PhD \\ University of Toronto, Faculty of Nursing and Sick Kids, Toronto, Ontario}

Pain is a common problem in children that can negatively impact all domains of quality of life. Parents may not receive adequate information from health care professionals about how to assess and manage their child's pain. Furthermore, children themselves may have many questions that go unanswered. The Internet is becoming an increasingly important source of health information for children and their parents about pain. However, parents need a valid and comprehensive online pain resource to inform and guide decisions that will ultimately influence the health outcomes and quality of life of their children. Relatively little is known about parents and children's Internet-based health information needs.

The objective of this talk is to discuss patient needs and preferences pertaining to the design and development of the AboutKidsHealth pain website at Sick Kids. The critical success factors associated with the development and implementation of this web-site for children, parents and other health care consumers will be discussed.

4:00 PM - SESSION 111
IMPROVED TRIAGE AND MANAGEMENT OF
SPINAL PAIN TRANSLATING BASIC SCIENCE DATA
INTO IMPROVED CLINICAL CARE

Chair: Ellen N Thompson MB BS FRCP

Staff Anaesthesiologist and Consultant in Pain Management, Department of Anaesthesia, The Ottawa Hospital, Ottawa, Ontario Speakers: Ellen N Thompson MB BS FRCP, Eugene Wai MSc FRCSC

Ellen N Thompson MB BS FRCP ${ }^{1}$, Eugene K Wai MD FRCSC ${ }^{2}$

${ }^{1}$ Chair, Staff Anaesthesiologist and Consultant in Pain Management, Department of Anaesthesia, The Ottawa Hospital; 2Assistant Professor, University of Ottawa, Division of Orthopaedic Surgery, Spinal Unit, The Ottawa Hospital, Ottawa, Ontario

Learning Objective:

a. Following a review of pertinent basic science data, participants will see how application of this knowledge to clinical care may result in improved outcomes, particularly in spinal pain states, with a goal of preventing the transition from acute to chronic pain.

Over the past three decades a great deal of important data furthering our understanding of pain mechanisms have been provided by basic neuroscientists. This knowledge has generally not been adopted by clinicians. By applying data from the genetics of pain (Mogil J), data regarding central sensitization and "wind-up" (Wall PD, Woolf C), and spinal glial activation (Watkins L) to name just a few, clinicians could reduce the percentage of acute pain states becoming chronic. A risk scoring system to identify individuals most at risk for chronicity will be proposed. In Canada, waiting time to access tertiary spinal care such as CT/MRI scans, specialist consultations, and elective interventions and surgery, vary by geographic region; however, they are universally considered excessive and deteriorating with time. Despite this, the majority of CT/MRI scans have been performed for inappropriate indications and do not lead to changes in management decisions. Furthermore, the majority of patients referred to spinal surgeons, do not undergo surgical intervention. To confound this, a significant proportion of patients on these waiting lists do not receive any evidence based primary care interventions. The development of an effective triage program to identify patients that would benefit from tertiary imaging, interventional and surgical care would help reduce wait times and expedite the rapid treatment of patients who would benefit from these services.

$$
\text { 4:00 PM - SESSION } 112
$$

ADVOCACY FOR CLINICAL PAIN SERVICES IN CANADA

Chair: Dwight Moulin MD FRCPC

Departments of Clinical Neurological Sciences and Oncology, University of Western Ontario, London, Ontario Speakers: Helen Tupper RN, Allan Gordon MD FRCPC, Patricia Morley-Forster MD FRCPC, Celeste Johnston RN DEd The prevalence of chronic pain in Canada is in the range of $25 \%-30 \%$. It is therefore not surprising that there is a huge gap between the supply and demand for pain management services. At present, the medical community cannot possibly meet the needs of the chronic pain population in Canada and this has reached crisis proportions. This workshop will explore strategies to address the problem of chronic pain in Canada through advocacy mechanisms.

\section{COPING WITH CHRONIC PAIN - A PATIENT'S PERSPECTIVE Helen Tupper RN \\ Founding Member, Co-Chair Canadian Pain Coalition, Artist}

\section{STRATEGIES FOR PATIENT ADVOCACY FOR CHRONIC PAIN Allan Gordon MD FRCPC}

Wasser Pain Management Centre, Mount Sinai Hospital, and Centre for the Study of Pain, University of Toronto, Toronto, Ontario

ROLE OF UNIVERSITY-AFFILIATED PAIN CLINICS IN ADVOCATING FOR POLITICAL CHANGE - UNITED WE STAND...

Patricia Morley-Forster MD FRCPC

Earl Russell Chair/Director of Interdisciplinary Pain Program, University of Western Ontario, London, Ontario

HOW THE CANADIAN PAIN COALITION CAN HELP Celeste Johnston RN DEd

James McGill Professor, School of Nursing, McGill University, Montreal, Quebec; and President, Canadian Pain Coalition 


\section{SCIENTIFIC PROGRAM \\ SATURDAY, MAY 14, 2005}

\begin{tabular}{c} 
8:15 AM - KEYNOTE SPEAKER \\
THE SOCIAL COMMUNICATION PERSPECTIVE ON PAIN: \\
SEARCH FOR AN INCLUSIVE MODEL \\
\hline
\end{tabular}

Chair: Patrick McGrath PhD, Department of Psychology, IWK Health Centre, Dalhousie University, Canada Research Chair in Pediatric Pain, Halifax, Nova Scotia Ken Craig PhD

2004 Canadian Pain Society Distinguished Career Recipient, Department of Psychology, University of British Columbia, Vancouver, British Columbia

The Social Communication Perspective on Pain: Search for an Inclusive Model Pain often remains poorly recognized, under-assessed, under-estimated, and under-managed. Addressing these problems requires appreciation of interpersonal determinants of the experience and expression of pain and delivery of care, considerations often neglected in models of pain featuring intrapersonal, biological and psychological mechanisms. The social communications perspective will be illustrated with studies examining socialization of pain experience, language development, misrepresentation of pain, and biases in judging and delivering pain services, particularly with persons with communication limitations.

\section{0:15 AM - PLENARY SESSION \\ PARADOXICAL EFFECTS OF OPIOIDS}

Chair: Jana Sawynok PhD

Department of Pharmacology, Dalhousie University, Halifax, Nova Scotia

\section{FROM ANALGESIA TO HYPERALGESIA: NEW CONCEPTS FOR NEW THERAPIES \\ Guy Simonnet PhD}

Laboratoire "Homéostasie-Allostasie-Pathology", Université Victor Ségalen Bordeaux 2, Bordeaux, France

Although opioids are the analgesics of choice for the treatment of moderate to severe pain, clinical studies have reported that opioids can unexpectedly elicit hyperalgesia and allodynia. In a series of animal experiments, we observed that a single administration of $\mu$ receptor agonists as heroin or fentanyl induced analgesia (hours) which was followed by long-lasting hyperalgesia (days) in non suffering rats (Laulin et al, 1998) and widely enhanced delayed hyperalgesia associated with inflammation or surgical incision (Rivat et al, 2002, Richebé et al, 2005). Such a pain hypersensitivity has been also reported in morphine pellet implanted animals (Vanderah et al, 2001). We also observed that a non nociceptive environmental stress which induced a short and moderate opioid-dependent analgesia (SIA) in naive rats, provoked hyperalgesia for several hours in rats with previous pain and/or opioid experiences. Repetition of such a non nociceptive stress induced a progressive enhancement of hyperalgesia for several days suggesting the development of a pain vulnerability. Interestingly, ultra-low doses of exogenous fentanyl which mimicks SIA in na?ve rats induced an opposite response (hyperalgesia) for several hours in rats with pain and/or opioid histories. Experimental evidences indicate that pharmacological agents or specific diets able to block or negatively modulate the NMDA receptor functioning, though not antinociceptive per se, oppose to central sensitization in animals with prior pain and/or opioid experiences and restore the opioid effectiveness by opposing tolerance underlain by pain hypersensitivity. This could facilitate the postoperative rehabilitation and perhaps limit the development of pain chronicisation following acute pain.
PARADOXICAL MODULATION OF MORPHINE ACTIONS BY ULTRA-LOW DOSES OF OPIOID RECEPTOR ANTAGONISTS Khem $\mathrm{H}$ Jhamandas PhD

Departments of Pharmacology and Toxicology, and Anesthesiology, Queen's University, Kingston, Ontario

Learning Objectives:

a. Participants will be able to describe the proposed role of paradoxical excitatory actions of opioid drugs in tolerance and physical dependence.

b. Participants will be able to describe the basis for blockade of opioid tolerancedependence by low dose opioid antagonists.

The development of tolerance and physical dependence on opioid drugs has been linked to their paradoxical excitatory actions on sensory neurons signaling pain. Since these actions are sensitive to ultra-low doses of opioid receptor antagonists, such doses may be able to influence the genesis of analgesic tolerance and dependence. In experimental models of antinociception, combined administration of ultra-low doses of naltrexone, a non-selective opioid receptor antagonist, with chronic morphine can augment analgesia, inhibit the induction of tolerance and reverse established tolerance. Such doses also suppress the neurochemical and behavioural responses reflective of morphine withdrawal, an indicator of physical dependence. The effects of naltrexone on chronic morphine tolerance are shared by antagonists selective for mu and delta opioid receptors, and these agents also block tolerance induced by acute morphine treatment. The actions of ultra-low doses of classical opioid receptor antagonists on analgesia and tolerance are mimicked by opioid modulatory neuropeptides that target the NPFF receptors. Thus, very doses of opioid antagonists or NPFF-related peptides may be useful in optimizing the analgesic action of opioid drugs.

Supported by CIHR

\section{2:30 PM - LUNCHEON SESSION AND SPEAKERS}

ADVANCES IN NEUROPATHIC PAIN MANAGEMENT

Chair: Dwight Moulin MD FRCPC

Departments of Clinical Neurological Sciences and Oncology, University of Western Ontario, London, Ontario Speakers: Allan Gordon MD FRCPC, Thomas Tölle

\section{UNCOVERING HIDDEN BURDEN OF NEUROPATHIC PAIN Allan Gordon MD FRCPC}

Wasser Pain Management Centre, Mount Sinai Hospital; and University of Toronto, Centre for the Study of Pain, Toronto, Ontario

EMERGENT TREATMENT OPTIONS IN THE MANAGEMENT OF NEP Thomas Tõlle, Professor of Neurology, Head, Interdisciplinary Clinic, Technical University, Munich, Germany

\section{1:30 PM - SESSION 113 \\ MICROVASCULAR DYSFUNCTION AND \\ ALPHA-ADRENOCEPTOR-RESPONSIVENESS - NOVEL IDEAS ON THE ETIOLOGY OF COMPLEX REGIONAL PAIN SYNDROME}

Chair: Gary J Bennett PhD

Department of Anesthesia, Faculty of Dentistry and Centre for Research on Pain, McGill University, Montreal, Quebec Speakers: Gary J Bennett PhD, Robert Teasell MD FRCPC, Terence Coderre PhD

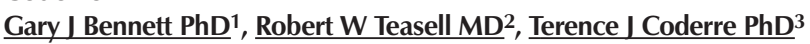
${ }^{1}$ Department of Anesthesia, Faculty of Dentistry and Centre for Research on Pain, McGill University, Montreal, Quebec; ${ }^{2}$ University of Western Ontario and London Health Sciences Center, Physical Medicine and Rehabilitation, London, Ontario; ${ }^{3}$ McGill University, Department of Anesthesia, Montreal, Quebec

Learning Objectives:

a. Participants will receive a review of the clinical characteristics and long-studied theories about the mechanisms of CRPS-I. 
b. Participants will be challenged to question old theories and entertain new ideas about the potential underlying mechanisms of CRPS-I.

Recently, the term reflex sympathetic dystrophy (RSD) has been replaced by complex regional pain syndrome - type I (CRPS-I). The name change reflected a growing dissatisfaction with the implied mechanisms that contribute to pain associated with CRPS-I. Although the name has changed, the pathophysiology of CRPS-I remains a mystery. The focus of this workshop is to take a fresh look at possible mechanisms that contribute to the pain of CRPS-I. Particular attention will be paid to mechanisms that influence vascular function in the affected tissue, and how that affects pain sensitivity in CRPS-I limbs. The workshop will examine two novel mechanisms, alpha-adrenoceptor hyperresponsiveness and microvascular dysfunction, as a critical underlying mechanisms of CRPS-I, and as potential contributors to some aspects of neuropathic pain.

\section{COMPLEX REGIONAL PAIN SYNDROME, CLINICAL} CHARACTERISTICS, HISTORICAL EVIDENCE AND THE NEED FOR A NEW THEORETICAL APPROACH

\section{Gary / Bennett PhD}

Department of Anesthesia, Faculty of Dentistry and Centre for Research on Pain, McGill University, Montreal, Quebec

Dr Bennett will introduce the topic by summarizing the clinical characteristics of CRPS-I, and providing a historical review of theoretical and experimental evidence concerning the etiology of CRPS-I. He will discuss the role of the sympathetic nervous system in CRPS-I, and the reasons why the nomenclature changed from RSD to CRPS-I. He will examine clinical cases that provide evidence that CRPS-I may depend on mechanisms other than hyperactivity of the sympathetic nervous system.

\section{ALPHA-1 ADRENOCEPTOR HYPERRESPONSIVENESS IN COMPLEX REGIONAL PAIN SYNDROME - TYPE I (CRPS-I), DIABETIC PERIPHERAL NEUROPATHIC PAIN AND CENTRAL PAIN FOLLOWING SPINAL CORD INJURY \\ Robert W Teasell MD \\ University of Western Ontario and London Health Sciences Centre, Physical Medicine and Rehabilitation, London, Ontario \\ Dr Teasell will examine three neurological disorders (complex regional pain disorder, painful diabetic neuropathy and spinal cord injury) which have been associated with neuropathic-like pain. He will review evidence which has shown that each of these disorders is associated with abnormal sympathetic nervous system function, and in particular alpha-1 adreno- ceptor hyperresponsiveness. He will assess whether increased alpha-1 hyper-responsiveness is a consequence of alpha-1 adrenoceptor post- synaptic hypersensitivity, or alpha-2 adrenoceptor presynaptic dysfunc- tion. Finally, he will examine plausible mechanisms, based on animal research, by which alpha-1 adrenoceptor hyperresponsiveness can lead to chronic neuropathic-like pain.}

CHRONIC POST-ISCHEMIA PAIN (CPIP): A NEW ANIMAL MODEL SUGGESTS THAT COMPLEX REGIONAL PAIN SYNDROME - TYPE I (CRPS-I) DEPENDS ON MICROVASCULAR DYSFUNCTION FOLLOWING ISCHEMIA-REPERFUSION INJURY

\section{Terence / Coderre PhD}

McGill Centre for Research on Pain and Department of Anesthesia, McGill University, Montreal, Quebec

Dr Coderre will describe experiments using a rat model where CRPS-I-like symptoms are produced following an ischemia-reperfusion injury to the rat's hind paw. He will present a hypothesis that CRPS-I depends on microvascular dysfunction and ischemia associated with no reflow or slow flow following ischemia-reperfusion injury. He will review behavioural evidence that experimental CRPS-I, or CPIP, is alleviated by free radical scavengers, anti-cytokine treatments, vasodilators and alpha- 1 adrenergic antagonists. He will also present recent data indicating that nociception, in the rat model of CRPS-I, is associated with muscle and endoneurial no reflow/slow flow, the release of pro-inflammatory cytokines, and ectopic activity in primary afferent fibers.
1:30 PM - SESSION 114

OFFICE-BASED CHRONIC PAIN MANAGEMENT

Chair: Dr Roman D lovey MD

Physician Director and Pain Consultant, Alcohol and Drug Treatment Program, Credit Valley Hospital, Mississauga, Ontario. Dr Pamela Squire MD CCFP ${ }^{1}$, Dr losh Foley MD $^{2}$ ${ }^{1}$ Family Physician, Community consultant in chronic pain management, and Director, Oncology Pain Clinic, Lion's Gate Hospital, North Vancouver, British Columbia; ${ }^{2}$ Family Physician, Community consultant, chronic pain and palliative care, and Director, Medicine Hat Cancer Clinic, Medicine Hat, Alberta

Attendees of this workshop will learn:

a. The key elements of the assessment process.

b. A stepwise approach to choosing treatment options.

c. A systematic approach to the management of the patient with pain using controlled substances.

d. Strategies for efficient documentation to protect the physician as well as the patient. The ideal management of a patient with chronic pain involves a timely comprehensive multi-disciplinary assessment and a multi-modal treatment approach. In Canada, such "one-stop" pain assessment and treatment programs are scarce and the waiting lists are very long. As a result, clinicians are usually faced with managing patients with complex pain problems in the office with little outside help.

Like many other complicated medical illnesses (ie, diabetes), there is much that an individual clinician can do to help decrease patient suffering. It requires knowledge of some basic principles and the development of a personalized system for data gathering, diagnosis, treatment and monitoring. The goals are to optimize outcomes for the patient and reduce risks for the doctor.

\section{1:30 PM - SESSION 115 \\ EXPANDING THE NOTION OF CHRONIC PAIN TO INFANCY}

Chair: Rebecca Pillai Riddell MA PhD

Department of Psychology, York University and Hospital for Sick Children, Toronto, Ontario

Speakers: Joel Katz PhD, Bonnie Stevens RN PhD, Rebecca Pillai Riddell MA PhD

Rebecca Pillai Riddell MA PhD ${ }^{1}$, Bonnie Stevens RN PhD ${ }^{2}$, loel Katz PhD ${ }^{3}$

${ }^{1}$ York University/Hospital for Sick Children, Department of Psychology, Atkinson; ${ }^{2}$ Faculty of Nursing and Medicine, University of Toronto, and Signy Hildur Eaton Chair in Paediatric Nursing Research, The Hospital for Sick Children; ${ }^{3}$ Department of Psychology, Arts, York University, Toronto, Ontario OVERALL AIMS: To stimulate discussion with clinicians and researchers regarding conceptualizations of chronic pain during infancy.

Learning Objectives:

a. To raise awareness of the paucity of research investigating chronic pain in infancy.

b. To present existing conceptual and research domains that could inform and challenge our understanding of chronic pain during infancy.

c. To elicit from participants their perspectives on chronic pain during infancy, possible infant populations that would be suffering from chronic pain, key indicators that could signal chronic pain in infants, and barriers to understanding chronic pain in infancy.

INTRODUCTION: Defining chronic pain is challenging in all populations due to the existence of multiple domains of inquiry. However, in health care research and practice, current notions of chronic pain have developed based on adult (and less frequently verbal children) models. Due to the consistent focus on acute procedural pain, very little theoretical exploration to date has been undertaken to understand or conceptualize chronic pain in infants. This session is designed to serve as a forum to discuss this unchartered area of pediatric pain. Attendees with clinical or research backgrounds in chronic pain from any stage of the lifespan are strongly encouraged to attend and participate. 
STRUCTURE: Participants will begin the workshop by watching videoclips of infant caregivers describing real case examples of infants they believed were suffering from chronic pain. The workshop will comprise of three speakers and a discussion period ( 4 sections). The workshop panelists will provide a cursory review of conceptual and research domains believed to be relevant to studying chronic pain in infancy: chronic pain in adults, chronic pain in children and acute pain in infants. The second half of the workshop will consist of the panelists facilitating discussion regarding central issues in studying chronic pain in infancy.

\section{EXPLORING POTENTIAL SIMILARITIES AND DIFFERENCES BETWEEN CHRONIC PAIN IN INFANTS AND CHRONIC PAIN IN VERBAL POPULATIONS \\ Dr Joel Katz PhD}

York University, Department of Psychology, Arts, Toronto, Ontario

Chronic pain can be clearly distinguished from acute pain in adult and verbal child populations. The temporal delineation within existing chronic pain definitions presents dilemmas when considering the concept in infants. In infants, the criterion of a fixed pain duration as integral to a definition seems out of place. Instead, consideration may have to be given to pain duration relative to total life span. In addition, infants have limited time comprehension abilities and cannot fully appreciate past, present and future or process information in a moment by moment fashion. Bioethicists have hypothesized that this limitation could result in more severe pain as the infant would neither be able to recall a time when they were not in pain nor hope for a time when they are able to be free of pain. Moreover, the steeper trajectory of physiological development during infancy may require unique timelines for chronicity. On the other hand, the nature of the suffering that often accompanies chronic adult pain is clearly different. Higher order cognitive and emotional processes that are associated with prolonged pain and poorer treatment outcome in adults (eg, catastrophizing, fear of pain, worry, depression, etc.) are absent in infants. Understanding the factors that predict the transition from acute pain to chronic pain in infancy may also have bearing on future pain experiences later in childhood and adulthood.

\section{SEARCHING FOR INDICATORS FOR INFANT CHRONIC PAIN: POSSIBLE CUES FROM THE INFANT ACUTE PAIN CONTEXT Dr Bonnie Stevens RN PhD}

Faculty of Nursing and Medicine, University of Toronto, Signy Hildur Eaton Chair in Paediatric Nursing Research, The Hospital for Sick Children, Toronto, Ontario

The nature and frequency of acute pain in infancy has been well studied and is generally appreciated by health professionals during infancy. Comprehensive examinations of the behavioural (eg, facial expression, body movements, flexion reflex and cry), physiological (ie, heart rate, respiratory rate, blood pressure, oxygen saturation, vagal tone, palmar sweating) and contextual (eg, sleep/wake state, stage of development, severity of illness) indicators of acute procedural pain has resulted in a plethora of validated acute pain measures for term and preterm neonates and infants. However, if research on chronic and acute pain in older children and adults is considered, application of indicators of initial sympathetic arousal (ie, heart rate, respiratory rate, blood pressure) and patterns of acute infant pain behaviours (eg, facial expressions, body movements) will likely not manifest themselves in the same way for chronic pain. Rather, akin to research with verbal children and adults, it is likely that similar categories of indicators will be integral in assessing chronic pain in verbal individuals, such as fatigue, emotional dysregulation, poor sleep, irritability, inability to accomplish developmental expectations, and lack of socialization with surroundings and others.

INVESTIGATING THE ROLE OF CAREGIVERS IN INFANT CHRONIC PAIN: EXAMINING THE RESEARCH ON CAREGIVER INFLUENCES IN INFANT ACUTE PAIN

Rebecca Pillai Riddell MA PhD

York University/Hospital for Sick Children, Department of

Psychology, Atkinson, Toronto, Ontario

Infants have suffered and continue to suffer needlessly due to failures to recognize pain and the resultant lack of pain management. Because infants are unable to report pain and they have a limited ability to self-regulate their pain, any understanding of pain, acute or chronic, must incorporate the dyadic relationship between caregiver and infant. Furthermore, the emotional development of an infant is dependent on his/her caregiver's physical availability and the caregiver's sensitivity to the infant's emotional and behavioural cues. Parents, nurses, and physicians all play important and distinct roles in decoding and managing infant pain. Because of their biological connectedness and the commitments parental guardianship engender, parents approach pain judgment of infants relying heavily on personal, familial and cultural experiences. Health professionals approach the pain judgment context with formal training, caring for infants with whom they will have a negligible relationship outside of the medical setting. Chronic pain during infancy provides an important area for investigating the caregiverinfant relationship due to the impact chronic unrelieved pain may have on the infants' developing perceptions of 'self' and 'other'.

\section{FACILITATED DISCUSSION WITH AUDIENCE}

Following the presentations by the panelists, questions will be posed to the audience in order to stimulate discussion for the latter half of the workshop. Questions were posed to encompass content areas postulated in the Socio Communication Model of Infant Pain: Infant Experience, Infant Expression, Caregiver Assessment, Action Dispositions).

Do you believe infants are capable of experiencing chronic pain?

Are there groups of infants that you think could be experiencing chronic pain or are at high-risk for potentially developing chronic pain?

Do you think there are differences in how an infant would experience chronic pain versus how an older child or an adult would experience chronic pain? What do you think would be useful timelines (ie, in terms of seconds, minutes, hours, days, or months) to distinguish between infant pain that is acute and pain that is chronic?

What are the differences, if any, between chronic pain and the type of pain where infants are in pain for a prolonged period of time because they are exposed to multiple painful acute procedures before pain from any one procedure could go away (eg, an infant who is four days post-surgery and is still in pain due to painful dressing changes)?

What indicators or cues do you think might suggest that an infant is in chronic pain (eg, behavioural cues, physiological cues, emotional cues)? How do you think these indicators differ from acute pain indicators? What ideas do you have regarding the best way to measure chronic pain in a hospital setting? (eg, what should be measured and how often? What type of measure would be feasible?)

No treatment guidelines appear to exist regarding how to treat chronic pain, how would you suggest chronic pain in infancy be treated (both pharmacologically and non-pharmacologically)?

\section{1:30 PM - SESSION 116 \\ TRANSFERRING CHRONIC PAIN MANAGEMENT RESEARCH EVIDENCE: THE ALBERTA HTA AMBASSADOR PROGRAM}

Chair: Paul Taenzer PhD

Chronic Pain Centre, Calgary Health Region Chronic Pain Centre, Calgary, Alberta

Speakers: Donald Schopflocher PhD, Christa Harstall MLS MHSA Pamela Barton MD

OVERALL AIM: To introduce participants to Health Technology Assessment and an innovative strategy for disseminating evidence-based knowledge of chronic pain management to practicing clinicians.

After the session, participants will:

a) Be familiar with Health Technology Assessment and how its methodologies are applicable to developing the evidence base for chronic pain management.

b) Understand the goals and objectives of the Ambassador Program

c) Review the 'evidence in brief' teaching tools developed for the Ambassador Program.

d) Understand the impact of the Ambassador Program on workshop participants in Alberta.

This workshop will review the scientific field of Health Technology Assessment or HTA. HTA researchers, senior clinicians, and representatives from Alberta Health and Wellness have collaborated in a pilot project, funded by a HTA Capacity Building Grant from the Canadian Coordinating Office of Health Technology Assessment. This project is 
exploring a novel strategy for transferring research evidence into the practice of chronic pain management. The project is based on a dissemination strategy initially developed by the Swedish national HTA organization, SBU. The SBU Ambassador Program utilizes recognized local clinical opinion leaders to disseminate HTA reports generated by SBU. In Alberta, three provincially recognized clinicians worked with the HTA Unit of the Alberta Heritage Foundation for Medical Research to develop a series of clinical teaching tools and a case-based workshop format for dissemination of the research evidence in chronic pain management to multidisciplinary groups of health care providers in all of Alberta's Health Regions.

REVIEW HIGHLIGHTS OF RECENT STUDY ON THE EPIDEMIOLOGY AND IMPACTS OF CHRONIC PAIN IN ALBERTA

Donald Schopflocher PhD

Team Lead Surveillance Methodology, Alberta Health and Wellness, Calgary, Alberta

AN OVERVIEW OF HEALTH TECHNOLOGY ASSESSMENT AND HOW RESEARCH EVIDENCE WAS ASSESSED

Christa Harstall MLS MHSA

Technology Assessment, Alberta Heritage Foundation for Medical Research, Calgary, Alberta

CREATE A SIMULATED AMBASSADOR WORKSHOP

Pamela Barton $\mathrm{MD}^{1}$, Christa Harstall MLS MHSA ${ }^{2}$

${ }^{1}$ Chronic Pain Centre, Calgary Health Region; ${ }^{2}$ Technology

Assessment, Alberta Heritage Foundation for Medical Research, Calgary, Alberta

\section{3:15 PM - SESSION 117 \\ ENVIRONMENTAL INFLUENCES ALTERING CHILDREN'S AND NEONATES' PAIN EXPERIENCE}

Chair: Celeste Johnston RN DEd

School of Nursing, James McGill Professor, McGill University, Montreal, Quebec

Speakers: Christine Chambers PhD, Margot Latimer RN PhD,

Marilyn Aita RN PhD (cand)

OUTLINE: Brief overview of known environmental aspects influencing children's and neonate's pain response.

Presentation from a more global perspective including, family, health care professionals and physical perspectives influencing pain assessment and effective treatment. (5-10 minutes)

Child and Family Perspective (15 minutes)

Health Care Professional Perspective (15 minutes)

Physical influences (15 minutes)

Summary (5-10 minutes)

Questions (10-15 minutes)

\section{CHILD AND FAMILY PERSPECTIVE}

Christine Chambers PhD

Canada Research Chair in Pain and Child Health, Departments of Pediatrics and Psychology, Dalhousie University, and IWK Health Centre, Halifax, Nova Scotia

The family setting provides a rich and readily accessible source of information about pain for children. Parents are often present when their children experience pain and hold the primary responsibility for responding to their children's pain and deciding on further courses of action as necessary. Clinical lore, in the form of speculation by physicians and other health professionals, and psychological theory often point to the important role that parents may play in influencing children's pain experiences. Indeed, it is now generally recognized that a number of environmental factors contribute to pain beyond physical pathology. This presentation will describe current research in this area, including results of our own observational and computerized, interactive studies and will highlight future directions for research.

\section{HEALTH CARE PROFESSIONAL PERSPECTIVE}

Margot Latimer RN PhD (cand)

Interdisciplinary Research Department, IWK Health Centre,

Halifax, Nova Scotia

Health care professional and organizational attributes require more rigorous examination when striving to understand how to effectively manage hospitalized children's pain. For health care professionals, appropriate pain knowledge, beliefs, and values are important antecedents to this necessary level of care. Organizational facilitators and barriers such as valuing pain control, interdisciplinary collaboration, resources and policy related mechanisms may influence pain assessment and management. These emerging research issues will be discussed in relation to their influence on the quality of pain outcomes for children in hospital.

\section{PHYSICAL PERSPECTIVES}

Marilyn Aita RN PhD (cand)

School of Nursing, Montreal University, Montreal, Quebec

Physical environmental factors such as light and noise are identified as important aspects in the Neonatal Intensive Care Unit influencing the neonates' physiological stability. There is also growing theoretical evidence that nonpainful sensory stimulations such as light and noise, may affect the pain response of preterm infants, further supporting the importance of limiting the preterm infant's exposure to these physical environmental factors. This presentation will offer a reflection on how the control of the physical environment may be an effective strategy in reducing the pain response of preterm neonates.

\section{IMPORTANCE OF THE TOPIC AND THE INTENDED AUDIENCE}

Discussions in this workshop may provide direction and incentive towards a better control of environmental perspectives that may alter the children and neonates' pain response.

Ultimately, the goal is to allow the children and neonates to be cared for in a supportive environment which will consequently promote their health and well-being. Various professionals working with these patients will benefit from the knowledge generated in this workshop and should receive guidance in order to perform care improving pain control.

\section{3:15 PM - SESSION 118 \\ GABA-MEDIATED EXCITATION IN PAIN AND HYPERALGESIA}

Chair: Terence J Coderre PhD

Department of Anesthesia, McGill University and McGill Centre for Research on Pain, Montreal, Quebec

Speakers: Fernando Cervero MD PhD, Simon Beggs PhD

ROLE OF NKCC1 CO-TRANSPORTER IN THE DEVELOPMENT OF HYPEREXCITABILITY IN THE SPINAL CORD

Fernando Cervero MD PhD

Director, Anesthesia Research Unit, McGill University, Montreal, Quebec

HYPEREXCITABILITY OF LAMINA 1 NEURONS FOLLOWING PERIPHERAL NERVE INJURY: THE ROLE OF MICROGLIA-DERIVED BDNF

Simon Beggs PhD

Brain and Behaviour, Hospital for Sick Children, Toronto, Ontario 


\begin{tabular}{c} 
3:45 PM - SESSION 119 \\
CURRENT APPROACHES TO MECHANICAL \\
LOW BACK PAIN MANAGEMENT \\
\hline
\end{tabular}

Chair: Katherine Harman PhD

School of Physiotherapy, Dalhousie University, Halifax, Nova Scotia Speakers: Katherine Harman PhD, Wendy Jardine MSc, Cheryl Hubley-Kozey PhD

\section{Katherine Harman $\mathrm{PhD}^{1}$, Wendy Jardine $\mathrm{MSc}^{2}$, \\ Cheryl Hubley-Kozey PhD ${ }^{1,2}$}

${ }^{1}$ School of Physiotherapy, Dalhousie University; ${ }^{2}$ School of Biomedical Engineering, Dalhousie University, Halifax, Nova Scotia OVERALL AIMS: To review current approaches and rationale to physical assessment and management of mechanical low back pain.

EDUCATIONAL OBJECTIVES: Participants will learn of the continued development of movement pattern-determined diagnosis and treatment and the effectiveness of commonly used therapeutic exercises for mechanical low back pain.

BRIEF DESCRIPTION OF CONTENT: Mechanical low back pain is a very challenging health care problem, with generally poor outcomes. The experience of low back pain is complicated by the interplay between physical and psychological responses to pain and its impact on movement. Where one particular tissue is not found to explain symptoms, a pathomechanic analysis of key functional movements provides an objective measure to develop a treatment program. Effective therapeutic exercise addresses the specific local changes in muscle and joint, in addition to global movement patterns and activity levels.

\section{MOVEMENT DYSFUNCTION IN LOW BACK PAIN PATIENTS Katherine Harman PhD}

School of Physiotherapy, Dalhousie University, Halifax, Nova Scotia Some movement dysfunction associated with low back pain can be explained by specific, local changes in muscle and joint physiology. However, the aversive nature of pain experienced on movement will result in avoidance of movement further impairing movement patterns. This self-reinforcing cycle can lead to complex compensatory patterns. In addition, the central nervous system changes known to occur (ie, sensitization) in response to injury or inflammation contribute to maladaptive responses to movement. Active, repetitive, non-painful specific and global exercise will encourage activity while stimulating movement-induced neuroplasticity in low back pain patients.

\section{THE PATHOMECHANIC APPROACH TO PHYSICAL DIAGNOSIS OF MECHANICAL LOW BACK PAIN}

Wendy Jardine MSc

School of Biomedical Engineering, Dalhousie University, Halifax, Nova Scotia

The term mechanical low back pain has been used to describe the symptoms of a group of patients with low back pain that are medically well, have no neurological compromise but have a break down in mechanical function (Porterfield and DeRosa, 1991; Waddell, 1998). Diagnosis of mechanical low back pain can be classified as either pathoanatomic or pathomechanic and have an important role to play in the overall care of an individual with low back pain. Although pathoanatomic diagnosis helps to identify the site and tissue source for the pain, for many patients the anatomy correlate of pain cannot be determined. Therefore, a pathomechanic diagnosis, which identifies the faulty mechanics that are associated with the pain symptoms is also determined through clinical tests of movement patterns. The diagnosis is the foundation for the basis of treatment and therefore the results and effectiveness of a treatment can only be examined if a particular pathology (eg, disc protrusion) or problem (eg, asymmetry in range of motion) has been identified (diagnosed) and classified (pathoanatomic or pathomechanic). The results of one treatment cannot be compared to the results of another treatment unless they have the same diagnosis (Fairbank and Pynsent, 1990). The difference between pathoanatomic and pathomechanic diagnoses of low back pain have to be understood to appreciate the different role clinical tests have, and how treatment approaches can differ due to the diagnostic classification used.

\section{EXERCISE AND LOW BACK PAIN: IMPLICATIONS FOR} MANAGEMENT

Cheryl Hubley-Kozey PhD

School of Physiotherapy and School of Biomedical Engineering, Dalhousie University, Halifax, Nova Scotia

Disability due to low back pain (LBP) is a major occupational health problem, with significant economic impact from work-time lost, compensation payments and health care costs. The high prevalence and reoccurrence of LBP supports the need to improve management approaches. Although considered more favourable than passive therapies; the evidence is often inconsistent that exercise is effective for relieving LBP and there is even less evidence of changes to biomechanical or physiological characteristics associated with exercise and LBP (Hubley-Kozey et al, 2003). There are several fundamental problems with the literature and the interpretation of the literature on exercise and LBP that contribute to the controversy. They are: i) not acknowledging treatment goals unique to phases of healing, ii) referring to exercise as a single treatment, iii) using only subjective measures of pain and function, iv) minimal use of objective measures of biomechanical or physiological characteristics v) duration of exercise programs that are too short for physiological change and vi) the lack of specificity in diagnosing LBP. There is solid evidence based on theoretical and modeling work linking impaired neuromuscular control strategies to mechanical instability and LBP, and this evidence supports exercise as an appropriate treatment option. The purpose of this presentation is to evaluate the pitfalls in the literature on exercise and LBP and to present the evidence linking mechanical-lumbar-spine instability, dysfunction of the neuromuscular system and LBP, and to relate these concepts to exercise management, and current state of knowledge.

\begin{tabular}{c} 
3:45 PM - SESSION 120 \\
"PSYCHOGENIC" PAIN AND SOMATIZATION: \\
PAST HISTORY AND PRESENT STATUS \\
\hline
\end{tabular}

Chair: Harold Merskey DM FRCPC

Professor Emeritus, Department of Psychiatry, University of Western Ontario, London, Ontario Speakers: Harold Merskey DM FRCPC, Ellen Thompson MB BS FRCP

\section{Harold Merskey DM FRCP ${ }^{1}$, Ellen Thompson MB BS FRCP2 1 Professor Emeritus, Department of Psychiatry, University of Western Ontario, London; ${ }^{2}$ Staff Anaesthetist and Consultant in Pain Management, The Ottawa Hospital, Ottawa, Ontario}

\section{Learning Objective:}

a. Following a review of the historical background to these terms, participants will be able to perceive flaws inherent in such concepts as "psychogenic" pain, "somatization", or "medically un-explained" pain, and will be able to appreciate organic causes underlying many conditions so labeled.

In the 1950s attempts were made by several workers to understand why some patients complained of pain problems for which no medical or surgical specialist could find a cause. The term "hysteria" had long been in use. In the 1950s Engel favoured the term "psychogenic pain", which was again superseded by "somatization", which is now being challenged by "medically unexplained" pain, or "partly unexplained pain". (Merskey 2004). Lists of "non-organic" pain symptoms (Waddell), and pain drawings purporting to also show "non-organic" pain states were published. (Ransford).

Since the publication of The Gate Theory, neuroscientists have provided new insights into causes of apparent "non-neuroanatomical" distribution of pain (Wall PD and McMahon, Bennett GB, Watkins L). Evolving knowledge about genetic mechanisms (Mogil J), and prospective data regarding past sexual/physical abuse and the lack of correlation of pain in adulthood (Raphael K), has reduced the importance of psychosocial mechanisms in understanding the aetiology of many pain states. The work of Bogduk et al demonstrating that removal of severe chronic pain by simple physical techniques returned previously abnormal psychological profiles to normal, is also important evidence of the causal relationship between pain and psychology: Chronic disabling pain and sleep deprivation are potent causes of depression, while depression is rarely seen to cause musculoskeletal pain. 


\section{POSTERS PRESENTED ON FRIDAY, MAY 13, 2005}

\section{P-1}

SASKATOON HEALTH REGION CHRONIC PAIN CENTRE: INITIAL DEVELOPMENT AND EARLY OUTCOMES

Shannon Sigfusson BSc PT, Phil Carverhill PhD, Kate Fast BSc PT, Dale Lyons BSc PT, Peggy Olson OT Reg, Anna Power-Horlick RN, Loren Regier BSP, Gregg Tkachuk PhD

Saskatoon Health Region Chronic Pain Centre, Saskatoon, Saskatchewan

AIM: The Saskatoon Health Region, Chronic Pain Centre (CPC) was developed based on empirical evidence and best practice. Funded through a partnership with public and private resources, it is located in an offsite facility. The assessment team consists of a registered nurse, psychologist, and consulting physicians from anesthesiology, family medicine, neurology, neurosurgery and physiatry. The multidisciplinary treatment team includes an occupational therapist, pharmacist, physical therapist, psychologist and registered nurse. Clients attend half days, daily for 5 weeks for participation in education, reactivation and individual and group sessions. Initial outcomes will be reviewed.

METHOD: Since March, 2004, 44 clients have completed the treatment program. Preliminary data on a sub-sample of clients $(n=16$, mean age $=48.25$ years, $56.25 \%$ male, $56.25 \%$ publicly funded) who completed the Chronic Pain Self-Efficacy Scale and the Canadian Occupational Performance Measure were collected before and after treatment.

RESULTS: Analysis of results indicated that there was a statistically significant improvement in self efficacy, $\mathrm{t}(11)=-3.68,(\mathrm{p}=.004)$, perceived performance, $\mathrm{t}(15)=-5.26, \quad(\mathrm{p}=.000)$, and perceived satisfaction $\mathrm{t}(15)=-5.54,(\mathrm{p}=.000)$, following participation in this program.

CONCLUSION: While statistically significant improvements were noted in pre and post test scores, there were no differences between public and private clients. Ongoing $\mathrm{CPC}$ research will examine differences based on this variable.

\section{P-2}

AN ANALYSIS OF NURSES' PAIN MANAGEMENT KNOWLEDGE AND EDUCATION

\section{Lorraine Ciccarelli RN MA}

Resource Nurse Pain Service, St Michael's Hospital, Toronto,

Ontario

The importance of assessing and managing pain has become foremost in today's hospitals. Poor pain management is associated with impaired health, decreased patient satisfaction and increased health costs. This quality care improvement study in the neurosurgical and trauma unit of an urban teaching hospital focused on the impact of nursing pain education and nursing practice. Educational programs have been shown to improve pain management. In this study, forty-one staff Registered Nurses were given a pre-test on Patient Controlled Analgesia (PCA) followed by a one-hour lecture on the use of Patient Controlled Analgesia in the management of patient's post-surgical pain. Simple summaries of the test results were done on a question by question basis. Data analysis was conducted using t-tests and a chi-square test for categorical data. In the overall summary of the pre-test and post-test scores it was found that the mean total correct pretest was $14.4 / 20$ (median 15). The mean total correct on the post-test was $18.5 / 20$ (median 19). The matched sample $t$-test, found that the average difference between pre-test and post-test scores was 4.1 ( $p<.0001)$. Overall scores were significantly higher on the post-test when compared to the pre-test.

Testing revealed significant knowledge deficits in the areas of technical aspects of PCA, pharmacology and monitoring protocols. Other areas of knowledge deficits that were identified included patient assessment, proper utilization of the pain service and patient safety issues. It was recommended that the nurses be retested in three months time to determine if they had retained the knowledge regarding PCA. This study showed a significant improvement in the nurses' PCA pain management knowledge following an educational session.

\section{P-3}

PAIN AND COACHES RESPONSES IN YOUNG GYMNASTS

Chrystal Coates ${ }^{1,2}$, Patrick McGrath OC PhD FRSC1,2, Meghan McMurtry BA (Hons) ${ }^{1}$, Patricia Lingley-Pottie BN RN CCRC ${ }^{2}$

1Dalhousie University and 'IWK Health Center, Dalhousie, Halifax, Nova Scotia

Pain related to sports has not been widely studied in children. Some sports, such as gymnastics, may result in frequent painful incidents. The present study examined the prevalence of pain in children participating in recreational gymnastic classes and the types of responses coaches' have to the painful incidents. To this end, 62 children aged $5-12$ years old in recreational gymnastics were observed at a gymnastics club. A checklist was used to record any painful incidents each child sustained. Responses of both the child and the coach to the incident were also recorded. Over the course of the study, the rate of painful incidents was 0.16 incidents per child per hour observed. No significant correlation was found to exist between severity and duration of the painful incidents. The largest number of incidents occurred on the floor apparatus. The most common painful incidents occurred when participants bumped into equipment. Most incidents were not severe and lasted for only a few seconds. Coaches often did not notice the painful incidents. When they did notice, they most often asked how the child was and what had happened to him or her. The number of painful incidents a child experienced did not decrease with age.

\section{P-4}

FACTORS INVOLVED IN PERSISTENT ALLODYNIA IN AN ANIMAL MODEL OF NEUROPATHIC PAIN

L] Dableh, SC MacDonald, V Rajapurohitam, K Yashpal, JL Henry

Department of Physiology and Pharmacology, University of Western Ontario, London, Ontario

Neuropathic pain is a debilitating, chronic condition that is not adequately treated with the pharmacological agents available. This study aims to identify factors that may give rise to persistent allodynia characteristic of neuropathic pain, including substance $\mathrm{P}$, nitric oxide $(\mathrm{NO})$, and glial cell activation. The Mosconi and Kruger model (1996) was used, and mechanical allodynia was measured with von Frey filaments. Removal of the cuff 24 hours after implantation led to allodynia that reversed after 2 weeks. However, removal of the cuff 4 or 8 days after implantation did not change model development. This suggests that there is a reversible phase and an irreversible phase in the model and thus possibly also in neuropathic pain in humans. The role of the NK-1 receptor in the 4-day cuff removal model was examined by daily administration of the antagonist CP 96,345, $(5 \mathrm{mg} / \mathrm{kg}$, ip) for four days while the cuff was in place. This treatment blocked the allodynia. As NO may be important in nociceptive transmission, levels of neuronal nitric oxide synthase (nNOS) were measured in the lumbar spinal cord of cuff-implanted rats, and showed a transient increase.

The role of glial cells in this model was evaluated by administration of an inhibitor of glial activation (minocycline; $15 \mathrm{mg} / \mathrm{kg}$, i.p.). Minocycline was found to decrease the allodynia in the permanent and the 4-day cuff models. This study suggests that substance P, NO and glial cells may contribute to the persistence of allodynia in this model of neuropathic pain. Supported by CIHR and UWO

\section{P-5}

\section{THE HIGH COST OF UNINTEGRATED CARE FOR PATIENTS WITH} FIBROMYALGIA

\section{Patricia Dobkin PhD ${ }^{1,2}$, John Penrod PhD}

${ }^{1}$ McGill University; ${ }^{2}$ AETMIS, Montreal, Quebec

RATIONALE: Patients with fibromyalgia (FM), a chronic pain syndrome, use conventional and complementary/alternative medical (CAM) services extensively. Given that $3 \%$ of the adult population has this syndrome, the direct and indirect costs associated with FM need to be studied. Our objectives were to describe the 6 -month costs in women with FM, and to identify determinants of direct costs.

METHODS: Subjects $(\mathrm{N}=180)$ completed a validated health resource questionnaire as well as measures of pain, psychological distress, comorbidity, and disability. Unit costs for resources were obtained from governmental, hospital, laboratory, and professional association sources. Regression modelling 
for 6-month direct costs included age, disability, comorbidity, pain intensity, psychological distress, education, and work status.

RESULTS: On average, subjects visited $7.1(\mathrm{sd}=4.7)$ physicians and 7.1 $(\mathrm{sd}=13.5)$ CAM providers. The average 6-month direct cost was \$CDN 2,298; (sd=2,303). The largest components were medications (\$CDN 758; $\mathrm{sd}=654$ ), CAM services ( $\$ \mathrm{CDN} 398 ; \mathrm{sd}=776$ ), and diagnostic tests (\$CDN $356 ; \mathrm{sd}=580$ ). Our most conservative estimate of average 6 -month indirect cost was $\$ \mathrm{CN} 5,035$ ( $\mathrm{sd}=7,439)$. Comorbidity and disability were statistically significant contributors to direct cost in the multivariate analysis. Costs increased by approximately $20 \%$ with each additional comorbid condition. Moreover, FM imposes important indirect costs, which were nearly $70 \%$ of the economic burden.

CONCLUSIONS: Our estimates of costs exceed those from most other studies; this may be due to our inclusion of a broader set of health services, medications, and indirect costs. Our findings highlight the need to offer integrated services to patients with FM that address comorbidity and disability.

\section{P-6}

LE QUESTIONNAIRE SUR LES ATTITUDES ENVERS LA DOULEUR

(QAD/F-SOPA): QUALITÉS MÉTRIQUES

losée Duquette MSc ${ }^{1}$, Patricia-Anne McKinley PhD², June Litowski OT BS $\mathrm{c}^{3}$

${ }^{1}$ Clinical Research Coordinator, CRIR, Constance-Lethbridge Rehabilitation Centre; ${ }^{2} \mathrm{School}$ of Physical and Occupational Therapy, McGill University, and Research Site Representative, CRIR, Constance-Lethbridge Rehabilitation Centre; ${ }^{3}$ Clinical Coordinator, Constance-Lethbridge Rehabilitation Centre, Montreal, Quebec

INTRODUCTION: The Questionnaire sur les attitudes envers la douleur (QAD/F-SOPA) (1,2), Quebec-French version of the Survey of Pain Attitudes (3), is a self-administered questionnaire consisting of 57 statements that permit the evaluation of 7 categories of beliefs and attitudes concerning pain that are considered critical for the adjustment to long-term chronic pain.

AIM: To determine the test-retest reliability and internal consistency of the QAD/F-SOPA.

METHOD: A convenience sample of 69 francophone adults, with musculoskeletal pain for a minimum of 6 months, was used. They had to complete the QAD/F-SOPA twice, within a two week interval. Pain condition had to remain stable pain during that interval. The main outcomes were test-retest reliability (Pearson $r$ and 2-tail Student paired t-test) and internal consistency (Cronbach's at time1).

RESULTS: Fifty-six subjects completed the QAD/F-SOPA on both occasions. The Pearson $r$ values fell between .7 and .9 (high correlation) except for the Disability subscale (.55). The test-retest stability is confirmed by the Student t-test, all subscales showing a p value greater than .05 except for Control and Medication. All subscales demonstrate very satisfactory internal consistency estimates (.7 to .9) except for the Harm (.67) and Disability (.64).

CONCLUSION: Globally, the QAD/F-SOPA demonstrates good reliability properties. It meets the pre-requisites to be used for clinical and research purposes. The Disability subscale shows weaker properties; further studies would help to verify how it could be improved.

References

1. Duquette J, McKinley PA, Litowski J. Traduction et pré-test du Questionnaire sur les attitudes envers la douleur (Survey of Pain Attitudes). Revue Québécoise d'Ergothérapie 2001;10:23-30.

2. Duquette J, McKinley PA \& Litowski J. Test-retest reliability and internal consistency of the Quebec-French version of the Survey of Pain Attitudes (QAD/FSOPA). Arch Phys Med Rehabil 2005 (In press).

3. Jensen MP, Turner JA, Romano JM, Lawler B. Relationship of pain-specific beliefs to chronic pain adjustment. Pain 1994;57:301-9.
P-7

\section{DEVELOPMENT OF A 10-ITEM SHORT-FORM OF THE PARENTS' POST-OPERATIVE PAIN MEASURE (PPPM-10)}

Darby Eakins ${ }^{1}$, Christine T Chambers PhD $^{1,2}$, G Allen Finley MD ${ }^{3}$, Patrick J McGrath PhD 1,2,4

${ }^{1}$ Departments of Psychology, 2Pediatrics, ${ }^{3}$ Anaesthesiology, and 4Psychiatry, Dalhousie University and IWK Health Centre, Halifax, Nova Scotia

AIM: The aim of the current study was to determine the feasibility and provide validation for a 10-item short-form of the Parents' Postoperative Pain Measure, a behavioural measure of pain in children.

METHODS: Participants were 264 children (146 males, and 118 females) between the ages of 7 and 12 years $(M=9.12, S D=1.73)$ and one of their parents from data bases from four previously published studies. The 10 (out of 15) items most highly correlated with children's self-reports of pain were selected for inclusion in the PPPM-10.

RESULTS: The PPPM-10 showed good internal consistencies (alphas $=.84$ and .83 ) and was highly correlated with children's self-reports of pain ( $r$ 's=0.56 and 0.54 ) for each of two postoperative days. In terms of construct validity, scores on the PPPM-10 decreased in the first to second postoperative day.

CONCLUSIONS: This study provides preliminary validation for the PPPM-10. Availability of the PPPM on a 0-10 metric should enhance its utility for both research and clinical practice. Future prospective validation comparing the PPPM-10 with the original PPPM is needed.

\section{P-8}

PAIN LANGUAGE DEVELOPMENT IN CHILDREN: A STUDY USING THE CHILDES DATABASE

NS Fairbairn ${ }^{1}$, Elizabeth A Job BA ${ }^{1}$, Kenneth D Craig PhD1, Christine T Chambers PhD ${ }^{2}$

1 University of British Columbia, Vancouver, British Columbia; 2Dalhousie University and IWK Health Centre, Halifax, Nova Scotia AIM: The purpose of this study was to examine parent-child interactions with toddler aged children in the context of spontaneous pain language use. Interactions were coded to look at trends in communication.

METHODS: One-hundred and ninety transcripts obtained from the Child Language Data Exchange System (CHILDES) database were searched for seven primary pain word stems: 'ache', 'boo-boo', 'hurt', 'ouch', 'ow', 'pain', and 'sore'. The 52 parent-child interactions with use of a pain word stem were then coded for content, using adaptations of Blount et al. (1997) and Dunn-Geier et al. (1986) coding schemes, with some categories added.

RESULTS: The majority of parent-child interactions involved pain in the present $(61 \%)$. Most pain language referenced real pain $(73 \%)$, rather than contemplated pain. The child was the person being cared for in the majority of interactions $(59 \%)$. The most common parental reaction to a child's use of pain language was to encourage expression (36\%).

CONCLUSIONS: Most verbal interactions between toddlers and their parents addressed current pain, suggesting that early in life children use language to access care and learn the social complexities of pain. Of the 13 parent-reaction categories coded, the most common encouraged expression of pain, or seemed predicated to ensure parents were informed.

\section{P-9}

HEARING THE PATIENT: A PATIENT CENTRED APPROACH TO PAIN MANAGEMENT EDUCATION

Dianne Fleming RN1 1 , Heidi Carr RN BScN²

1Professional Practice Coordinator, Headwaters Health Care Centre, Orangeville; ${ }^{2}$ Nurse Educator, Surgical Program and Pain Resource Nurse, Southlake Regional Health Centre, Newmarket, Ontario

The philosophy of Patient Centred Care and its corresponding Eight Dimentions of Patient Centred Care are evidence based on extensive research conducted by the Picker Institute of Boston, Massachusetts. Recently, the patient surveys done for the Ontario Hospital Association has begun to use those Eight Dimensions to measure the patient experience in the hospitals of Ontario. The results of these surveys of patients are published on a yearly basis in the Hospital Report Cards. One of those Eight Dimentions of Patient Centred Care, which were identified by 
patients as the eight issues most important to them when accessing the health care system, is physical comfort. As a result, nurses at some hospitals in Ontario are being educated about assessing pain and pain management using the philosophy of Patient Centred Care.

Southlake Regional Health Care Centre and Headwaters Health Care Centre are working toward educating all nurses in their organization in being patient centred in their assessment and management of pain. To support nurses in this endeavor a pain in-service is offered at Nursing Orientation where this topic is discussed at length. This in-service is interactive where nurses are encouraged to participate with examples they may have had where a patient centred approach was utilized and successful for both patients and nurses. Patients need to be active participants in the assessment and planning of their pain management including goals and objectives. To assist in this, an initial in-depth pain assessment is completed on admission. This assessment includes among other things: pain history, aggravating and alleviating factors, methods of pain management that have been helpful and/or unhelpful in the past as well as the patients personal goal of pain relief.

\section{P-10}

EXPERIENTIAL AVOIDANCE MEDIATES THE RELATIONSHIP BETWEEN A HISTORY OF SEXUAL ABUSE AND EMOTIONAL ADJUSTMENT IN CHRONIC PAIN PATIENTS

Heather Getty 1,2, Allan Shapiro1,2,3, Robert Teasell1, Pat MorleyForster $^{3}$, Kim Horrill ${ }^{3}$, Keith Sequeira ${ }^{1}$

1Department of Physical Medicine and Rehabilitation, and ${ }^{2}$ Rheumatology Institute, St Joseph's Health Care, London; ${ }^{3}$ University of Western Ontario Interdisciplinary Pain Clinic, London; and ${ }^{4}$ Hamilton Health Sciences Foundation, Hamilton, Ontario

Research has demonstrated a link between self-reported sexual abuse and various types of chronic pain problems, included chronic pelvic and gastrointestinal pain. More recently, sexual abuse has been linked to musculoskeletal pain problems in general population samples. Some researchers propose that sexual abuse may be an important factor in the etiology of and adjustment to chronic pain, but studies of potential emotional and behavioural process variables that may influence the relationship between sexual abuse and pain are scarce. The present research sought to determine whether a self-reported history of sexual abuse was associated with greater disability among individuals with chronic pain, and whether a variety of mediating or moderating variables influenced the relationship between sexual abuse and adjustment among these individuals. Patients $(\mathrm{N}=226)$ recruited from tertiary, outpatient chronic pain clinics (PM\&R, Anaesthesiology), completed questionnaires assessing outcome (pain intensity, disability, and distress), personality traits, and sexual abuse history. Results suggest that sexual abuse is associated with greater emotional distress among chronic pain patients, and that experiential avoidance mediates this relationship. Ways in which experiential avoidance may compromise adjustment among individuals with pain, as well as implications for treatment are discussed.

\section{P-11}

EXPECTANCY-MEDIATED MODULATION OF ENDOGENOUS PAIN CONTROL: SPINAL AND CORTICAL MARKERS

Philippe Goffaux PhD, William John Redmond, Etienne Leclerc, Serge Marchand PhD

Faculté de Médecine, Université de Sherbrooke, Sherbrooke, Quebec

AIM: We investigated how expectations of pain affect the actions of diffuse noxious inhibitory control (DNIC), an endogenous pain modulatory system. By measuring subjective pain ratings, spinal withdrawal reflexes (WR) and somatosensory evoked potentials (SEP) it was possible to investigate how expectation and DNIC modulate nociceptive signals.

METHODS: Seven healthy volunteers participated in this project. DNIC activity was triggered by immersion of the arm in cold water for 2 minutes. Electrical stimulation of the sural nerve was repeated every 7 seconds for 12 minutes while arm immersion started 5 minutes after testing began. Pain ratings relative to the electrical stimulations were recorded every minute. Prior to testing, expectations regarding the effects of the immersion procedure were measured by having participants rate the anticipated change in electrical pain.
RESULTS: Analyses showed that DNIC activity decreased subjective pain ratings, WR amplitude during and after the immersion procedure and the late N2-P2 peak amplitude difference (all p's <.05). Expectancy effects on DNIC-related activity showed that when subjects anticipate more as opposed to less pain, they obtained significantly smaller reductions in WR and P2 component amplitudes $(\mathrm{p}$ 's $<.05)$ and a trend showing smaller reductions in subjective pain ratings.

CONCLUSIONS: This study showed that subjective pain ratings, WR and SEP amplitudes following electrical stimulation are decreased during immersion of the arm in cold water. These physiological effects are also modulated by expectancy. Expectancy effects suggest that cognitive-evaluative changes in pain perception interact with DNIC activity to produce changes at different levels of the CNS.

\section{P-12}

PREVALENCE AND PSYCHOSOCIAL CORRELATES OF RECURRENT PAIN IN CHILDREN: A CANADIAN POPULATION-BASED STUDY Crystal Holly BSc, Christine Chambers RPsych Departments of Psychology and Pediatrics, Dalhousie University, Halifax, Nova Scotia

\section{P-13}

CHILDREN'S REFLEXIVE AND RETROSPECTIVE RESPONSES TO PAIN VIGNETTES

Elizabeth A Job MA ${ }^{1}$, Kelly Hayton BSc ${ }^{2}$, Christine T Chambers PhD², Kenneth D Craig PhD ${ }^{1}$

1 University of British Columbia, Vancouver, British Columbia; 2Dalhousie University and IWK Health Centre, Halifax, Nova Scotia AIM: The purpose of this study was to describe the verbalizations of preschool children in response to pain vignettes and to compare their scores to their overall language abilities.

METHODS: 113 healthy children ( 57 female) between the ages of 3 to 6 years (mean age $=59.8$ months) were cued to respond verbally to the 4 "high pain" vignettes from the Charleston Pediatric Pain Pictures (Belter et al., 1988). For reflexive pain, children stated what they would say in the moment of the pain experience. For retrospective pain, children stated what they would say to their parent, after the pain experienced had passed. Children also completed the Peabody Picture Vocabulary Test - IIIA (PPVT-IIIA) as a measure of general language ability. Reflexive and retrospective responses were coded by two independent coders using a scheme developed in Job, Chambers and Craig (in press) that codes for specificity to the experience of pain and negative affectivity.

RESULTS: Reflexive pain language was positively associated with retrospective pain language $(\mathrm{r}=0.55, \mathrm{p}<0.01)$. Both reflexive and retrospective pain language were positively associated with children's age in months (reflexive: $r=0.20, p<0.05$; retrospective: $r=0.24, p<0.05$ ). Reflexive, but not retrospective, pain language was positively associated with general language abilities (reflexive: $\mathrm{r}=0.28, \mathrm{p}<0.01$; retrospective: $\mathrm{r}=0.18, \mathrm{p}>0.05$ ). CONCLUSIONS: Children's ability to communicate about pain develops over the preschool period. The ability to communicate pain is critical to pain assessment. More research should investigate how this ability develops in young children, using methods that involve children's responses in real pain situations.

\section{P-14}

VULVAR VESTIBULITIS SYNDROME: THE INFLUENCE OF DYADIC ADJUSTMENT AND ANXIETY

Mélanie Jodoin BSc1ㅡㄹ Marie-Josée Dupuis $\mathrm{MD}^{3}$, Geneviève Desrochers BSC $^{1}$,

Tina Landry BSc ${ }^{1}$

${ }^{1}$ Université du Québec à Montréal (UQAM); ${ }^{2}$ Montreal Jewish General Hospital; ${ }^{3}$ Centre Hospitalier de l'Université de Montréal Pavillon Saint-Luc, Montreal, Quebec

OBJECTIVES: The present study aimed to determine whether dyadic adjustment is associated with global sexual functioning and psychological distress in women with vulvar vestibulitis syndrome, independently of pain. METHODOLOGY: Data were obtained from 67 participants who took part in a gynaecological examination, a structured interview, and standardized questionnaires focusing on dyadic adjustment, psychological distress, anxiety and pain during intercourse. 
RESULTS: The results of hierarchical regression analyses revealed that dyadic adjustment predict both the degree of psychological distress $(\mathrm{F}=4.63) \mathrm{p}<.05$ and the sexual functioning $(\mathrm{F}=5.68) \mathrm{p}<.05$ of these women after controlling for the intensity of pain during intercourse. Higher levels of dyadic adjustment were associated with better sexual functioning and lower psychological distress. Results also showed that state anxiety predicted dyadic adjustment reported by these women even if the effect of psychological distress and the intensity of pain was controlled $(\mathrm{F}=17.00) \mathrm{p}<.001$. Therefore, higher levels of state anxiety were related to more dysfunctional dyadic adjustment.

CONCLUSION: Overall, in relation with gynaecological pain, these results suggest that dyadic adjustment is a powerful predictor of psychological distress and sexual impairment in women with vulvar vestibulitis syndrome despite their pain intensity.

\section{P-15}

ENDOGENOUS PAIN INHIBITORY SYSTEMS ACTIVATED BY SPATIAL SUMMATION ARE OPIOID-MEDIATED

\section{Nancy Julien $\mathrm{MSc}^{1}$, Serge Marchand $\mathrm{PhD}^{1,2}$}

1Département des Sciences de la Santé, Université du Québec en Abitibi-Témiscamingue, Rouyn-Noranda; ${ }^{2}$ Faculté de Médecine, Université de Sherbrooke, Sherbrooke, Québec

AIM: To determine whether the opioid antagonist naloxone inhibits the endogenous pain inhibitory systems activated by the spatial summation procedure.

METHODS: Twenty healthy volunteers ( 10 men, 10 women) participated in a randomized, four-session, cross-over study. Each session consisted of ratings of pain (visual analog scale) during the immersion of different surfaces of the arm in circulating noxious cold water $\left(12^{\circ} \mathrm{C}\right)$. The arm was arbitrarily divided into 8 segments from the fingertips to the shoulder. Two sessions were ascending (from the fingertips to the shoulder) and two sessions were descending (from the shoulder to the fingertips); they included 8 consecutive 2 -minute immersions separated by 5 -min resting periods. Intravenous injections of naloxone hydrochloride $(0.14 \mathrm{mg} / \mathrm{kg})$ or saline $(\mathrm{NaCl}, 0.9 \%)$ were administered under double-blind conditions.

RESULTS: We found that when saline was injected, there was a significant difference in pain intensity ratings between the ascending and descending sessions. The descending session resulted in lower pain intensity. As demonstrated previously, this lowering of the perception curve seems to be due to a full recruitment of inhibitory systems at the beginning of the descending session as opposed to a gradual recruitment during the ascending session. However, when naloxone was injected, no differences were found between the ascending and descending sessions.

CONCLUSIONS: Naloxone inhibits the endogenous pain inhibitory systems activated by the spatial summation procedure, thus suggesting that these systems have an opioid-mediated component, as in diffuse noxious inhibitory controls (DNIC).

\section{P-16}

\section{THE ACCEPTANCE OF CHRONIC PAIN}

Audrey Kinzel PhD (Cand), Derek Truscott (Research Supervisor), Department of Educational Psychology, University of Alberta

When pain persists beyond the expected time frame despite intervention, or is more severe than anticipated, patients are often told to 'learn to live with it' and to 'accept it'. Frank (1) states that sooner or later the person with a chronic condition will be presented with the idea of adaptation and asked to contemplate acceptance of a life with pain. Research has revealed that individuals who are more accepting of their pain, as measured by the Chronic Pain Acceptance Questionnaire (CPAQ) have improved work status and increased participation in daily activities. Individuals with increased acceptance of chronic pain, as indicated by higher scores on the CPAQ, also report lower pain intensity, less depression, less physical and psychosocial disability than individuals with a lower score on the CPAQ (2).

The purpose of this qualitative study is to explore and understand the experience of the acceptance of chronic pain. Based in the qualitative methodology of phenomenology, this study examines the process of acceptance of chronic pain with individuals who are currently experiencing pain. Participants are individuals who have had pain for a minimum of six months, who have experienced a disruption in their life as a result of the pain, and are living a meaningful life despite the pain. Data are being collected through semi-structured in-depth interviews. The constant-comparative method of analysis is being undertaken in order that themes will emerge which elucidate the experience, process, and meaning of the acceptance of chronic pain. Preliminary results of the study are presented.

\section{References}

1. Frank AW. At the Will of the Body: Reflections On Illness. Boston: Houghton Mifflin, 1991.

2. McCracken LM. Learning to live with the pain: Acceptance of pain predicts adjustment in persons with chronic pain. Pain 1998;74:21-7.

\section{P-17}

RESOURCE UTILIZATION IN DIABETIC PAINFUL NEUROPATHY PATIENTS, AN ANALYSIS OF THE RÉGIE DE L'ASSURANCE MALADIE DU QUÉBEC (RAMQ) DATABASE

lean Lachaine $\mathrm{PhD}^{1}$, Jean-Eric Tarride $\mathrm{PhD}^{2}$ 1Faculty of Pharmacy, University of Montreal, Montreal; 2Pfizer Canada, Kirkland, Quebec

AIM: Diabetic painful neuropathy (DPN) is a prevalent problem in patients with Diabetes Mellitus (DM). The aim of this study was to estimate medical resources utilization by patients with a diagnosis of DPN using the RAMQ administrative database.

METHODS: This study was performed with data from the RAMQ using a random sample representing $15 \%$ of the patients covered by the provincial drug plan. Patients with DPN were identified with the ICD-9 codes (250.6 and 357.2). Resource utilization over a one-year period was compared between DPN patients and 2 random control groups matched for age and sex in a 1:1 ratio: a control group of diabetic patients without DPN and a general control group of non-diabetic patients.

RESULTS: A total of 343 patients with a diagnosis of DPN were identified between 1998 and 2002. For most therapeutic drug categories, the number of patients reporting use was significantly higher in the DPN group than in the non-diabetic control group $\left(\chi^{2}<0.001\right)$. The average annual number of physician visits (GPs and Specialists) was significantly higher in the DPN group than in the diabetic and non-diabetic populations (26.4 vs 14.7 vs 8.3 , respectively; ANOVA: $\mathrm{p}<0.001$ ). The annual average cost of physician services was also significantly higher in the DPN group than in the diabetic and non-diabetic populations ( $\$ 1,274$ vs $\$ 743$ vs $\$ 439$, respectively; ANOVA: $\mathrm{p}<0.001$ ).

CONCLUSIONS: Results indicate that the burden associated with DPN is substantial and is greater than the burden associated with diabetic and non-diabetic patients.

\section{P-18}

\section{PAINFUL NEUROPATHIC DISORDERS, AN ANALYSIS OF THE RÉGIE DE L'ASSURANCE MALADIE DU QUÉBEC (RAMQ)} DATABASE

Jean Lachaine $\mathrm{PhD}^{1}$, Jean-Eric Tarride $\mathrm{PhD}^{2}$

1'Faculty of Pharmacy, University of Montreal, Montreal; 2Pfizer Canada, Kirkland, Quebec

AIM: Painful Neuropathic Disorders (PND) refers to neurologic disorders involving peripheral nerves where pain is a predominant symptom. The aim of this analysis was to assess health care resources utilization by patients with a diagnosis of PND using the RAMQ administrative database.

METHODS: This study was performed, using data from a random sample of patients covered by the RAMQ drug plan. Patients with PND were identified with the appropriable ICD-9 codes. A randomly selected age group and gender matched control cohort was created for comparison. To estimate level of comorbidities, the Von-Korff chronic disease score was calculated. Health care resources utilization in terms of medications, hospitalization and physician visits was estimated for year 2002.

RESULTS: A total of 4,912 patients with at least two diagnoses of a PND in 2002 were identified, representing about $1 \%$ of the patients covered by the drug reimbursement program. The chronic diseases score was significantly higher for PND patients than for the control group. (3.9 vs 2.5; ANOVA; $\mathrm{p}<0.001)$. Utilization of pain related medications was significantly higher in the PND group than in the control group. PND patients also used more of each of the health care resources considered in this study. Total annual cost of health care resources for the RAMQ was $\$ 4,163$ in the PND group and $\$ 1,846$ in the control group (ANOVA; $<<0.01$ ). 
CONCLUSION: PND is associated with higher level of comorbidities, higher medical resources utilization and higher health care costs than nonPND conditions.

\section{P-19}

DU MULTIDIMENSIONAL PAIN INVENTORY À L'INVENTIARE MULTIDIMENSIONNEL DE LA DOULEUR : TRADUCTION ET VALIDATION

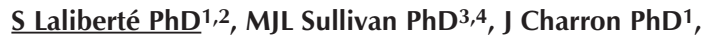
D Bouthillier PhD ${ }^{4}$, J-M Miller MSc ${ }^{1}$, I Tremblay BSc $^{3}$ ${ }^{1}$ Centre de réadaptation Lucie-Bruneau; ${ }^{2}$ Centre de recherche interdisciplinaire en réadaptation; ${ }^{3}$ Université de Montréal; ${ }^{4}$ Hôpital du Sacré-Coeur, Montreal, Quebec

Les difficultés associées à la douleur chronique sont multiples et affectent la personne souffrante dans sa globalité. Le Multidimensional Pain Inventory (MPI ; Kerns, Turk, \& Rudy, 1985), un outil largement utilisé, permet l'évaluation des aspects cognitifs, comportementaux et affectifs de la douleur (Walter \& Brannon, 1991). Traduit dans plusieurs langues, il est considéré comme un des instruments les plus appropriés dans l'évaluation psychosociale d'une problématique de douleur chronique (Bradley, McDonald Haile, \& Jaworski, 1992), particulièrement dans une contexte d'équipe interdisciplinaire. Il possède de bonnes propriétés psychométriques (fidélité, validité ; Kerns et al, 1985) et est sensible aux changements cliniques suite à un traitement. Dans le cadre de cette recherche, le MPI a été traduit de l'anglais au français et les valeurs psychométriques ont été évaluées auprès d'un petit échantillon. Ce questionnaire, devenu l'inventaire multidimensionnel de la douleur (IMD), a été présenté à des participants francophones souffrant de douleur chronique, et ce dans différents milieux cliniques de Montréal. Les résultats permettent d'évaluer la valeur psychométrique (fidélité, validité) des sous-échelles du questionnaire. Cet outil s'avère donc des plus utiles pour les cliniciens et chercheurs œuvrant auprès de personnes francophones souffrant de problématiques impliquant de la douleur.

\section{P-20 \\ RURAL COMMUNITIES AND ACCESS TO CARE: THE CHALLENGE OF CHRONIC PAIN MANAGEMENT \\ Diane Lewis RN BSCN1', Brenda Bouttell RN BScN1, \\ David Corman BScPharm ${ }^{2}$ \\ ${ }^{1}$ Comox Valley Nursing Centre, Courtenay, British Columbia; ${ }^{2}$ Cumberland Pharmacy, Vancouver Island Health Authority, Cumberland, British Columbia}

A 1994 pilot project, between the BC Ministry of Health, the Registered Nurse's Association of British Columbia and the citizens of the Comox Valley highlighted the need for chronic illness and in particular, chronic pain services. Established to provide direct access to nursing services, the Comox Valley Nursing Centre became a hub for chronic pain management - a surprising turn of events given that numerous historic needs surveys had not identified chronic pain as an issue. Clients living with chronic pain told us otherwise!

A community development approach led to a new model for the management of chronic pain in a rural setting. Elements of this model include: individual consultation for chronic pain assessment, support groups, educational events, fund raising, and the creation of a multidisciplinary team. Clients were actively involved in building community capacity as well as learning to understand and manage their pain.

Workshop participants will explore strategies to address chronic pain in a rural setting. Highlights from a successful and cost effective model will guide discussion about "what works", the role of various team members, and the potential barriers to implementing chronic pain services.

\section{P-21}

VASOACTIVE INTESTINAL PEPTIDE CAUSES SECONDARY HYPERALGESIA AND ALLODYNIA IN RAT KNEE JOINTS $\underline{Z}$ Li MD PhD, JJ McDougall PhD Department of Physiology \& Biophysics, University of Calgary, Calgary, Alberta

AIM OF THE STUDY: Vasoactive intestinal peptide (VIP) was identified in the synovial fluid of arthritis patients nearly 20 years ago; however, the function of this peptide in joints is still unknown. Here, we examine whether VIP is involved in the generation of joint pain.
METHODS: An incapacitance meter consisting of a dual channel weight averager was used to measure the weight distribution between treated (intraarticular injection of VIP: $0.1 \mathrm{ml}$ bolus; $10^{-11}-10^{-9} \mathrm{~mol}$ ) and contralateral non-treated hindlimbs of adult male Wistar rats. Mechanical hyperalgesia was measured by Von Frey hair algesiometry which involved the automated application of a fine plastic monofilament onto the plantar surface of the rat hindpaw with gradually increasing force. The time of paw withdrawal and the force required to elicit this response were recorded in treated and contralateral non-treated hindlimbs. All measurements were carried out at $10 \mathrm{~min}, 30 \mathrm{~min}, 1,3,6$, and 24 hours after VIP injection.

RESULTS: Intraarticular injection of VIP caused an increase in joint discomfort with weight re-distributing 60:40 in favour of the contralateral non-injected knee (saline injected joints produced a weight distribution of 50:50). The maximal allodynic effect of the peptide occurred $10 \mathrm{~min}$ after injection and recovered back to control levels 3 hours post-treatment. VIP also caused secondary mechanical hyperalgesia as evidenced by a reduction in paw withdrawal time and force to withdrawal compared to contralateral and saline injected control joints $(\mathrm{P}<0.001, \mathrm{n}=10)$.

DISCUSSION: This study showed for the first time that local application of VIP causes an increase in knee joint allodynia and secondary hyperalgesia in rats. Antagonists which inhibit VIP activity may prove beneficial in the alleviation of knee joint pain.

\section{P-22}

IMPACT OF PSYCHOEDUCATION ON THE MEANING OF CARDIAC PAIN FOR PEOPLE WITH CHRONIC STABLE ANGINA: PRELIMINARY RESULTS

Michael McGillion RN PhD (c) ${ }^{1}$, Judy Watt-Watson RN PhD'1, Bonnie Stevens RN PhD' 1 , Sandra LeFort RN PhD², Peter Coyte PhD ${ }^{1}$ ${ }^{1}$ University of Toronto, Toronto, Ontario; ${ }^{2}$ Memorial University of Newfoundland, St John's, Newfoundland

AIM: Chronic stable angina (CSA) patients have major learning needs about the meaning of angina with respect to perceived severity of illness, disease-related uncertainty and limitations. The purpose of this study was to examine the impact of a standardized angina self-management psychoeducation program on the meaning of cardiac pain for CSA patients.

METHOD: As part of an RCT $(\mathrm{N}=130)$, CSA patients documented what angina meant to them at sessions 1 and 6 of a six-week standardized psychoeducation program. Braden's Self-help model was used to code these data for major themes, yielding a 95\% inter-rater agreement between two nurse-raters. RESULTS: At session 1, angina was seen as a warning sign, a reminder of ill-health, and retribution for an unhealthy lifestyle. Angina signified a sudden life change characterized by frustration, limitation, suffering, fear of death, and anxiety. Lack of knowledge about adequate angina management beyond the use of nitroglycerine and modification of diet and exercise habits was a major concern. Patients described angina as a broad and ongoing pain problem at session 6 . The need for continual self-management was emphasized. Planning, learning from others, relaxation, pacing, goal setting, documenting symptoms and communication were viewed as additional strategies for living with angina in order to maximize quality of life and retain desired life goals.

CONCLUSIONS: During psychoeducation perceptions of angina symptom burden and related limitation were followed by perceptions of angina as a broad pain problem requiring ongoing self-management to retain life goals and functioning. These results are preliminary and analysis is ongoing.

\section{P-23}

TRIGGER POINT THERAPY AND PHYSICAL THERAPY IN THE MANAGEMENT OF MYOFASCIAL PAIN OF THE HEAD AND NECK: AN INTERIM ASSESSMENT

A Moncarz DDS dip anaes MSc FRCDC ${ }^{1}$, D Bielawski BSc BSC $(\mathrm{PT})^{2}$, A Gordon MD FRCPC ${ }^{3}$, MB Goldberg MSc DDS dip perio ${ }^{1}$, D Mock DDS PhD FRCDC ${ }^{4,5}$

${ }^{1}$ Department of Dentistry; ${ }^{3}$ Neurologist and Director; ${ }^{4}$ Associate Director, ${ }^{2}$ Wasser Pain Management Centre, Mount Sinai Hospital; 5Professor and Dean, Faculty of Dentistry, University of Toronto, Toronto, Ontario

AIM: The aim of this prospective clinical trial was to evaluate the effectiveness of trigger point injections in combination with physiotherapy and home exercise in the management of myofascial pain in the head and neck region. 
METHODS: Eighteen female subjects entered the trial. All subjects completed VAS for pain, the McGill Pain Questionnaire and the Pain Disability Index. Tender/trigger points were injected with either $0.25 \%$ lidocaine or $0.25 \%$ lidocaine with Botulinum Toxin Type-A. All participants received a multi-week course of physiotherapy and were to complete prescribed exercises daily. Follow-up appointments at 4, 8, and 12 weeks included completion of questionnaires.

RESULTS: Participant mean age was 42.6 years. Mean duration of suffering was 6.3 years. Two subjects withdrew mid-trial and two subjects were not included in the interim analysis. 10 of 14 subjects (71\%) reported that they "felt better" at the completion of the trial. Repeated-measures ANOVA showed that mean VAS scores dropped significantly from pretreatment/first recall $(51 \mathrm{~mm} / 52 \mathrm{~mm})$ to $34 \mathrm{~mm}$ ( 8 weeks) and $30 \mathrm{~mm}$ (12 weeks) $(\mathrm{p}<0.05)$. Mean MPQ scores showed a significant decrease from pre-treatment to 8 weeks and to 12 weeks $(p<0.05)$. No statistically significant changes in PDI scores were noted at follow-up.

CONCLUSIONS: Trigger point injections followed by physiotherapy and home exercise appear to be effective in reducing pain scores in various outcome measures in individuals suffering from myofascial pain of the head and neck. Further analysis will investigate whether the specific substance injected into trigger/tender points has a significant effect over time.

\section{P-24}

USING THE PAIN COPING INVENTORY TO MEASURE OUTCOMES IN AN INTERDISCIPLINARY PAIN MANAGEMENT PROGRAM FOR INJURED WORKERS WITH CHRONIC PAIN

Rhonda Nemeth PhD CPsych'1, Ted Robinson MD CCFP FCFP2, Jesse Goetz-Gadon BA Psych ${ }^{3}$, Jacqueline Van Es BSc OT 4 ${ }^{1}$ Consultant Psychologist; ${ }^{2}$ Clinical Associate; ${ }^{4}$ Staff Occupational Therapist, ${ }^{3}$ Rehabilitation Solutions, Functional Restoration Program, Toronto Western Hospital, UHN, Toronto, Ontario OBJECTIVE: To determine the efficacy of the Pain Coping Inventory (PCI) in measuring change in injured workers with chronic pain who participate in our cognitive-behavioural interdisciplinary pain management program.

BACKGROUND: The Functional Restoration Program (FRP) is groupbased program for patients with chronic pain that focuses on acquisition of adaptive coping skills, increasing functional activity and return to work. The questionnaires used previously in the FRP were not standardized on populations of pain patients and contained many items reflective of somatic problems. The PCI was designed to assess risk factors for pain-related disability, and was normed on chronic pain patients. The various scales reflect phenomena such as catastrophizing, perceived self-efficacy, depression, and symptom magnification.

METHODS: The sample was composed of 65 (37 male, 28 female, Mean age $=43, \mathrm{SD}=8.06$, Range $=25-60$ years) participants with chronic muskuloskeletal pain who attended the FRP for six weeks in the Fall of 2004. Participants completed the PCI at the beginning and end of the program in a group format, and all scales and indices were examined for change using paired sample t-tests. Participants who required an interpreter were excluded from this study.

RESULTS: There was statistically significant improvement in the multiscale indices reflecting behavioral interference $\left(\mathrm{p}<.05, \mathrm{r}^{2}=0.15\right)$, pain coping $\left(\mathrm{p}<.001, \mathrm{r}^{2}=0.23\right)$, health-related behaviors $\left(\mathrm{p}<.001, \mathrm{r}^{2}=0.27\right)$, and psychological coping and self-efficacy $\left(\mathrm{p}<.05, \mathrm{r}^{2}=0.14\right)$. There were other significant findings, but the effect sizes were small. For example, symptom magnification decreased $\left(\mathrm{p}<.05, \mathrm{r}^{2}=0.09\right)$.

CONCLUSIONS: The results suggest the PCI is a useful instrument for measuring physical, behavioral, and psychological changes in pain patients participating in our cognitive-behavioral pain management program. We will continue to collect data to determine the nature and magnitude of change in our patients. Future research will aim to determine longer-term effects of the program by analyzing data collected at three-month follow-up.
P-25

FACTORS THAT AFFECT PEDIATRIC PAIN MANAGEMENT

Sudaporn Payakkaraung MNS ${ }^{1,2}$, Janice Lander PhD $^{2}$, Jariya Wittayasoo-porn DNS1

${ }^{1}$ Mahidol University, Thailand; ${ }^{2}$ University of Alberta, Edmonton, Alberta

Decades ago researchers identified widespread poor pain management, ultimately caused by research not being taken up and put to use by practitioners. Researchers tried to identify individual factors that predict nurses' and physicians' pain management practices with a view to identifying them and developing strategies to improve practice. These factors include education, age, attitudes and personal pain experience. Since most of these factors are not amenable to intervention, researchers should concentrate on factors that can be modified. One of these is organizational factors, including the work environment, that influence pain management; little attention has been paid to this.

AIM: Is to investigate the influence of pain management policies and the work environment on pediatric pain management.

METHODS: This study uses a descriptive comparative design. Ten hospitals with pediatric units in Bangkok, Thailand are participating. Nursing staff $(n=200)$ and their pediatric patients $(n=200)$ over 3 years of age represent the primary study sample. All tools have been used in various studies in Canada. They have been back-translated into Thai for collection of information about: informal pain policies; views about pain and its management, and the work environment; and children's pain ratings. Pain scales have also been back-translated with age appropriate scales being used (VAS and Poker Chip). Managers are helping to identify all written institutional policies about pediatric pain management in each participating hospital; these are being assessed and described.

RESULTS AND CONCLUSIONS: Pain management polices and their impact will be described in this presentation using comparison between Canada and Thailand.

\section{P-26}

KINDLING-LIKE EVOLUTION OF TRIGEMINAL NEURALGIA AFTER LINGUAL NERVE INJURY

Yael Perez PhD, Ralph Kern MD MHSc FRCPC

Division of Neurology, Faculty of Medicine, University of Toronto, Toronto, Ontario

Trigeminal neuralgia (TN) is characterized by recurring episodes of triggered or spontaneous pain paroxysms felt in the trigeminal nerve distribution. Most of the pathophysiology has been ascribed to peripheral abnormalities involving demyelination. However, with reports of TN associated with centrally located lesions, the question of peripheral vs central pathology has been much debated. The response of TN to anticonvulsants suggests an element of seizure-like activity in its pathology. The course of TN seemingly follows a kindling-like evolution where symptoms progress from allodynia, to triggered and spontaneous pain. In the classical sense, kindling involves progressive increases in responses to brief intermittent subthreshold electrical stimulations. Responses progress through stages of lowered afterdischarge threshold, triggered seizure activity and spontaneous seizures. Behavioral kindled seizures follow a parallel course. Here, we present the case of a patient with TN which began 5 years after a lingual nerve injury. Symptoms progressed from lingual pain, paresthesia and sensory loss, to triggered then spontaneous pain paroxysms in the trigeminal distribution. There was also a temporal association between increases in lingual pain and TN worsening. Following injury, peripheral nerves exhibit high frequency activity or irregular burst discharges which can provide the initial kindling stimulus. In this case, a kindling-like evolution of symptoms can be traced back to the time of nerve injury. Parallels can be made between kindling and TN progression both in terms of electrophysiological changes and pain symptoms, providing a conceptual framework to integrate peripheral and central causes and insights into pathophysiology and treatment of TN. 
P-27

REGISTRY SYSTEMS FOR MULTIDISCIPLINARY PAIN MANAGEMENT CENTRES - SAMPLING FRAMES FOR AUDIT AND RESEARCH

Gaylene Pron PHD, Marilyn Gallonski RN BScN, Diana Bereti, Lesley Gordon BA, Allan Gordon MD, Philip Peng MD,

David Mock DDS PhD

Wasser Pain Management Centre, Mount Sinai Hospital, Toronto, Ontario

OBJECTIVE: To describe a functional registry database system and its' potential applications for multidisciplinary pain management centres.

METHODS: A database system was constructed with information that could serve as a registry, characterize a heterogeneous pain population and enable temporal trend analyses. The development of the registry material and the implementation of the registry system will also be detailed. The primary purpose of the registry is to provide a sampling frame for administrative, quality assurance and clinical research activities.

RESULTS: Prospective consecutive patients referred to the pain center were assigned unique identifiers. Information for the database was obtained from several sources. These included the referral, patient completed intake questionnaires and clinician assessments at intake. The database was constructed in several sections including information on referral source, wait time, patient demographics, management complexity, presenting pain characteristics and comorbid physical and psychological conditions. Screening information was also included on depressed mood, general health, sleep quality, and coping. Information on pain included, location(s), presumed origin, duration, age at onset, pain intensity, pain disability and distress scores.

CONCLUSIONS: The sampling frame provided by a registry system facilitates the conduct of research and performance of quality assurance activities at multidisciplinary pain management centers.

\section{P-28}

CANNABIS USE IN A MULTIPLE SCLEROSIS POPULATION

Manijeh Ryan MD ${ }^{1}$, Lilian Iskander BSc LAcu ${ }^{1}$, Sheryl Clarke RN

BSN MEd (c) ${ }^{2}$, Rae Dolman MASc ${ }^{1}$; Marilyn Galonski RN,

Trevor Gray MD FRCPC ${ }^{2}$; Paul O'Connor MD MSc FRCPC ${ }^{2}$, Allan Gordon, MD FRCPC ${ }^{1}$

1Edward Bronfman Family Foundation Research Clinic in Secondary Progressive Multiple Sclerosis, Mount Sinai Hospital; ${ }^{2}$ Multiple Sclerosis Clinic, St Michael's Hospital, Toronto, Ontario

AIM: There has been an increasing interest regarding the use of medicinal cannabis in Canada particularly in the MS population. A previous study carried out in Halifax (1) suggested that $36 \%$ used cannabis at one time. We decided to survey patients of the MS clinic at SMH using a questionnaire modified from Clark + to see if there was interest in Cannabis use in this population.

METHODS: We administered our questionnaire on a first-come basis on clinic days. Two hundred patients were surveyed and the results analyzed. RESULTS: The population age range was evenly spread in decades starting from $20 \mathrm{yrs}$ of age to $60 \mathrm{yrs}$ of age. Each decade had 20\% of the population and over age 61 yrs was $10 \%$. Ratio of M/F: 87/113.

72/200 (36\%) had used Cannabis. 60/72 had used it for recreational purposes. 34/72 used it to relieve MS symptoms such as pain, weakness, spasm, poor sleep, nausea, poor mood and low sex drive.

CONCLUSION: Although 36\% of our patients reported use of Cannabis, only $17 \%$ used it for relief of medical symptoms. A prospective study of the use of cannabis is justified and indicated in this population.

\section{Reference}

1. Clark AJ, Ware MA, Yazer E, Murray TJ, Lynch ME. Patterns of cannabis use among patients with multiple sclerosis. Neurology 2004;62:2098-100.

Funded by the Edward Bronfman Family Foundation
P-29

CANNABIS USE IN A CHRONIC NON-CANCER PAIN POPULATION Manijeh Ryan MD, Lilian Iskander BSc LAcu, Rae Dolman MHSc, Marilyn Galonski RN, Allan Gordon MD FRCPC

Wasser Pain Management Centre, Mount Sinai Hospital, Toronto, Ontario

AIM: Cannabis use is prevalent in chronic non-cancer pain population (1). We wished to survey Cannabis use our clinic which specializes in CNCP

METHOD: We administered our questionnaire on a first-come basis. The questionnaire was modified from Clark et al (2) and Ryan et al, this meeting. RESULTS: 200 patients responded to the questionnaire. 42/200 used cannabis in this population. Of this number $92 \%$ used it for recreation and $57 \%$ used it for medical relief. In the population using cannabis we asked for the reason for taking cannabis, and the degree of symptom relief for those conditions for which they took cannabis for is reported as follows: Fifty percent had pain relief of mild to moderate level. All of the patients used it for stress, mood and sleep relief and they gained moderate to mild relief. Fifty percent used it for muscle stiffness and muscle spasm and gained moderate relief. One third used it for low sex drive and gained mild relief.

CONCLUSIONS: Cannabis use in this population is not as common as it is in the MS population, ie, $36 \%$ (Ryan et al, this meeting). Nonetheless there is a need for prospective evaluation of cannabis use in pain populations.

References

1. Ware MA, Doyle CR, Woods R, Lynch ME, Clark AJ. Cannabis use for chronic non-cancer pain: Results of a prospective survey. Pain 2003;102:211-6.

2. Clark AJ, Ware MA, Yazer E, Murray TJ, Lynch ME. Patterns of cannabis use among patients with multiple sclerosis. Neurology 2004;62:2098-100.

Supported by the Edward Bronfman Family Foundation

\section{P-30}

PAIN BEHAVIOURS MEDIATED BY PERIPHERAL VR1 RECEPTORS: MODULATION BY INFLAMMATORY MEDIATORS AND NERVE INJURY

lana Sawynok PhD, Alison Reid BSc, Jason Meisner

Department of Pharmacology, Dalhousie University, Halifax, Nova Scotia

\section{P-31}

THE EFFECT OF SOY-ENRICHED DIET ON NEUROPATHIC PAIN IN HUMANS: PRELIMINARY RESULTS

Yoram Shir MD, Jordi Perez MD

Pain Centre, McGill University Health Center and Anesthesia

Research Unit, McGill University, Montreal, Quebec

INTRODUCTION: We have previously shown that diets based on soy protein and oil suppressed neuropathic pain related disorders in rats following partial nerve injury. Studies examining the analgesic role of dietary modifications in humans are rare and only one previous study looked at the analgesic role of dietary soy in acute pain conditions.

AIM: To test the analgesic properties of soy-enriched diet in humans with chronic neuropathic pain.

METHODS: We conducted an open label prospective study testing soyenriched diets in patients with chronic neuropathic pain. Dietary manipulation included substituting $50 \%$ of the daily amounts of protein and fat for soy products for 6 weeks, followed by a 6 weeks washout period of normal diet. Pain levels, mood, disability and measurement of the intensity and area of dynamic mechanical allodynia were evaluated prior to the beginning of the study, at the end of the 6 weeks of soy supplementation and at the end of the study.

RESULTS: Fifteen patients completed the twelve-week study. Five of the patients reported $>30 \%$ pain relief following soy consumption. However, average pain scores, levels of dynamic allodynia and mood have not changed significantly during or following the soy-rich period. Patients were less disabled following the soy diet $(\mathrm{P}<0.001)$ but not at the end of the study. The area of dynamic allodynia shrank after the six weeks of soy consumption period $\left(5 / 15\right.$ patients; $98.9 \pm 24.7 \mathrm{~cm}^{2}$ vs $177.5 \pm 39.7 \mathrm{~cm}^{2}$; $\mathrm{P}<0.09$ ) but not at the end of the study.

CONCLUSIONS: Dietary modification is feasible and well tolerated in chronic pain patients. Palliative supplementation of soy-enriched diet did not decrease chronic neuropathic pain in humans. However, the shrinkage of the area of allodynia might suggest a dietary effect beyond placebo. 
P-32

EXPLORING THE HEALTH INFORMATION NEEDS OF CHILDREN AND PARENTS IN REGARDS TO A PAIN INTERNET SITE: A PILOT PROJECT

lennifer Stinson RN MSc ${ }^{1}$, Janet Yamada RN MSc ${ }^{2}$, Fiona Campbell MD1, Ross Hetherington $\mathrm{PhD}^{3}$, Bonnie Stevens RN PhD ${ }^{2}$

${ }^{1}$ Departments of Anaesthesia and ${ }^{2}$ Nursing, and the ${ }^{3}$ Community Health Systems Resource Group, The Hospital for Sick Children, Toronto, Ontario

AIMS: The purpose of this pilot study was to elicit from children and families their perceived Internet-based health information needs about pain. METHODS: An exploratory case study design with taped semi-structured interviews was used to determine the perceived health information needs of 10 children and their parents. The sample included children (a) between 8 and 18 years of age and their parents; (b) who experienced acute and/or chronic pain in hospital or community-based settings; and (c) who spoke English. Interview questions addressed what children and parents thought about pain, pain assessment, pain management, pain at home and general characteristics of Internet learning. After each interview session, the interview data and field notes were transcribed verbatim and managed using NVivo. Using simple content analyses, data were organized into categories that reflected the emerging themes.

RESULTS: Preliminary results indicate that children and their parents are very comfortable using the Internet. Four major themes are beginning to emerge including: (a) knowing what to expect (eg, about pain, treatment, and pain at home), (b) knowing how to communicate (eg, about amount and type of pain, to health care professionals), (c) what effective management involves (eg, knowing about medicines, who and what pain teams in hospitals do, what to do at home) and (d) making the information credible and relevant.

CONCLUSIONS: These data will be used to generate future research questions on the usability testing of the AboutKidsHealth website dealing with pain and how this model of providing pain information influences child and family outcomes.

\section{P-33}

RELATIONSHIP BETWEEN OPTIMISM AND COPING SCORES IN UNIVERSITY STUDENTS WITH RECURRENT HEADACHES Michael R Thomas PhD, Erin Warwick, Tiffany Scott BA, Crystal Garside BA

Department of Psychology, University of Manitoba, Winnipeg,

Manitoba

AIM OF INVESTIGATION: Compared pain coping scores for headache in university males and females with high and low optimism scores.

METHODS: Participants were of 100 young adult males and 100 young adult females who reported headaches with a weekly or greater frequency. These participants were divided into four groups, 1) high optimism, males, 2) high optimism, females, 3) low optimism, males and 4) low optimism, females. All participants filled out a questionnaire that included demographic questions on headache, frequency, and severity, the Optimism/Pessimism Scale, the Life Orientation Scale and the Pain Coping Scale. Participants were recruited from first year university students.

RESULTS: The responses for the four groups were compared statistically. There were significant differences in pain behaviors across the four groups. High optimism male participants reported less severe headache ratings than the other groups. In comparison the low optimism female participants reported highest headache severity and frequency ratings. Coping scores for headache were significantly correlated with sex, high Life Orientation scores, low depression scores and high self-esteem scores. Other significant differences are reported between the four groups.

CONCLUSIONS: Optimism was related to reported headache frequency and severity. There were significant differences between the correlations for pain severity, sex, optimism scores and pain coping scores. Implications are discussed.
P-34

COMPARISONS OF LEVEL OF SENSATION SEEKING, DISABILITY LEVEL AND HEADACHE PAIN IN A UNIVERSITY POPULATION Julia Berestiansky BA, Michael R Thomas PhD, Ranjan Roy ADSW, Jeff Lawson BA

Department of Psychology, University of Manitoba, Winnipeg, Manitoba

AIM OF INVESTIGATION: Compared self-reported disability and sensation seeking levels in university students with high and low headache frequencies.

METHODS: Participants $(\mathrm{N}=140)$ were comprised of two groups. The groups were divided into high and low frequency headache individuals. All participants filled out a questionnaire which included a specific disability form for university students and a Sensation Seeking Inventory. Participants were recruited from first year university students.

RESULTS: Level of sensation seeking was not found to significantly differ between the high and low frequency headache pain groups. Congruent with the literature on sensation seeking males were found to exhibit higher sensation seeking scores. There were numerous significant differences between the high and low frequency headache pain groups on level of daily activity disturbance (disability).

CONCLUSIONS: Disability includes a wide range, from inconveniences to significant impairments in an individual's ability to carry out daily life. Functional limitations can prevent the fulfillment of peoples' roles. Of specific interest was the impact of particular functional limitations from headache that occur in a university population. Headache pain is the most frequently reported pain in this population.

\section{P-35}

COMPARISONS OF PAIN ATTITUDES BETWEEN ATHLETES IN CONTACT AND NON-CONTACT SPORTS

Anouchka Lenoski MA, Michael R Thomas PhD, Ranjan Roy ADSW Department of Psychology, University of Manitoba, Winnipeg, Manitoba

AIM OF INVESTIGATION: Compared attitudes toward pain between athletes in contact and not contact sports.

METHODS: Participants $(\mathrm{N}=150)$ were comprised of three groups of 50 males. The groups were a contact sport group (hockey, football, etc), a non contact sport group (swimming, squash, etc), and a no sport participant group. All participants filled out a questionnaire which included the SOPA, a pain attitude questionnaire, BDI, and a pain disability questionnaire. Participants were recruited from first year university students.

RESULTS: The responses for the three groups were compared statistically. There were significant differences in pain attitudes across the three groups. Contact sport athletes reported being more able to control their pain than the other two groups. Non athletes were less accepting of pain and sought medical services more often. Contact sport athlete reported more stoic attitudes toward pain of all types. Other significant differences are reported in pain attitudes between the three groups.

CONCLUSIONS: Athletes who engage in contact and non-contact sports differ in their attitudes toward pain and both groups differ from nonathletes in attitudes toward pain. Number of injuries and their location and severity are correlated with pain attitudes. Some attitudes toward acceptance of sports pain appear to be more a function of the sport engaged in. Implications are discussed.

\section{P-36}

AUTONOMIC AND CARDIAC RESPONSES TO EXPERIMENTAL PAIN IN IBS PATIENTS

Y Tousignant-Laflamme BSc (PT) MSc (c), P Bourgault RN PhD (c), M Robinette, S Marchand PhD

Faculty of Medicine, University of Sherbrooke, Sherbrooke, Quebec AIM: Recent literature on pain perception concerning patients suffering from irritable bowel syndrome (IBS) suggests that these patients present either hypo/hyperalgesia depending on the studies. However, little is known about the physiological responses to pain in these patients. The main goal of this project was to study autonomic nervous system (ANS) responses and the cardiac response to experimental pain in IBS patients. METHODOLOGY: Twenty-seven women, 14 IBS and 13 healthy control volunteers $(\mathrm{HC})$ participated in this study. All subjects underwent a cold water (7 C) immersion test of the forefoot for 2 minutes. Galvanic 
skin responses (GSR), reflecting peripheral sympathetic activity, and heart rate (HR) where monitored during and after the immersion.

RESULTS: For comparable pain perception, a significant group difference $(p<0.02)$ in the cardiac response was observed during the immersion. The peak rise in $\mathrm{HR}$ was much higher for $\mathrm{HC}$ reaching $22 \%$ at 30 seconds postimmersion while it only reached $8 \%$ for IBS patients. Meanwhile, we also observed significant $(\mathrm{p}<0.05)$ group difference regarding GSR, where HC showed a typical rise/fall response within the 2 minutes immersion, while IBS demonstrated a slow but constant rise in GSR activity throughout the painful immersion.

CONCLUSION: Differences exist in ANS adaptation to a painful stimulus between IBS and HC, where IBS patients have a continuous rise in sympathetic activity but a lower rise in HR. These observations might contribute to the persistent and more diffuse pain observed in IBS patients.

\section{P-37}

CHARACTERIZATION OF ADRENOCEPTORS IN

ATP-NORADRENALINE INTERACTIONS IN PERIPHERAL SIGNALING OF NOCICEPTION

Łames Waldron BSc, Jason Meisner, Jana Sawynok PhD

Department of Pharmacology, Dalhousie University, Halifax,

Nova Scotia

\section{P-38}

COMPLEMENTARY AND ALTERNATIVE MEDICINE USE AMONG PATIENTS WITH CHRONIC NONCANCER PAIN

lianing Yang student-MD ${ }^{1}$, Nga Man Lau student-MD ${ }^{1}$, Yoram Shir MD PhD1, Jean-Paul Collet MD PhD², Mark Ware MRCP(UK) MSc ${ }^{1}$ Montreal General Hospital Pain Center, McGill University Health Center; ${ }^{2}$ Department of Epidemiology and Biostatistics; McGill University, Montreal, Quebec

AIMS: CAM includes therapies such as natural herbal products, vitamins, nutritional supplements and alternative practitioners. The purpose of this project was to describe the epidemiological profile of CAM use among patients attending a multidisciplinary pain clinic, focusing specifically on the types of CAM used, reasons for use, duration of use and beliefs about effectiveness.

METHODS: We conducted a cross-sectional questionnaire study to describe and compare the prevalence of CAM use among chronic pain patients. We approached patients attending the Pain Clinic at the Montreal General Hospital in the waiting room. A research assistant administered a paper survey and entered the responses in a Microsoft Access database for data analysis.

RESULTS: 170 chronic non-cancer pain subjects were recruited over an eight-week period. Glucosamine (6.5\%) and cannabis (4.7\%) were the natural herbal products most frequently taken. $34.7 \%$ patients were at least on one nutritional supplement of which Multivitamins (11.8\%), Omega Complex $(8.4 \%)$ and Calcium/Vitamin D $(7.6 \%)$ were the most popular ones. Finally, $11.2 \%$ of patients were using massage therapy and $7.2 \%$, meditation. Approximately half of CAM users reported improved pain control whereas the other half did not perceive significant changes.

CONCLUSIONS: The identification of the above CAM modalities that have high prevalence of use and good subjective efficacy is important for further research. It is also important to keep physicians, patients and policymakers aware of the proportion of the chronic pain population taking non-prescribed treatments to detect potential interactions.

\section{P-39}

A SYSTEMATIC REVIEW OF PREOPERATIVE PAIN EDUCATION FOR PAIN FOLLOWING CORONARY ARTERY BYPASS GRAFT

Diana Zaft RN MN (c), Michael McGillion RN PhD (c), Judy Watt-

Watson RN PhD

University of Toronto, Toronto, Ontario

AIM: Coronary artery bypass grafting (CABG) accounted for 30,000 surgeries in Canada in 2003, with a projected increase of $21.1 \%$ per annum in Ontario. Few studies have examined the effect of preoperative education on CABG pain outcomes. The aim of this review was to examine the impact of preoperative education on CABG postoperative pain.
METHOD: A systematic review of preoperative educational interventions for $\mathrm{CABG}$ postoperative pain was conducted. Comprehensive literature review yielded four primary studies (1994-2004) with (a) specified treatment and controls, (b) patients undergoing CABG, and (c) preoperative educational interventions with a pain focus. Studies were reviewed for methodological quality and rigor via standard Cochrane techniques.

RESULTS: Positive findings were reported for pain-related interference prior to discharge and length of stay. However, methodological problems in three studies included variability in inclusion criteria, lack of clarity in details of the intervention delivery, and variable timing of measures which made results difficult to interpret and precluded generalization. The impact of the care delivery context on implementation of the intervention was not examined.

CONCLUSIONS: The effectiveness of preoperative education to decrease postoperative CABG-related pain is inconclusive. Future trials require robust methods and adequate descriptions of the impact of the context of care to enhance validity of findings.

\section{P-40}

CLOSING THE GAP BETWEEN EVIDENCE AND PRACTICE: EXPLORING STRATEGIES FOR PAIN MANAGEMENT IN NURSING Lynne E Young RN PhD ${ }^{1}$, Janice Muir RN MSN ${ }^{2}$

${ }^{1}$ Associate Professor, University of Victoria; ${ }^{2}$ Clinical Nurse Specialist, Pain Management, Providence Health Care, Vancouver British Columbia

Pain management in nursing is a resistant issue. Since the prevalence of unmanaged pain has changed little over the past three decades, this problem needs to be addressed in new ways. One year ago, we undertook an approach guided by health promotion principles rather than educational principles. To this end, we developed partnerships, fostered intersectoral networking, mobilized and shared resources, and encouraged collaboration to open spaces for dialogue with the goals of raising consciousness and influencing policy-development. Our motivation is inspired by a strong commitment to social justice.

The project has evolved through two phases. In Phase One we developed an understanding of the issue through consultations and literature reviews. A review of the literature in light of our reflections and dialogues suggest that four key issues underpin ineffective pain management in nursing: lack of awareness/knowledge of pain management outside communities of pain nurses; inadequate practice models for pain management by staff nurses; lack of preparation of nurse educators about pain management; and, the absence of a strong voice for nursing in Canada about the issue of pain management. In Phase Two we focused on developing partnerships and networks. The products of Phases One and Two include: a contact list of 90 nurses representing all areas of practice across 5 provinces; a website; membership on a Canadian Association of Schools of Nursing Task Force and the Canadian Accreditation Manual Task Force; a display for professional conferences and meetings; and, a working partnership with the Health Canada Office of Nursing Policy.

References

1. Lasch K, Greenhill A, Wilkes G, Carr D, Lee M, Blanchard R. Why study pain? A qualitative analysis of medical \& nursing faculty \& student nurses' knowledge of and attitudes to cancer pain management. J Palliat Med 2002;5:57-70.

2. Peter E, Watt Watson, J. Unrelieved pain: An ethical and epistemological analysis of distrust in patients. Can J Nurs Res 2002;34: 65-80

3. Vallerand AH, Hasenau SM, Templin T. Barriers to pain management by home care nurses. Home Health Nurse 2004;22:831-8. 
P-41

\section{WHAT ARE CANADIAN HOSPITALS DOING TO IMPROVE PAIN MANAGEMENT PRACTICES?}

Patti Kastanias ACNP Acute Pain Service RN MSc(A) ACNP1, Salima Ladak ACNP Acute Pain Service BScN RN MN ACNP2, Carolyn McPhee RN MN33, Meredith Muscat ACNP Acute Pain Service BScN RN MN ACNP2 ${ }^{2}$, Sandra Robinson RN BScN Acute Pain Service ${ }^{2}$, Mona Sawhney ACNP Acute Pain Service BScN RN MN ACNP1, Cindy Shobbrook ACNP Cancer Pain Program RN MN ACNP CON(C) ${ }^{2}$, Kianda Snaith ACNP Acute Pain Service ${ }^{2}$, Linda Turner RN MN CNS Pain², Baiba Zairins RN BScN CNCC (C) MHS 4

${ }^{1}$ Lecturer; ${ }^{3}$ Nursing Education Coordinator; ${ }^{4}$ University Health Network, 2Faculty of Nursing, University of Toronto, Toronto, Ontario

OBJECTIVE: This poster will describe the strategies in place at a quaternary care, three-site teaching hospital in Toronto serving 29000 inpatients and 948,000 ambulatory and emergency visits annually. This facility has adopted the Picker Institute's Patient-Centered Care framework (PCC), where patients' physical comfort is one of the central dimensions. Strategies include implementation of a pain resource nurse program, development of a corporate pain committee, assessment of staff knowledge and attitudes, ongoing evaluation of patient satisfaction and patient education. PLANNING AND IMPLEMENTATION: This poster will describe steps that have been taken to build an institutional commitment to pain management. The poster will include a description of the committee structure and operation, the development and implementation of the pain resource nurse program, evaluation of patient satisfaction and patient education strategies.

EVALUATION: An evaluation of the work to date will be provided. BENEFIT TO CONFERENCE PARTICIPANTS: Participants will benefit from a description of an innovative organizational approach to pain management and practical advise about implementation of such a model. This is the first comprehensive Canadian model for improving pain management hospital wide.

\section{POSTERS PRESENTED ON SATURDAY, MAY 14, 2005}

\section{P-44}

PAINTING A CLINICAL PORTRAIT OF 218 PATIENTS AT THE NS ENVIRONMENTAL HEALTH CENTRE, WITH MULTIPLE CHEMICAL SENSITIVITY (MCS) AND/OR CHRONIC FATIGUE SYNDROME (CFS) AND FIBROMYALGIA (FM) Barbara A Adams BSc PT

Cert Business Management, Physiotherapist, NS Environmental Health Centre, Capital District Health Authority, Fall River, Nova Scotia

PURPOSE: To examine the relationship between (pedometer) activity and symptom scores of Chemically Sensitive patients (MCS) with and without CFS or FM.

METHODS: Mean pedometer diary scores for pain, fatigue, sleep, exercise, exposures and step count from 218 pedometer reports were analyzed. RESULTS: Only 26\% of MCS patients functioned in the Healthy Adult Activity Category. MCS patients took 7173 steps per day while patients with all three medical conditions walked the least (4884 steps/day). Females and males who walked the least steps per day, had higher scores for pain $(p=0.02 ; p=0.003)$, fatigue $(p=.004 ;(p=0.0003)$, lower exercise level $(\mathrm{p}<0.0001 ; \mathrm{p}=0.03)$ and higher BMI (females $\mathrm{p}=0.05)$. Patients (MCS patients, especially those with CFS and FM) who exceeded their average daily step count by $>150 \%$ frequently triggered a physical relapse and experienced an increase in their number of sleep disruptions that night. CONCLUSIONS: Lower step counts correlated with higher pain/fatigue, reduced exercise capacity and a CFS/FM diagnosis. Patients reporting chemical intolerance (especially those walking $<5000$ steps/day) should be screened for FM and/or CFS. By introducing a graphic picture of pedometer results, one can more easily teach patients how to both predict and prevent relapse from over-exertion.
$\mathrm{P}-45$

SELECTIVE ATTENTIONAL PROCESSING OF PAIN CUES IN CHRONIC HEADACHE PATIENTS: A DOT-PROBE EVALUATION Gordon JG Asmundson PhD, R Nicholas Carleton BA Hons, Jane Ekong BA Hons Anxiety and Illness Behaviours Laboratory, University of Regina, Regina, Saskatchewan

There is mixed evidence that chronic pain patients have attentional biases for pain words, and that these biases are mediated by fear of pain (for review see Pincus and Morley, 2001). The current investigation attempted replication and extension of findings from published dotprobe investigations of chronic pain patients. Thirty chronic headache patients and 19 healthy controls were tested using a dot-probe task with affect pain, sensory pain, and neutral words. The bias index (ie, initial allocation of attention toward or away from threat), congruency index (ie, attentional engagement with threat), and incongruency index (ie, attentional disengagement from threat) were used as indicators of selective attention. Analyses were also conducted using raw dot-probe detection latencies as the dependent variable. No significant between-group differences or interactions between group and word type were observed for the bias index, congruency index, incongruency index, or raw dot-probe detection latencies. However, evidence was found for a significant across-groups association between affective description of current pain and the incongruence index for affect pain words, and between anxiety sensitivity and the bias index for sensory pain words. These results do not provide convincing evidence that patients with chronic headache selectively attend to affect or sensory pain cues when compared to healthy controls. Nevertheless, the significant across-groups associations between anxiety sensitivity, current pain descriptions, and indices of selective attention do support the idea that attentional biases are influenced by current concerns and anxiety-based fear propensity (Asmundson et al, 1997; Eccleston and Crombez, 1999). Implications of the findings are discussed.

\section{P-46}

SELF-REPORTED ANXIETY AND RESPONSE STYLE IN CHILDREN AND ADOLESCENTS WITH COMPLEX PAIN $\underline{\text { S Bennett PhD RPsych }}{ }^{1,2}$, N Egeli BA ${ }^{1}$, C Chambers PhD ${ }^{3}$, L Cain BSc PT1, C Court RN BSN1, T Oberlander MD FRCPC1,2, H Siden MD MHSc FRCPC 1,2

1BC Children's Hospital; 2University of British Columbia, Vancouver, British Columbia; ${ }^{3}$ Department of Psychology and Pediatrics, Dalhousie University, Halifax, Nova Scotia

AIM: The purpose of this study was to examine the levels of self-reported anxiety in a clinical sample of children and adolescents with complex pain, and to explore the possible influence of response style.

METHODS: As part of a treatment outcome study, a sample of 11 boys and 58 girls, 8 to 19 years old, completed a battery of questionnaires assessing pain and its impact on their lives. Anxiety was measured using the Revised Children's Manifest Anxiety Scale. The RCMAS has an embedded "Lie scale" subscale reflecting unrealistically ideal behaviour. Mean anxiety scores were compared for participants with significantly elevated "lie scale" scores, versus those who scored within norms.

RESULTS: Sixty-eight percent of the sample reported anxiety levels within norms. Twenty percent reported mild anxiety and twelve percent reported moderate to severe anxiety. Eight of the 68 participants had a significantly elevated "Lie scale" score on the RCMAS. When the total anxiety scores were compared, this subset reported significantly lower levels of anxiety, compared to the remainder of the sample.

CONCLUSIONS: For a small subset of this clinical sample of children and adolescents with complex pain, there is evidence that their self-report questionnaire responses may be affected by a bias towards an overly positive self-representation. For these patients, there may also be a tendency to under-report anxiety. Future work is needed to confirm whether this subgroup of pain patients differs meaningfully in their clinical presentation and treatment needs. 
P-47

CANADIAN PAIN STUDY II: USE OF STRONG OPIOIDS IN

CANADA, 2004

A Boulanger MD ${ }^{1}$, AJ Clark MD², P Squire MD³, GLA Horbay PhD ${ }^{4}$,

E Cui MBA ${ }^{4}$

1Department of Anaesthesia, University of Montreal, Montreal, Quebec; ${ }^{2}$ Chronic Pain Centre, Calgary Health Region, Calgary, Alberta; ${ }^{3}$ Lions Gate Hospital, Oncology Pain Clinic, Vancouver, British Columbia; ${ }^{4}$ Janssen Ortho Inc, Toronto, Ontario

AIM: Assess the use of opioids in the treatment of moderate-to-severe chronic non-cancer pain (CNCP) and compare results to a similar 2001 study.

METHODS: An Omnibus telephone survey was used to measure changes in physician attitudes toward chronic pain, treatment algorithms and usage of strong analgesics, from 100 Canadian GPs, writing $\geq 20$ analgesic prescriptions for CNCP in the previous month.

RESULTS: Disease-states primarily associated with CNCP visits were arthritis $(47 \%)$ and back pain $(26 \%)$. In moderate-to-severe CNCP first line treatment included opioids $51 \%$ (includes codeine compounds $23 \%$, oxycodone $11 \%$, transdermal $4 \%$ ), NSAIDs $17 \%$, and acetaminophen $13 \%$ vs opioids $30 \%$, NSAIDS $29 \%$, and acetaminophen $20 \%$ in 2001 . On average, $37 \%$ of CNCP patients are prescribed strong analgesics, vs $31 \%$ in $2001 ; 20 \%$ are prescribed strong opioids first line, mainly due to pain severity $(45 \%)$ or failure of previous medications $(30 \%)$. In initiating strong opioids, $60 \%$ are started with short acting strong opioids: $62 \%$ of these will be switched to long acting formulations.

Physician rated analgesic attributes of highest importance were: pain control $98 \%$, good for compliance $85 \%$, reduction of breakthrough pain $81 \%$, low potential for abuse/diversion $80 \%$, low potential for addiction $76 \%$. The main barriers to strong opioids are: potential for addiction $32 \%$, cost $22 \%$, constipation $14 \%$, potential for misuse $14 \%$, vs $40 \%, 6 \%, 20 \%$ and $31 \%$ respectively, in 2001.

CONCLUSIONS: Since 2001, Canadian first line treatment for moderateto-severe CNCP has shifted somewhat away from NSAIDs and acetaminophen towards opiates, with many patients eventually being switched to long-acting strong opioids.

\section{P-48}

LOCAL ANESTHETIC-LIKE EFFECTS OF DICLOFENAC ON MUSCLE NOCICEPTORS

Elisa Mok, Mandeep Mann BSc, Xudong Dong BDS PhD,

\section{Brian E Cairns PhD}

Faculty of Pharmaceutical Sciences, University of British Columbia, Vancouver, British Columbia

AIM: Topical application of diclofenac may be effective in reducing noninflammatory masticatory muscle pain, which suggests that mechanisms other than cyclooxygenase inhibition contribute to this drug's analgesic efficacy. We tested the hypothesis that injection of diclofenac into normal muscle would exert a local anesthetic-like effect on the mechanical threshold and hypertonic saline-evoked discharge of rat masticatory muscle nociceptors.

METHODS: Putative muscle nociceptors were recorded in the trigeminal ganglion and identified by their response to mechanical stimulation of the temporalis or masseter muscle and projection to the caudal brainstem. To assess the effect of diclofenac on chemically-evoked nociceptor discharge, an initial intramuscular injection of hypertonic saline was followed $30 \mathrm{~min}$ later by a second injection of hypertonic saline alone (control, $n=9$ ), with lidocaine $2 \%$ (positive control, $\mathrm{n}=8$ ), or with diclofenac sodium $0.1 \%$ (test drug, $n=7$ ). The second response was divided by the first to yield relative nociceptor discharge. An electronic Von Frey Hair (IITC Model 1601c) was used to measure nociceptor mechanical threshold before the initial and $10 \mathrm{~min}$ after the second intramuscular injection.

RESULTS: Compared with injections of hypertonic saline alone, coinjection of either diclofenac or lidocaine with hypertonic saline significantly decreased relative nociceptor discharge $(p<0.05$, ANOVA and Holm-Sidak post-hoc tests). None of the treatments had a significant effect on mechanical threshold.

CONCLUSIONS: The similar effect of diclofenac and lidocaine on hypertonic saline-evoked nociceptor discharge suggests that diclofenac may have local anesthetic-like properties. These findings may indicate that mechanisms other than cyclooxygenase inhibition contribute to diclofenac-mediated analgesia.
P-49

EXAMINING THE CONTRIBUTIONS OF CATASTROPHIZING AND INTERPERSONAL SENSITIVITY TO PAIN, AFFECTIVE DISTRESS, AND DISABILITY

Douglas Cane PhD, Mary McCarthy PhD

Pain Management Unit, Queen Elizabeth II Health Sciences Centre, Halifax, Nova Scotia

PURPOSE: Numerous studies have examined the contribution of interpersonal factors to the experience of pain, and the affective distress and disability that accompanies pain. Catastrophizing, the tendency to focus upon pain and to communicate about pain to others, has been associated with increased pain intensity, affective distress, and disability. More recently it has been suggested that interpersonal sensitivity, an excessive awareness of and concern about the responses of others, may also contribute to affective distress and disability. The present study examined the relative contributions of these factors to the experience of pain, affective distress, and disability among patients receiving treatment for the management of chronic pain.

METHOD: One hundred and twenty-four patients participating in a fourweek, interdisciplinary pain management program completed measures of catastrophizing, interpersonal sensitivity, pain intensity, depression, anxiety, and disability both before and after treatment. Regression analyses were conducted to examine the relationships among these variables.

RESULTS: Consistent with previous studies, catastrophizing was positively related to pain intensity, affective distress, and perceived disability. Interpersonal sensitivity was positively associated with affective distress only. Each of these variables contributed uniquely to the prediction of affective distress. Neither variable contributed differentially to treatment outcome.

CONCLUSION: Both catastrophizing and interpersonal distress contribute to the experience of affective distress in patients with chronic pain. Catastrophizing, but not interpersonal sensitivity, also contributed to pain intensity and disability. The implications of these results for research further examining the relationships among these variables are discussed.

\section{P-50 \\ WITHDRAWN}

\section{P-51}

PAIN MANAGEMENT IN VULNERABLE GROUPS: UNDERSTANDING PAIN MANAGEMENT IN THE ELDERLY Rochelle Caratao RN MSN

Al Hertz Clinical Nurse Specialist-Pain Management, Baycrest

Centre for Geriatric Care, Toronto, Ontario

Pain is often under diagnosed and under treated in our society, particularly with the elderly population. The identification and treatment of pain are often complex in the presence of underlying medical conditions. Health care providers are often challenged in providing the individualized care to manage pain in both the cognitive and cognitively impaired elderly persons. The learning objectives of this workshop are: 1) to review aging physiology and discuss relevance to analgesic treatments, 2) to identify facial and behaviour indicators that suggests pain in the elderly, and 3) to discuss drug therapy in older persons with respect to administration, monitoring and health teaching.

\section{DIALYSIS \& PAIN MANAGEMENT: A CHALLENGE Corsita Garraway RN MSN FNP CON(C) CHPCN(C) Acute Care Nurse Practitioner Oncology \& Palliative Care, St Joseph's Health Centre, Toronto, Ontario}

Management of cancer pain is a complex process in itself without the presence Chronic Renal Failure co-morbidity. There is a plethora of treatments available to manage a patient's pain. Chronic Renal Failure is an added challenge to care providers in modifying treatment plans and providing individualized care to patient. In this workshop, participants will be provided with: 1) a review of the pain pathway, 2) cause of cancer pain, 3) treatment modalities in cancer pain, 4) review of renal system, and 5) challenges of pain management in CRF patient receiving dialysis. 
P-52

\section{THE ECONOMIC BURDEN OF NEUROPATHIC PAIN}

Manon Choiniere PhD ${ }^{1}$, Allan Gordon MD FRCPC ${ }^{2}$, Jean-Eric Tarride $\mathrm{PhD}^{3}$, Margaret Hux MSc${ }^{4}$, Jean-Paul Collet MD PhD ${ }^{1}$ Montreal Heart Institute, Montreal, Quebec; ${ }^{2}$ Mount Sinai Hospital, Toronto, Ontario; ${ }^{3}$ Pfizer Canada Inc, Montreal, Quebec; ${ }^{4}$ Innovus Research Inc, Burlington, Ontario; 5 Jewish General Hospital, Montreal, Quebec

AIM: The management of Neuropathic Pain $(\mathrm{NeP})$ is a major health care consideration, both from a treatment and funding perspective. One of the objectives of this research was to evaluate the economic burden of $\mathrm{NeP}$ in Canada. METHODS: A cross sectional, observational study was conducted at primary care sites across three provinces (Alberta, Ontario and Quebec) amongst patients with diabetic peripheral neuropathy, post-herpetic neuralgia, cervical radiculopathy and postoperative neuropathy. Economic burden of illness data were collected through an investigator chart review and patient self-administered questionnaires.

RESULTS: 126 subjects were enrolled. The mean age was $58.7( \pm 13.5)$. Over the last 3 months of study visit, the mean number of General Practitioner visits related to NeP was reported at $2.2( \pm 1.9)$ and $25.4 \%$ of subjects visited other health care professionals (eg, physical therapist). In that same recall period, $34.9 \%$ of the subjects underwent a diagnostic test and $27.8 \%$ consulted a specialist for their NeP. $16.7 \%$ were currently waiting for an appointment with a specialist (waiting average time: 3.2 months \pm 2.5 ). The mean number of classes of pain-related medication taken over the last 3 months was $2.3( \pm 1.6) .84 .1 \%$ had taken a pain-related OTC over the last week. Missed full unpaid days due to NeP (eg, housework, volunteer work) over the last 4 weeks was $4.7( \pm 7.8)$. Among subjects working, the mean number of full days of work missed due to $\mathrm{NeP}$ over the last 4 weeks was $2.6( \pm 6.4)$.

CONCLUSIONS: $\mathrm{NeP}$ is a costly disease from a payer, employer and patient perspective.

\section{P-53}

AN INNOVATIVE APPROACH TO WAIT-LIST MANAGEMENT IN A PAIN MANAGEMENT PROGRAM

Alexander I Clark MD ${ }^{1}$, Ian G Beauprie MD², Lynne B Clark², Mary E Lynch MD2

${ }^{1}$ Chronic Pain Centre, Calgary Health Region, Calgary, Alberta; 2Pain Management Unit, Capital Health, Halifax, Nova Scotia INTRODUCTION: Chronic pain patients frequently wait months to years for assessment and care. In Halifax more than 500 patients are on the waiting list, a wait of up to 27 months from referral to assessment. We developed an innovative approach to encourage and educate referring physicians to continue active care.

METHODS: Referrals to the QEIIHSC PMU from 12/2002 to 11/2003 were triaged as either "regular wait-list", a 27 month wait, or "fast-track", seen within 3 months. Treatment recommendations for the former were faxed to the referring physician. A follow-up questionnaire was sent to each physician.

RESULTS: Recommendations faxed ( $\mathrm{N}=297$ )

\begin{tabular}{lr}
\hline Add to current therapy & 228 \\
Physiotherapy & 68 \\
IR opioids & 11 \\
CR opioids & 52 \\
Tricyclics & 184 \\
Anticonvulsants & 100 \\
Other medications & 60 \\
Group program & 134 \\
\hline
\end{tabular}

149 physicians returned the follow-up questionnaire. 95 physicians had used and 68 patients had followed the recommendations. 79 physicians felt the recommendations were helpful and in 39 patients the recommendations were beneficial. The most frequently used recommendations concerned medications - tricylics (57), anticonvulsants (34), and CR opioids (12). Other modalities included our group program (34) and physiotherapy (19).

CONCLUSION: $2 / 3$ of physicians had utilized the faxed recommendations. $40 \%$ of patients had received benefit from these interventions. $50 \%$ of physicians believed these recommendations had been helpful.

Funded by an unrestricted grant from Purdue Pharma
P-54

ANXIETY, DEPRESSION AND SLEEP INTERFERENCE IN NEUROPATHIC PAIN PATIENTS

Jean-Paul Collet MD PhD ${ }^{1}$, Allan Gordon MD FRCPC ${ }^{2}$, Jean-Eric Tarride $\mathrm{PhD}^{3}$, Nancy Ryan $\mathrm{MSc}^{4}$, Manon Choiniere $\mathrm{PhD}^{5}$ 1Jewish General Hospital, Montreal, Quebec; ${ }^{2}$ Mount Sinai Hospital, Toronto, Ontario; ${ }^{3}$ Pfizer Canada Inc, Kirkland, Quebec; ${ }^{4}$ Innovus Research Inc., Burlington, Ontario; ${ }^{5}$ Montreal Heart Institute, Montreal, Quebec

AIM: Neuropathic Pain $(\mathrm{NeP})$ is a chronic condition that can last for many years. In addition, $\mathrm{NeP}$ is suspected to have a severe impact on many aspects of patients' lives. One of the objectives of this research was to evaluate the humanistic burden of $\mathrm{NeP}$ in Canada.

METHODS: A cross sectional, observational study was conducted at primary care sites across three provinces (Alberta, Ontario and Quebec) amongst patients with diabetic peripheral neuropathy, post-herpetic neuralgia, cervical radiculopathy and postoperative neuropathy. Patients completed several questionnaires including the Hospital Anxiety and Depression Scale (HADS) and the MOS Sleep Scale (MOS-S).

RESULTS: 126 subjects were enrolled. The mean age was $58.7( \pm 13.5)$. Moderate to severe levels of anxiety (HADS-A scores $\geq 11$ on 0.21 scale) occurred in $32.3 \%, 22.4 \%$ and $53.6 \%$ of subjects with mild, moderate and severe pain, respectively. Moderate to severe levels of depression (HADS-D scores $\geq 11$ on $0-21$ scale) occurred in $9.7 \%, 13.4 \%$ and $42.9 \%$ of subjects with mild, moderate and severe pain, respectively. On a scale from 0 to 100 , the MOS Sleep Score (higher scores to Q3-Q12 of the MOS-S indicates better sleep) was $59.8 \%, 52.6 \%$ and $41.9 \%$ for subjects with mild, moderate and severe pain, respectively. Statistical differences were observed in depression and sleep scores between mild and severe pain and between moderate and severe pain (Tukey's Studentized range test: $\mathrm{p}<0.05$ ).

CONCLUSIONS: $\mathrm{NeP}$ is associated with decrements in many aspects of patients lives: emotional functioning, affective symptoms, and sleep.

\section{P-55}

PAIN AND IMPAIRMENT BELIEFS OF PERSONAL INJURY ATTORNEYS: ANOTHER SOURCE OF MISINFORMATION IN WHIPLASH ASSOCIATED DISORDER?

$\underline{R}$ Thomas Evans MD FRCP ${ }^{1}$, Douglas J French PhD $^{2}$

1The Atlantic Spine Clinic; 2 École de Psychologie, Université de Moncton, Moncton, New Brunswick

The treatment of Whiplash Associated Disorder (WAD) is often complicated by ongoing litigation. Previous studies suggest that the pain-related beliefs of health care providers involved in the treatment of these patients may influence their functional outcome through the communication of maladaptive information and by influencing treatment selection. Little is known about the beliefs of personal injury attorneys involved in these cases. The present study assessed the extent to which personal injury lawyers endorsed beliefs that chronic pain is necessarily impairing. A version of the Pain and Impairment Relationship Scale modified for use by third parties (HC-PAIRS) was administered to 57 personal injury attorneys from the province of New Brunswick. The HC-PAIRS is a 15 item questionnaire assessing respondents' beliefs about the degree to which pain warrants impairment and justifies disability in chronic pain sufferers. HC-PAIRS scores obtained in this sample were more comparable to published scores obtained from chronic pain patients than rehabilitation health care professionals suggesting that these lawyers may share a number of beliefs with their injured clients that have been associated with poor functional outcomes and increased disability. An examination of HCPAIRS factor scores revealed that $60.2 \%$ of these attorneys endorsed the belief that pain eradication is a necessary perquisite for normal function. Furthermore, $43.4 \%$ endorsed beliefs that individuals with chronic pain should not be expected to meet usual occupational and family responsibilities. It is suggested that, like health care providers, the cognitive set of personal injury attorneys may influence the functional status of WAD patients and their rehabilitation outcomes. 
P-56

PERCEIVED DISABLITY AND CLINICAL PAIN IN CHRONIC PAIN SUFFERERS ARE RELATED TO FEAR-AVOIDANCE BELEIFS BUT NOT TO NOCICEPTIVE RESPONSIVENESS

Douglas | French PhD ${ }^{1}$, Marie-Andrée Hébert MPs1, Christopher $\mathbf{R}$ France $\mathbf{P h D}^{2}$, $\mathbf{R}$ Thomas Evans MD FRCP3

1 École de Psychologie, Université de Moncton, Moncton, New Brunswick; ${ }^{2}$ Department of Psychology, Ohio University, Athens, Ohio; ${ }^{3}$ The Atlantic Spine Clinic, Moncton, New Brunswick

Recent cognitive-behavioural conceptualisations of chronic pain have highlighted the importance of fear-avoidance beliefs and negative affect as primary determinants of pain-related disability. Unfortunately, these models do not address the influence of individual differences in nociceptive processing. The nociceptive flexion reflex (NFR) is a polysynaptic withdrawal reflex that has been used to examine central nervous system modulation of nociceptive transmission both between groups and within individuals. This study examined the relative contribution of nociceptive and psychological processes to the prediction of self-reported disability in twenty individuals ( 10 males, 10 females) suffering from chronic back pain (mean duration=18.0 months, $\mathrm{SD}=21.1)$. Participants completed selfreport measures including the pain catastrophizing scale (PCS), Tampa Scale of Kinesiophobia (TSK), the McGill Pain Questionnaire (MPQ) and the Roland-Morris Disability Questionnaire (RMDQ). Participants then underwent an assessment of their NFR threshold followed by a separate pain threshold and tolerance assessment involving increasing levels of electrocutaneous stimulation. Consistent with previous investigations of pain-related disability, Pearson correlation coefficients in the present study revealed that PCS, TSK and MPQ scores were all significantly related to perceived disability as assessed with the RMDQ (all $\mathrm{p}$ values $<.01$ ). Although NFR thresholds were significantly associated with self-reported NFR procedural pain and to subjective pain threshold and tolerance assessed in the laboratory, NFR thresholds were not significantly related to clinical pain or RMDQ scores. These results suggest that individual differences in pain-related disability may be better accounted for by psychological factors than differences in nociceptive responsiveness.

\section{P-57}

PAIN SEVERITY AFFECTS PERCEIVED QUALITY OF LIFE IN PATIENTS WITH NEUROPATHIC PAIN

Allan Gordon MD FRCPC 1 , Manon Choiniere $\mathrm{PhD}^{2}$, Jean-Eric Tarride PhD ${ }^{3}$, Nancy Ryan $\mathrm{MSc}^{4}$, Jean-Paul Collet MD PhD ${ }^{5}$

${ }^{1}$ Mount Sinai Hospital, Toronto, Ontario; ${ }^{2}$ Montreal Heart Institute, Montreal, Quebec; ${ }^{3}$ Pfizer Canada Inc, Kirkland, Quebec; ${ }^{4}$ Innovus Research Inc, Burlington, Ontario; ${ }^{5}$ Jewish General Hospital, Montreal, Quebec

AIM: Neuropathic Pain $(\mathrm{NeP})$ is a chronic condition suspected to have a severe impact on the quality of life ( $\mathrm{QoL})$ of affected individuals. One of the objectives of this research was to evaluate the humanistic burden of $\mathrm{NeP}$ in Canada.

METHODS: A cross sectional, observational study was conducted at primary care sites across three provinces (Alberta, Ontario and Quebec) amongst patients with diabetic peripheral neuropathy, post-herpetic neuralgia, cervical radiculopathy and postoperative neuropathy. Patients completed several questionnaires including the modified-Brief Pain Intensity Inventory $(\mathrm{m}-\mathrm{BPI})$ questionnaire and the EQ-5D, a generic disease QoL instrument.

RESULTS: 126 subjects were enrolled. The mean age was $58.7( \pm 13.5)$ and the mean duration of $\mathrm{NeP}$ was 6.6 years $( \pm 6.6)$. On a scale from 0 to 10 , mean $( \pm \mathrm{SD})$ current, average, worst, and least pain over the last week due to NeP were $4.8( \pm 2.6), 5.4( \pm 2.0), 6.7( \pm 2.4)$, and $3.5( \pm 2.4)$ respectively. On a scale from 0 (death) to 1 (perfect health), subjects with "mild" pain had a mean EQ-5D utility score of $0.71( \pm 0.24)$ while those with "moderate" or "severe" pain had mean values of $0.47( \pm 0.33)$ and 0.20 $( \pm 0.29)$ respectively. NeP had a substantial impact on most of the dimensions of the $\mathrm{m}$-BPI ( $\geq 5$ on a $0-10$ scale) and the EQ-5D: general/usual activity, normal work, mood, sleep, enjoyment of life, pain/discomfort and anxiety/depression. Pain severity significantly affects QoL and overall level of interference.

CONCLUSION: Pain intensity due to NeP is substantial, and has a profound impact on QoL.

\section{P-58}

\section{CHARACTERISTICS OF NEUROPATHIC PAIN PATIENTS AND TREATMENT SATISFACTION}

Allan Gordon MD FRCPC ${ }^{1}$, Manon Choiniere $\mathrm{PhD}^{2}$, Jean-Eric Tarride PhD ${ }^{3}$, Barbara Zrinscak BScN ${ }^{4}$, Jean-Paul Collet MD PhD ${ }^{5}$ ${ }^{1}$ Mount Sinai Hospital, Toronto, Ontario; ${ }^{2}$ Montreal Heart Institute, Montreal, Quebec; ${ }^{3}$ Pfizer Canada Inc, Kirkland, Quebec; ${ }^{4}$ Innovus Research Inc, Burlington, Ontario; ${ }^{5}$ Jewish General Hospital, Montreal, Quebec

AIM: The management of Neuropathic Pain $(\mathrm{NeP})$ is a major health care consideration, both from a treatment and funding perspective. One of the objectives of this research was to describe the characteristics of patients with $\mathrm{NeP}$ in Canada and satisfaction with $\mathrm{NeP}$ treatment.

METHODS: A cross sectional, observational study was conducted at primary care sites across three provinces (Alberta, Ontario and Quebec) amongst patients with diabetic peripheral neuropathy, post-herpetic neuralgia, cervical radiculopathy and postoperative neuropathy. Data were collected through an investigator chart review and patient self-administered questionnaires like Visual Analog Scales (VAS) and the modifiedPain Treatment Satisfaction Scale.

RESULTS: 126 subjects were enrolled. The mean age was $58.7( \pm 13.5)$. $23.8 \%$ of the subjects reported being in short or long term disability. $27.8 \%$ of the subjects have seen a deterioration of their health state compared to one year ago and $51.6 \%$ indicated no improvement. Subjects reported a $44 \%$ improvement in their general health if they were free of NeP (VAS scores: 0.54 for current $\mathrm{NeP}$ health state vs 0.78 for no- $\mathrm{NeP}$ health state). The mean number of concomitant medical conditions was $3.1( \pm 2.0)$ per subject and $61.1 \%$ had three or more concomitant medical conditions. Subjects spent on average 12.6 hours $( \pm 8.5)$ per day in pain. The mean number of classes of pain medications taken over the last 3 month was 2.3 $( \pm 1.6)$. Only $44.4 \%$ of subjects were satisfied or very satisfied overall with their current pain medications.

CONCLUSIONS: NeP patients have many co-morbidities and pain treatment satisfaction is low.

\section{P-59}

MULTIPLE SCLEROSIS PAIN AND ACUPUNCTURE: A REVIEW Marjorie Hammond RN BScN MHScN (c)

\section{DAC, York Central Hospital , Richmond Hill, Ontario}

AIM: There has been a steady increase in the use of Complementary and Alternative Medicine (CAM) internationally (1). A large percentage of individuals using CAM have one or more chronic diseases (1). Persons with Multiple Sclerosis (MS) are using CAM therapies for a variety of MS related symptoms (2-10). MS is a debilitating neuromuscular disorder with a reported high prevalence of unrelieved pain (approximately 50\%-76\%) $(8,11-22)$. Acupuncture is a recognized complementary therapy for the relief of pain (23-25). The aim of this review was to investigate the use of acupuncture as a complementary approach in the management of pain in MS.

METHODS: The Medline, National Institutes of Health/National Centre for Complementary and Alternative Medicine, MS CAM, PubMed and Cochrane Library databases were searched using the key words: Multiple Sclerosis, pain, acupuncture, complementary and alternative medicine. Criteria for inclusion in this review were: that the researchers had to have reported acupuncture as an independent modality, and report pain as an outcome of acupuncture treatment. Only articles published in English were requested. Only two articles were retrieved meeting the inclusion criteria $(26,27)$.

CONCLUSION: Research published in English on MS pain and acupuncture is almost non existent. Some MS patients are reporting a reduction in pain from acupuncture. Methodological issues limit the clinical utility of the research findings in this review (28-32). More rigorous research is required to address disease related methodological challenges, the utilization and efficacy of acupuncture as a complementary intervention for the management of MS related pain. 
P-60

RELATIONSHIPS AMONG PAIN APPRAISALS, COPING, AND ADJUSTMENT TO CHRONIC ARTHRITIS AND FIBROMYALGIA PAIN DL LaChapelle PhD ${ }^{1}$, T Hadjistavropoulos PhD ${ }^{2}$, T Dever ${ }^{1}$

1 University of New Brunswick, Fredericton, New Brunswick; 2University of Regina, Regina, Saskatchewan

AIM: Adjustment to pain is often considered dependant upon the individual's evaluation of the pain and the coping strategies he or she chooses to employ in order to manage the pain. While a large body of literature documenting the association between coping and adjustment to pain exists, there has been little focus on how appraisals of pain impact coping or adjustment. According to the transactional theory of coping, however, appraisals are a primary determinant of coping strategy usage. Similarly, cognitive-behavioural theories give appraisals a central role in the adjustment process. The purpose of this study was to examine the relationships among pain appraisals, coping, and adjustment.

METHOD: Fifty-three adults with arthritis and/or fibromyalgia responded to questionnaires relating to demographic variables, the pain experience, coping strategy use, pain-related beliefs, and adjustment.

RESULTS: Correlational analyses revealed that negative appraisals including perceptions of harm, disability, and lack of control were associated with higher levels of avoidant coping (eg, guarding, resting, asking for assistance) and with lower levels of problem-oriented coping (eg, task persistence, exercise). A series of hierarchical regression analyses controlling for demographic variables and pain severity revealed that negative appraisals contributed to poor adjustment including higher levels of pain interference (predicted by appraisals of low controllability and high disability) and anxiety (predicted by appraisals of harm). Appraisals did not significantly contribute to depression.

CONCLUSIONS: These results support the transactional model of coping and cognitive-behavioural formulations of adjustment. Treatment targeting pain-related appraisals may be a necessary initial focus in multidisciplinary treatment programs.

\section{P-61}

PROMOTING PARTNERSHIPS TO EXTEND THE CLINICAL APPLICABILITY OF THE BIOPSYCHOSOCIAL MODEL IN CHRONIC PAIN MANAGEMENT: A NEW SERVICE MODEL Mary Lawlor MSc, Susan Sinnott RPT, Elsie Thistle RN Centre for Pain and Disability Management, Dr LA Miller Centre, Health Care Corporation of St John's/Eastern Regional Integrated Health Authority, St John's, Newfoundland

A fundamental premise for effective chronic non-cancer pain management is recognition of the multidimensional nature of chronic pain. Rehabilitation then requires a comprehensive and systematic intervention approach, often over an extended time period. While multidisciplinary/ interdisciplinary pain management centers are believed to provide optimal intervention opportunities, long wait lists, economic and social costs, and the geographic reality of a scattered population limit or prevent accessibility for many. Recognizing this to be of significance within the province of Newfoundland and Labrador, the Centre for Pain and Disability Management, Health Care Corporation of St. John's/Eastern Regional Integrated Health Authority, has initiated a project to extend a more biopsychosoical approach to chronic pain management service across the province.

This study demonstrates and evaluates a framework for a clinical collaborative/partnership model designed to meet the challenge of more equitable access to providing pain management services at the community level. The project implements a structured program of educational sessions, partnershipdevelopment with community-based practitioners, teleconferencing, and individual-referral consultation. The goal is to address issues of wider awareness for, and availability of, a relevant multidimensional focus for chronic-pain rehabilitation. Benefits, obstacles and ethical professional limits are highlighted.

The first phase of evaluative data strongly reinforces the need for expanded clinical education and professional partnerships between tertiary and primary care providers in the area of chronic pain rehabilitation.

\section{P-62}

INABILITY OF ENDOMORPHIN-1 TO REDUCE NOCICEPTION IN CHRONIC ARTHRITIS IS DUE TO DOWNREGULATION OF PERIPHERAL MU-OPIOID RECEPTORS

II McDougall PhD, Z Li MD PhD Department of Physiology \& Biophysics, University of Calgary, Calgary, Alberta

AIM: To assess the effect of the endogenous mu-opioid receptor ligand endomorphin-1 on joint mechanosensitivity in normal and arthritic knees. Also, to determine whether endomorphin-1 responsiveness correlates with mu-opioid receptor levels in the synovium.

METHODS: Electrophysiological recordings of knee joint primary afferent nerves were performed in male Wistar rats $(263-380 \mathrm{~g})$. Neural activity was determined in response to a defined level of noxious joint rotation in normal and chronically inflamed knees (1 week adjuvant monoarthritic knees). This painful mechanical stimulus was modulated by close intraarterial injection of endomorphin-1 to the joint across the dose range $10^{-11}-10^{-8} \mathrm{~mol}$. Immunohistochemistry was also used to assess any changes in mu-opioid receptor levels between normal and chronically inflamed joints.

RESULTS: Administration of endomorphin-1 to normal rat knees caused a dose-dependent reduction in joint afferent activity $(\mathrm{P}<0.0001 ; \mathrm{n}=12)$ with the top dose of the opioid causing a $60 \%$ decrease in nerve firing rate. In chronically inflamed knees, however, the desensitizing effect of locally applied endomorphin-1 was significantly abrogated $(\mathrm{P}<0.001 ; \mathrm{n}=7-12)$. Immunohistochemical analysis of adjuvant monoarthritic synovium revealed a dramatic decrease in mu-opioid receptor staining compared to normal controls.

CONCLUSIONS: Peripheral administration of the endogenous mu-opioid peptide endomorphin-1 to normal rat knee joints reduced the sensory activity of primary afferent nerves following a painful mechanical stimulus. This antinociceptive effect of the neuropeptide was attenuated in a model of chronic arthritis due to downregulation of synovial mu-opioid receptors. These observations highlight a potential inadequacy of the endogenous opioid system to ameliorate joint pain and may explain the limited analgesic effectiveness of peripherally administered mu-opioids in inflammatory joint disease.

\section{P-63}

PROSPECTIVE STUDY OF THE MANAGEMENT OF CHRONIC NEUROPATHIC NON-CANCER PAIN

DE Moulin MD, PK Morley-Forster MD, B Connolly BSc, J Guerin BMath, C Watling MD, J Watson MD Interdisciplinary Pain Program, University of Western Ontario, London, Ontario

AIM: To evaluate the longterm management of chronic neuropathic pain. METHODS: A prospective study of 144 patients with chronic neuropathic non-cancer pain using a computerized database (Microsoft Access) and standard outcome measures for pain, level of function, mood, quality of life and overall treatment satisfaction.

RESULTS: The mean age was 49.8 \pm years (range 18.9-84.6). The major pain syndromes were failed back syndrome with nerve root fibrosis $(18.8 \%)$, complex regional pain syndrome $(16.7 \%)$, peripheral nerve entrapment $(13.8 \%)$ and central pain $(11.8 \%)$ with a mean duration of $5.5 \pm 6.4$ years. Primary treatment modalities were tricyclic antidepressants (23.6\%), anticonvulsants $(27.1 \%)$ and opioid analgesics including methadone $(56.3 \%)$ with a mean maximum morphine (or equivalent) dose of $347.5 \pm 899.5 \mathrm{mg}$ per day. Data were available on 71 patients at three months and 50 patients at six months. There was a significant reduction in mean average pain intensity (Numerical Rating Scale 0-10) at three months $(6.44 \pm 2.3$ vs $7.14 \pm 2.1, p=.01)$ and six months $(5.95 \pm 2.4$ vs $6.81 \pm 2.2, \mathrm{p}=.04)$ and improvement in overall treatment satisfaction at three months $(p=.002)$ and six months $(p=.04)$. However, there was no significant improvement in other outcome measures.

CONCLUSIONS: Pharmacologic management of chronic neuropathic non-cancer pain over six months resulted in significant improvements in pain and treatment satisfaction, but not in other outcome measures. We need to treat chronic neuropathic pain earlier and utilize non-pharmacologic approaches to improve our overall management of this disabling condition. 
P-64

PREVALENCE OF SEXUAL DYSFUNCTION IN PATIENTS

ATTENDING PAIN CLINIC AND FAMILY PHYSICIANS

Philip Peng FRCPC, Rae Dolman BSc, Gaylene Pron PhD,

Lilian Iskander BSc, Patrick Wong, Allan Gordon FRCPC

Wasser Pain Management Centre, Mount Sinai Hospital, Toronto,

Ontario

INTRODUCTION: Sexual dysfunction is prevalent in the general population ( 1 in 3 and 2 in 5 in men and women respectively in both the UK and US) and in patients in family practice (22\% in men and $40 \%$ in women). Prevalence of sexual difficulties in chronic pain patients was reported as high as $73 \%$ in UK. The present survey is designed to examine the prevalence of sexual dysfunction in chronic pain patients in our clinic and its correlation with pain, disability, depression and the effects of various medications such as anti-depressant and opioids.

METHOD: A 4-page questionnaire was developed and modified based on a similar survey conducted in UK. The key elements in defining sexual dysfunction in ICD-10 and DSM-IV were incorporated in 2 questions for the definition of prevalence of sexual dysfunction. Following REB approval and patients consent, 300 chronic pain patients and 300 patients attending their family physicians were surveyed. Categorical and parametric data will be compared with Chi Square and Student $\mathrm{t}$ tests respectively. Logistic regression analysis will be performed for possible association with physical and psychological variables.

RESULT: Only the data on chronic pain patients were analyzed. A total of 73 patients completed the questionnaire ( $\mathrm{M}: \mathrm{F}=23: 50)$. 68\% had a history of depression. The prevalence of sexual difficulties in our chronic pain population is $42 \% .72 \%$ are not satisfied with the frequency of sexual activity. Full analysis of data will be presented in CPS.

CONCLUSION: Our preliminary data suggest high prevalence of sexual dysfunction in chronic pain patients.

\section{P-65}

EXPERIENCE OF METHADONE THERAPY FOR PAIN IN 100 CONSECUTIVE CHRONIC PAIN PATIENTS

Philip Peng FRCPC, Paul Tumber FRCPC, Michael Stafford FFARSCI, Patrick Wong, Lilian Iskander BSc, Allan Gordon FRCPC, Doug Gourlay FRCPC, David Evans FRCPC, Marilyn Galonski RN Wasser Pain Management Centre, Mount Sinai Hospital, Toronto, Ontario

INTRODUCTION: The objective is to describe the experience of methadone use in 100 consecutive chronic pain patients managed in a single multidisciplinary center.

METHOD: Chart review of chronic pain patients on methadone therapy initiated at Wasser Pain Management Clinic from Jan 2001 to Jun 2004 was performed.

RESULT: 100 methadone patients (age $45 \pm 11$ yo; M/F: 3/7; duration of pain $129 \pm 110$ months) managed by 5 physicians were reviewed. The main reasons for the initiation of methadone therapy are opioid rotation $(72 \%)$, stabilization of opioid effect $(41 \%)$ and presence of neuropathic pain (30\%). The average morphine equivalent dose is $77 \mathrm{mg}$ per day (range: $3-450 \mathrm{mg}$ ) before methadone therapy and the methadone dose after initial stabilization (no dose changes for 3 weeks) is $42 \mathrm{mg}$ (range: 4-190 mg). No consistent conversion ratio can be observed when the two doses are plotted in scatterplot. The mean duration of methadone therapy is 11 months. Most of the patients $(91 \%)$ are taking concomitant medications, mostly antidepressant and anticonvulsant. The efficacy of methadone treatment is shown in Table 1. The average VAS before and after methadone treatment is $7.2 \pm 1.7$ and $5.2 \pm 2.5(\mathrm{p}<0.0001)$. The side effects and their frequency are shown in Table 2. Judged by the treating physicians or the addiction specialists, $34 \%$ of the methadone patients are of moderate to high risk of addiction. Thirty-five patients discontinue their methadone treatment due to the side effects $(23 \%)$, ineffectiveness $(37 \%)$ or both $(26 \%)$.

CONCLUSION: Methadone is an effective alternative to the conventional opioid in chronic opioid therapy.
TABLE 1

\begin{tabular}{lccc}
\hline & Pain relief (\%) & Function (\%) & Sleep (\%) \\
\hline Improved & 72 & 60 & 54 \\
Same & 21 & 29 & 27 \\
Deteriorate & 7 & 11 & 19 \\
\hline
\end{tabular}

TABLE 2

Side effects Incidence (\%)

Nausea and vomiting

Drowsiness

Constipation

Swelling in extremities

Weight gain

Diaphoresis/headache/cognitive impairment

Rash/hypersensitivity

16

16

16

13

5

$3 / 3 / 3$

2

\section{P-66}

RANDOMIZED PLACEBO CONTROLLED TRIAL OF BUPRENORPHINE TRANSDERMAL SYSTEM IN PATIENTS WITH CHRONIC LOW BACK PAIN

$\underline{\text { S Rashiq MD }}$, DE Moulin MD², J Sibley MD33, AJ Clark MD4,

A Beaulieu MD5, A Gordon MD6, J Eisenhoffer MD7, Z Harsanyi $\mathrm{MBA}^{7}$, AC Darke $\mathrm{PhD}^{7}$

1University of Alberta, Edmonton, Alberta; ${ }^{2}$ London Health Sciences Centre, London, Ontario; ${ }^{3}$ Royal University Hospital, Saskatoon, Saskatchewan; ${ }^{4}$ Queen Elizabeth II Health Science Centre, Halifax, Nova Scotia; ${ }^{5}$ Centre de Rhumatologie St-Louis, Ste-Foy, Quebec; ${ }^{6}$ Wasser Pain Clinic, Mount Sinai Hospital, Toronto, Ontario; ${ }^{7}$ Purdue Pharma, Pickering, Ontario

AIM: This randomized, double-blind, crossover study evaluated the efficacy and safety of a 7-day buprenorphine transdermal system (BTDS) and placebo, with prn codeine plus acetaminophen for unrelieved pain, in patients with at least moderate low back pain for a minimum of 6 weeks. METHODS: $41 \%$ of patients were receiving opioids, which were discontinued 2-7 days before randomization to $5 \mu \mathrm{g} / \mathrm{hr}$ of BTDS or placebo, with acetaminophen $300 \mathrm{mg}$ plus codeine $30 \mathrm{mg}, 1-2$ tablets q4-6 h prn for rescue. The dose was increased weekly to $10 \mu \mathrm{g} / \mathrm{h}$ and a maximum of $20 \mu \mathrm{g} / \mathrm{h}$ BTDS. Each phase was a maximum of 4 weeks.

RESULTS: Fifty-three patients were evaluable for efficacy having completed at least two weeks in each phase (26 men, 25 women, mean age $54.5 \pm 12.7$ years). Baseline pain was $62.1 \pm 15.5 \mathrm{~mm}$ (100 mm VAS) and 2.5 \pm 0.6 ( 5 point ordinal). BTDS resulted in lower mean daily pain scores $(37.6 \pm 20.7$ vs $43.6 \pm 21.0 \mathrm{~mm}$ VAS, $\mathrm{p}=0.0487$ and $1.7 \pm 0.6$ vs $2.0 \pm 0.7$ ordinal, $\mathrm{p}=0.0358$ ) than in the control group. The mean daily dose of active and placebo BTDS for the last week of each treatment was lower in the active BTDS phase than in the placebo treatment phase $(15.5 \pm 5.7 \mu \mathrm{g} / \mathrm{h}$ and $18.6 \pm 3.7 \mu \mathrm{g} / \mathrm{h}$, respectively; $\mathrm{p}=0.0018)$. The distribution of doses while receiving active BTDS was 59\% $20 \mu \mathrm{g} / \mathrm{h}, 31 \% 10 \mu \mathrm{g} / \mathrm{h}$, and $10 \% 5 \mu \mathrm{g} / \mathrm{h}$. There were more opioid related side effects with BTDS treatment than in the placebo group. There were no serious adverse events.

CONCLUSION: These results indicate that BTDS $(5-20 \mu \mathrm{g} / \mathrm{hr})$ is an effective analgesic, suitable for initiation of continuous opioid therapy in patients with chronic low back pain.

\section{P-67}

EXAMINING THE ROLE OF ADVANCED PRACTICE NURSES IN THE MANAGEMENT OF PAIN

Monakshi Sawhney RN MN ACNP

Acute Pain Service, Department of Anesthesia and Pain Management, University Health Network, Toronto General Hospital, Toronto, Ontario 
P-68

IDENTIFICATION OF DISTINCT PATIENT SUBGROUPS AT RISK FOR DYSFUNCTION SECONDARY TO PAIN

Allan Shapiro ${ }^{1,2,3}$, Heather Getty ${ }^{1,3}$, Robert Teasell1, Pat MorleyForster $^{3}$, Sungjin Hong ${ }^{4}$, Keith Sequeira ${ }^{1}$, Kim Horrill ${ }^{3}$

${ }^{1}$ Department of Physical Medicine and Rehabilitation, and

2Rheumatology Institute, St Joseph's Health Care London, London; ${ }^{3}$ University of Western Ontario Interdisciplinary Pain Clinic, London; ${ }^{4}$ Hamilton Health Sciences Foundation, Hamilton, Ontario A small percentage of patients with persistent pain, those most disabled and distressed, account for an unusually large percentage of costs (medical, disability) associated with pain. This study attempted to identify, on the basis of personality traits, distinct patient subgroups at risk for dysfunction secondary to pain. Patients $(\mathrm{N}=226)$ recruited from tertiary, outpatient chronic pain clinics (PM\&R, Anaesthesiology), completed questionnaires assessing outcome (pain intensity, disability, and distress) and personality traits. Cluster analysis of personality measures revealed three distinct groups: an "Obsessive-Perfectionistic" Cluster 1 distinguished by high scores on traits descriptive of obsessive personality, such as emotional avoidance, worry, and fear of anxiety, and perfectionistic/Type A behaviour; an "Avoidant-Pain Anxious" Cluster 2 characterized by high scores on emotional avoidance and fear of and emotional reactivity to pain; and a "Low" Cluster 3, which scored lower than Clusters 1 and 2 on all personality dimensions. Cluster 1 and 2 patients did not differ in adjustment, but reported greater pain, disability, and distress than Cluster 3 patients. Moreover, patients in Clusters 1 and 2 were more impaired, and scored significantly higher on their distinguishing personality traits than nonpatient and persistent pain (rheumatoid arthritis) control samples. This suggests that these traits reflect a pre-morbid vulnerability and are not secondary to persistent pain. Future research must address the processes through which personality traits affect adjustment to chronic pain, and the ways in which treatment can be tailored to address these processes.

\section{P-69}

PAIN EXPERIENCE AND EXERCISE INTENTIONS: THE MEDIATING ROLE OF SELF-EFFICACY

Michael IL Sullivan PhD1', Wendy Rodgers $\mathrm{PhD}^{2}$, Gordon Bell PhD², Shawn Fraser MA², Philip Wilson PhD $^{3}$, Pascal Thibault MSc ${ }^{1}$, Jeff Lackner $\mathrm{PhD}^{3}$

1Département de Psychologie, Université de Montréal, Montreal, Quebec; ${ }^{2}$ Faculty of Physical Education and Recreation, University of Alberta, Edmonton, Alberta; ${ }^{3}$ Department of Physical Education and Kinesiology, Brock University, St Catharines, Ontario;

3University at Buffalo, SUNY, ECMC, Buffalo, New York

AIMS: The present study examined the effect of experimentally induced muscle pain on exercise intentions. Of particular interest was examination of the mediating role of self-efficacy for different components of exercise behaviour (task efficacy, scheduling efficacy, coping efficacy).

METHODS: A sample of 40 (13 men, 27 women) sedentary undergraduates participated in an exercise protocol designed to induce muscle soreness, and were asked to return two days later to perform the same physical maneuvres. Participants performed five strength exercises that emphasized the eccentric component of the muscle contraction in order to induce delayed onset muscle soreness.

RESULTS: Analyses revealed that increases in pain from the first to the second session were associated with significantly lower exercise intentions $(\mathrm{r}=-.36, \mathrm{p}<.05)$. Increases in pain were also associated with decreases in exercise task efficacy $(\mathrm{r}=-.38, \mathrm{p}<.01)$. There was no significant relation between pain and coping and scheduling efficacy. Regression analyses revealed that task efficacy mediated the relation between increased pain and exercise intentions.

CONCLUSIONS: These findings extend previous research in demonstrating that efficacy judgments can be significantly influenced by variations in pain, and these in turn, might impact negatively on individuals' intentions to engage in future physical activity. The findings are addressed in relation to theoretical models of the development of sedentary behaviour associated with pain.
P-70

THE UTILIZATION OF MEDICAL RESOURCES IN THE MANAGEMENT OF DIABETIC PERIPHERAL NEUROPATHY AND POST HERPETIC NEURALGIA

lean-Eric Tarride PhD ${ }^{1}$, Johanne Guarda BA², Anthony Aversano B Com²

1Pfizer Canada Inc, Kirkland; ${ }^{2} \mathrm{P} \backslash \mathrm{S} \backslash \mathrm{L}$ Research Canada, Montreal, Quebec

AIM: The aim of this research was to describe the utilization of medical resources consumed in the management of Diabetic Peripheral Neuropathy (DPN) and Post Herpetic Neuralgia (PHN) patients in Canada.

METHODS: An internet-based Survey was conducted among Canadian generalists and specialists. They were invited to fill a questionnaire on the utilization of medical resources they observed on their patient population: number of physician visits, referral to specialists and waiting times, diagnosis tests and non-pharmacological treatments.

RESULTS: 50 general practitioners (GPs) and 30 specialists (10 anaesthesiologists, 10 endocrinologists and 10 neurologists) participated in this survey. The mean number of GP visits over a 3-month time period varied from 3.2 (patients with none or mild pain) to 5.9 (patients with severe pain) for DPN and from 2.5 (none or mild pain) to 8.6 (severe pain) for PHN patients. Over a one-year time horizon, the majority of DPN and PHN patients with a moderate or severe pain will be referred to a specialist. The number of weeks elapsed between the referral and the first specialist visit was reported to range from 6 weeks (severe pain) to 12 weeks (none or mild pain). Diagnostic tests (eg, nerve conduction studies) and non-pharmacological treatments (eg, physical therapy) were prescribed by generalists and specialists to varying degrees. Substantial delays were observed between the decision to conduct a diagnostic test/prescribe a non-pharmacological treatment and when the test was conducted/nonpharmacological treatment received.

CONCLUSIONS: The management of DPN and PHN is associated with an important use of medical resources.

\section{P-71}

\section{INTRAVENOUS LIDOCAINE WITH LOW DOSE KETAMINE AND MIDAZOLAM FOR REFRACTORY CHRONIC PAIN. A CLINICAL CASE SERIES}

Ellen $N$ Thompson MB BS FRCP

Staff Anaesthesiologist and Consultant in Pain Management,

The Ottawa Hospital, Ottawa, Ontario

AIM: Relief of chronic refractory pain by intravenous infusion of lidocaine with low dose ketamine and midazolam.

A subset of patients do not derive adequate relief from optimal oral pharmacotherapy: Large doses of combinations of opioids and coanalgesics do not drop pain scores below 7. Zelman et al showed that a score of 4 or less is required for "self chosen" daily activities and adequate sleep. Many workers have reported the benefit of intravenous lidocaine. The addition of midazolam reduces neuroexitatory side effects, while ketamine adds further analgesia through NMDA receptor blockade.

METHODS: Ten patients were offered this treatment starting in June 2002. Patients signed a detailed written information/consent form. All patients had widespread pain of at least 3 years' duration. Four patients, a male with "failed back", two women with post-traumatic spinal pain, and one female with multisite pain of unknown aetiology received repeated infusions over a long period ( $>1$ year). Lidocaine $1 \mathrm{mg} / \mathrm{kg}$ plus ketamine $20-30 \mathrm{mg}$ and midazolam 2-3.5 $\mathrm{mg}$ in a bolus was followed by lidocaine infusion over $30 \mathrm{~min}$ to total $5 \mathrm{mg} / \mathrm{kg}$. ECG/HR and $\mathrm{O}_{2}$ Saturation was monitored.

RESULTS: Duration of significant relief (pain score $<4$ ) lasted $48 \mathrm{hrs}$ to 3-4 weeks. No ECG or significant O2 saturation changes were observed in any patients during treatments.

One patient with short duration relief has received this treatment $\times 2-3 / w k$ since June 2002 with no ill effects. Her sleep and quality of life is greatly improved.

CONCLUSIONS: For a subset of patients with intractable pain intravenous infusion of lidocaine in combination with ketamine and midazolam can provide significant relief without ill effects even in prolonged usage.

References

1. Devor M, Wall PD, Catalan N. Systemic lidocaine silences ectopic neuroma and DRG discharge without blocking nerve conduction. Pain 1992;48:261-8. 
2. Galer BS, Miller KV, Rowbotham MC. Response to intravenous lidocaine infusion differs based on clinical diagnosis and site of nervous system injury. Neurology 1993;43:1233-5.

3. Zelman D, Hoffman D, Reed L, et al. Quantifying a "day of manageable pain control": The relationship between pain severity and patient daily functional expectations. APS, Annual Scientific Meeting, poster presentation, Chicago 2003.

\section{P-72}

PAIN, EMOTIONS AND INTENTION TO EXERCISE

Pascal Thibault BSc, Michael JL Sullivan PhD,

Nathalie Gauthier BSc, André Savard MPS, Isabelle Tremblay BSc, Dorothée lalongo-Lambin BSC

Département de psychologie, Université de Montréal, Montreal,

Quebec

AIM: This study examines the effect of induced pain on emotions and future intention to exercise.

METHOD: 40 sedentary undergraduate students with a mean age of 21.7 years participated in a exercise protocol designed to induce delayed onset muscle soreness (DOMS). Participants returned to the laboratory two days later and completed measures of pain, mood and intention to exercise. Change scores were computed to derive indices of exercise induced pain (post-exercise pain - pre-exercise pain), and delayed onset muscle pain (two day post exercise pain - pre-exercise pain).

RESULTS: Results revealed that increases in pain for time 1 to time 2 (immediately before and after exercise) were not associated with changes in mood, nor with intentions to exercise. However, increases in pain for time 1 to time 3 (immediately before exercise and two days later) were significantly associated with changes in mood as well as changes in intention to exercise. In regard to changes in the mood, higher levels of sadness at time 3 were uniquely associated with a reduction of intention to exercise. CONCLUSION: Discussion addresses how attributional processes may account for the differential effects of exercise related pain on mood variables. The clinical implications of the specificity of the relation between increased sadness and intentions to exercise is also addressed.

\section{P-73}

IS "GROWING PAINS" A HOMOGENEOUS CONDITION? A DESCRIPTIVE STUDY OF CHILDREN'S SYMPTOMS AND PARENTS' CONCERNS

Faizah Visram BA(Hon) ${ }^{1}$, Alan M Rosenberg MD FRCPC FAAP2,

Carl L von Baeyer PhD RDPsych 1,2

Departments of 1 Psychology and 2Pediatrics, University of

Saskatchewan, Saskatoon, Saskatchewan

OBJECTIVE: So-called 'growing pains' are common but not well understood. The purpose of this study was to identify common features of recurrent idiopathic limb pain in children and to develop a definition of the condition for use in future research.

METHOD: A stratified random sample of pediatric and adult rheumatologists, general pediatricians, and family physicians from across Canada were surveyed by mail regarding how they define growing pains. In addition, descriptive questionnaire data from 38 parents, whose children had been referred to a rheumatology clinic and diagnosed with growing pains, were obtained. Parents described their children's symptoms as well as their own concerns about their children's symptoms.

RESULTS: 75 physicians responded for a response rate of $40 \%$. Content analysis was used to distinguish common definitions of growing pains. While some physicians included arm pain and pain occurring in the daytime, others included only night-time leg pain in their definitions. This was consistent with parents' descriptions: most parents described lower leg pain, but a few described arm pain. Most parents were concerned that the pain might indicate a more severe condition and that it was affecting their child's sleep.

CONCLUSIONS: This study indicates that growing pains could be defined as a heterogeneous condition, where some children experience recurrent upper limb pain and daytime pain, but the majority experience only recurrent night-time leg pain. Nomenclature for this puzzling condition is discussed. Researchers need to be clear with regard to inclusion and exclusion criteria in order to facilitate comparison across research studies.
P-74

WHAT CHANGES FROM AGE THREE TO SEVEN? METHODS TO STUDY CHILDREN'S DEVELOPING ABILITY TO USE SELF-REPORT PAIN SCALES

Carl L von Baeyer PhD ${ }^{1,2}$, Sasha J Forsyth BEd ${ }^{1}$, Christine T Chambers PhD $^{3}$

Departments of ${ }^{1}$ Psychology and 2 Pediatrics, University of Saskatchewan, Saskatoon, Saskatchewan; ${ }^{3}$ Departments of Pediatrics and Psychology, Dalhousie University, Halifax, Nova Scotia

AIM: Most 7-year-olds are able to provide reliable pain scores using tools such as visual analog scales, while most 3-year-olds are not. We are conducting a series of studies designed to clarify the development of selfreport skills over this age span. Here we report three initial methodological studies.

METHODS AND RESULTS: To select items from the Charleston Pediatric Pain Pictures (CPPP) for use in subsequent studies, 36 adults (mean age 28 years; 27 female) and 38 children (mean age 10.7 years; 15 female) scored pain intensity. Three low-pain, three medium-pain, and three high-pain items were selected. Four published verbal top scale anchors were assessed by quantitative and qualitative methods: "the biggest hurt you could ever have"; "most pain"; "hurts as much as you can imagine"; "very much pain." The anchor "most hurt" was selected for subsequent use. To refine the instructions used with young children, 3- to 5 -year-olds in daycare were asked to rate the selected CPPP items using three instruction methods: standard FPS-R instructions; comparative words instructions (naming each face based on the amount of hurt it showed); and minimal language instructions (prompting children to point to the FPS-R face that matched how they would feel).

CONCLUSION: Methods were established for subsequent studies of screening (ie, identifying young children who are able to use self-report scales) and training (ie, teaching those who have difficulty with the task to understand it and make reliable ratings of pain). The results are expected to improve pain assessment in 3- to 7-year-old children.

\section{P-75}

\section{INTRAVENOUS LIDOCAINE FOR CHRONIC PAIN:} CLINICAL EXPERIENCE AND RECOMMENDATIONS

Mark Ware MBBS MRCP MSc, Louise Lamb RN, Yoram Shir MD PhD Montreal General Hospital Pain Centre, McGill University Health Centre, Montreal, Quebec

AIM: Lidocaine, a local anesthetic and anti-arrhythmic agent, possesses analgesic properties in a range of chronic pain conditions including post-herpetic neuralgia and diabetic neuropathy. We present our experience of intravenous lidocaine therapy with a view to conducting randomized clinical trials.

METHODS: Subjects with refractory pain of any cause where considered for treatment. The sole exclusion criterion was ischemic heart disease or arrhythmias. Informed consent was obtained from all subjects. Lidocaine was administered at a loading dose of $1 \mathrm{mg} / \mathrm{kg}$ followed by an infusion of $4 \mathrm{mg} / \mathrm{kg}$ in $100 \mathrm{ml}$ normal saline over 1 hour. Vital signs were recorded every 15 minutes. The Neuropathic Pain Scale was administered prior to infusion, and at 1 hour, 4 days and 14 days after infusion.

RESULTS: Over a one year period, a total of 210 infusions were administered to 104 subjects with median age 47 yrs (IQR 38.5-54.6 y), of whom $55(53 \%)$ were female. Forty subjects received two infusions, 21 received three, 12 received four, and 33 subjects received 5 or more infusions. At day 14 , pain intensity and heat pain were significantly reduced following the first infusion $(p=0.002$ and $<0.001$, respectively). Further analysis of response predictors by age, gender, and disease are underway and will be presented. Adverse events were chiefly mild and expected and no serious adverse events were reported.

CONCLUSIONS: Intravenous lidocaine produces significant pain relief which lasts well beyond the expected half-life of the drug. Repeated infusions are feasible and well-tolerated. This treatment deserves further consideration in clinical practice and in randomized trials. 
P-76

WHAT IS THE COMPARATIVE EFFICACY AND SAFETY OF

DIFFERENT ANALGESICS FOR NEUROPATHIC PAIN?

C Peter N Watson MD FRCPC, Mary L Chipman BA MSc

University of Toronto, Toronto, Ontario

P-77

TRIGEMINAL NEUROPATHIC PAIN: A SYSTEMATIC REVIEW OF

THE PHARMACOTHERAPY

C Peter N Watson MD FRCPC

University of Toronto

AIM: The purpose of this poster is to review the pharmacological treatment of trigeminal neuropathic pain.

METHOD: A systematic review.

RESULTS: Thirty such randomized controlled trials and important historical and uncontrolled studies in trigeminal neuralgia and trigeminal postherpetic neuralgia were identified.

CONCLUSIONS: Trigeminal neuralgia is a unique neuropathic pain disorder with a specific therapy. It does not respond to the usual drugs used for other neuropathic pain problems either trigeminal or elsewhere. The drug therapy of trigeminal neuropathic pain other than trigeminal neuralgia is similar to trigeminal postherpetic neuralgia.

\section{P-78}

PATIENTS' PAIN MANAGEMENT FOLLOWING DISCHARGE AFTER CABG SURGERY

ludy Watt-Watson RN PhD ${ }^{1}$, Bonnie Stevens RN PhD ${ }^{1}$, Judy Costello RN MSc ${ }^{2}$, Michael McGillion RN PhD (C) ${ }^{1}$

${ }^{1}$ University of Toronto; ${ }^{2}$ University Health Network - Toronto

General Hospital, Toronto, Ontario

P-79

WITHDRAWN
P-80

MODULATION OF ASPARTAME INDUCED ANALGESIC AND ANTIINFLAMMATORY EFFECTS BY OPIOIDS AND NSAIDS

Sameer Sharma MPharmacy, NK Jain PhD, SK Kulkarni PhD

Pharmacology Division, University Institute of Pharmaceutical Sciences, Panjab University, Chandigarh, India

Aspartame (N-L-alpha-aspartyl-L-phenylalanine-1-methyl ester), a noncaloric compound is a widely known artificial sweetener and is used in the preparation of various foods and beverages. Recently some newer uses of aspartame have been reported such as analgesic, antipyretic, in homeostasis and bone mass regeneration. However, exact mechanism of action of sweetening agents induced antinociception remains unclear. It is expected that aspartame co-treatment with opiates or NSAIDs may reduce the cost of the therapy, side effects and possibly improve the gross margins. The purpose of the present study was to investigate whether aspartame possesses analgesic and anti-inflammatory properties and its combination with various opioids and NSAIDs may give synergistic response at lowered doses. Oral administration of aspartame $(2-16 \mathrm{mg} / \mathrm{kg}$, po) significantly decreased the number of acetic acid-induced writhes in mice. Co-administration of aspartame ( $2 \mathrm{mg} / \mathrm{kg}$, po) with nimesulide $(2 \mathrm{mg} / \mathrm{kg}$, po) or naproxen $(5 \mathrm{mg} / \mathrm{kg}$, po) significantly reduced acetic acid-induced writhes as compared to effect per se effects of individual drugs. Similarly, when morphine $(1 \mathrm{mg} / \mathrm{kg}$, po) or pentazocine $(1 \mathrm{mg} / \mathrm{kg}$, po) was co-administered with aspartame it reduced the number of writhes as compared to their effects per se. Aspartame $(4,8$, $16 \mathrm{mg} / \mathrm{kg}$, po) significantly decreased carrageenan-induced increase in paw volume and also reversed the hyperalgesic effects in rats. This study indicated that aspartame exerted analgesic and anti-inflammatory effects on its own and its interaction with other analgesics is highly speculative.

\section{P-81}

VALIDATION IN FRENCH OF « LA GRILLE D'EVALUATION DE LA DOULEUR-DEFICIENCE INTELLECTUELLE » (GED-DI)

Geneviève $M$ Breau ${ }^{1}$, Marie-Claude Grégoire $M D^{1,2}$,

Chantal Wood $\mathrm{MD}^{3}$, Marc Zabalia $\mathrm{PhD}^{4}$, Christine Lévèque $\mathrm{MD}^{5}$, Lynn M Breau PhD²

1Dalhousie University and 2IWK Health Centre, Halifax, Nova Scotia; ${ }^{3}$ Hôpital Robert Debré, Paris, France; ${ }^{4}$ Université de Caen Basse-

Normandie, Caen, France; ${ }^{5}$ Hôpital St-Vincent de Paul, Paris, France 


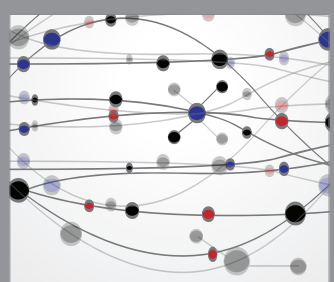

The Scientific World Journal
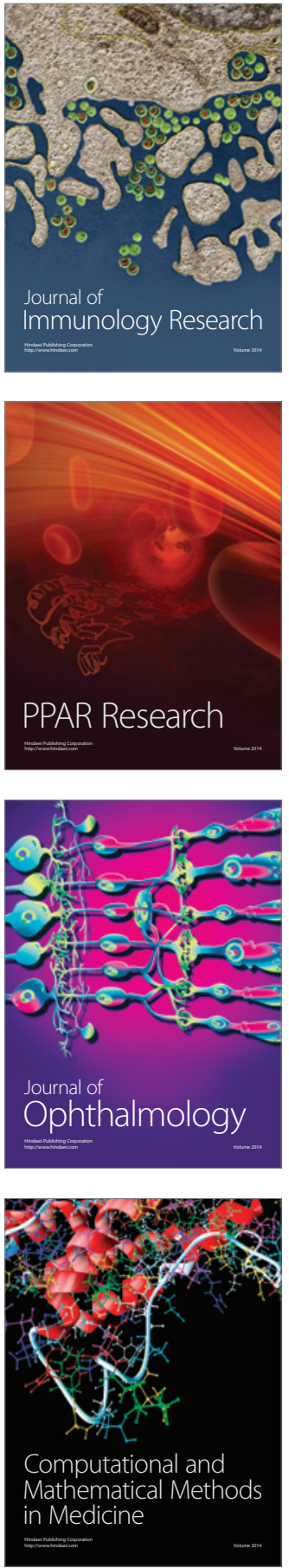

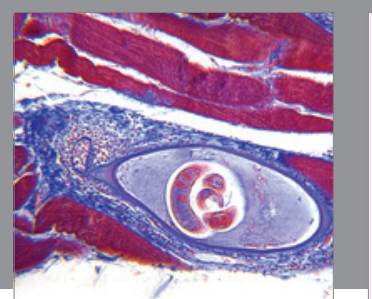

Gastroenterology Research and Practice

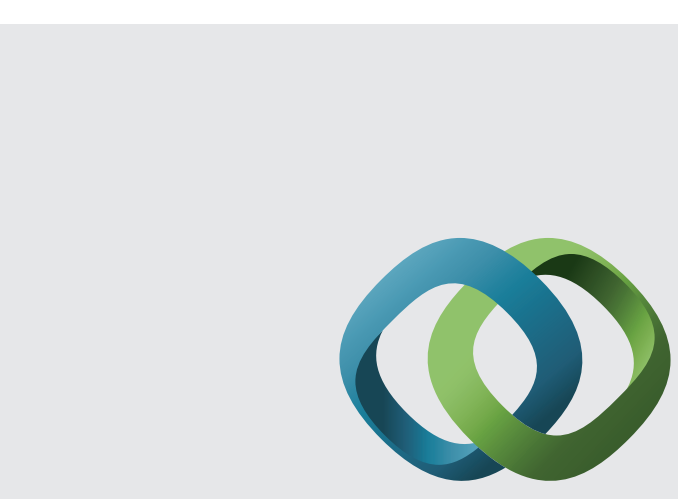

\section{Hindawi}

Submit your manuscripts at

http://www.hindawi.com
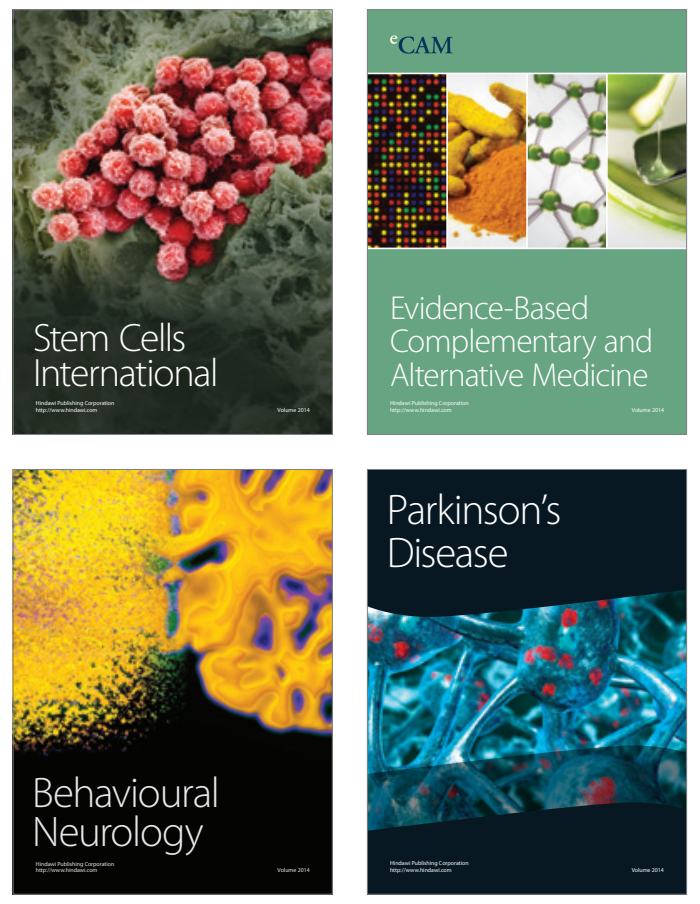
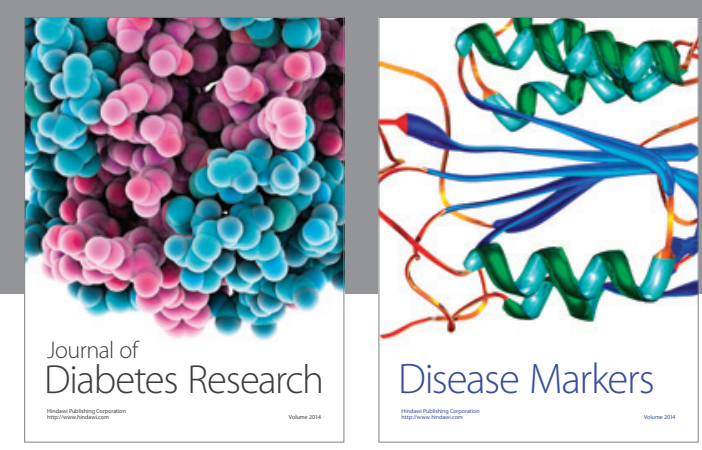

Disease Markers
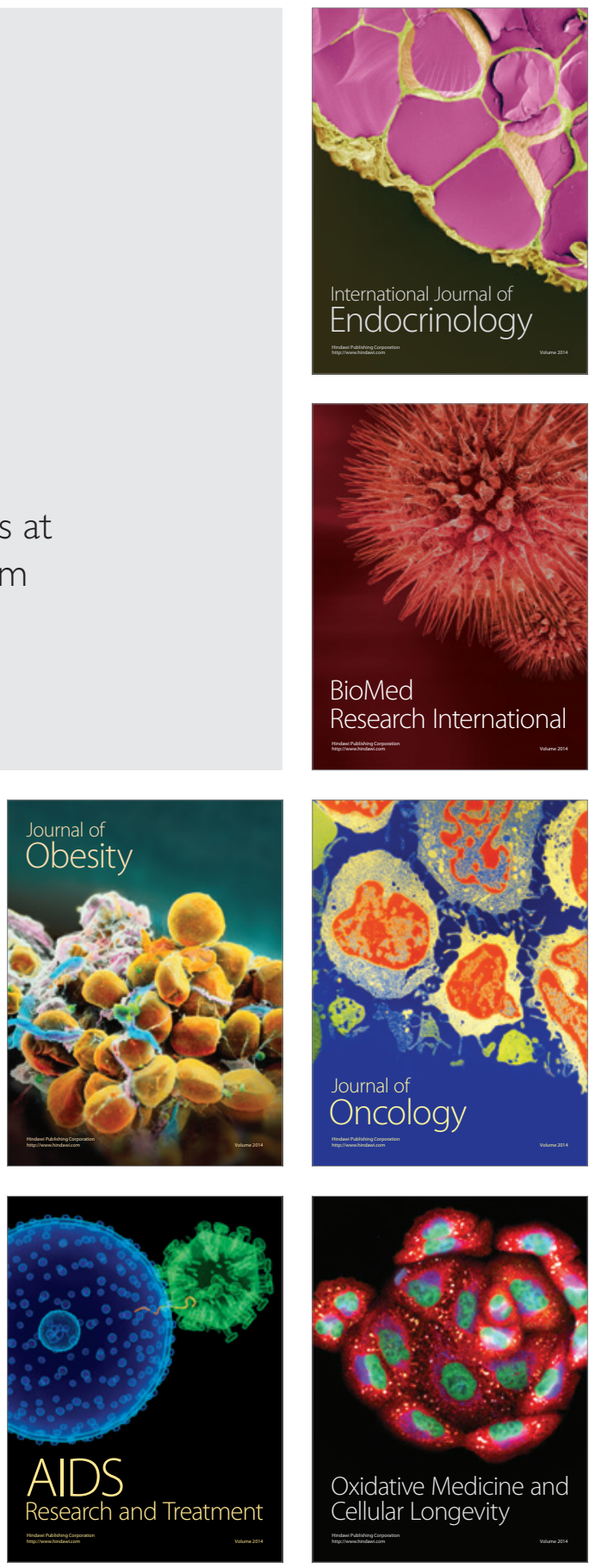